\title{
5 Die Präsenz spätantiker Inschriften zwischen alten Räumen und neuen Kontexten
}

\subsection{Was ist ,Präsenz` und wozu nach ihr fragen?}

Im Vergleich zum Begriff der ,Materialität‘ ist uns der Begriff der ,Präsenz‘ vertrauter und seine Bedeutung erscheint uns einfacher $\mathrm{zu}$ begreifen. Im Alltagsgebrauch bezeichnen wir damit die sinnlich wahrnehmbare Gegenwärtigkeit oder Unmittelbarkeit von jemandem oder von etwas. Im Speziellen benutzen wir den Begriff, wenn es darum geht, die außergewöhnlich starke Anziehungskraft und optische Wirkmacht einer Person zu beschreiben. Diese Spannung zwischen Alltagserfahrung und außeralltäglicher Besonderheit war auch schon im lateinischen praesentia angelegt, das auf der einen Seite die Bedeutung von körperlicher Anwesenheit, auf der anderen Seite von unmittelbarer Wirkung hatte. ${ }^{512}$ Ähnliches gilt für die griechische Entspre-

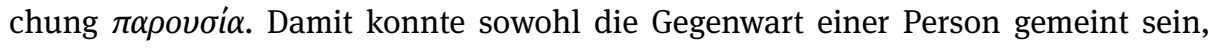
aber auch ,günstige Gelegenheit', ,Beistand', und im christlichen Sinne ,Ankunft des Heilands ${ }^{6}{ }^{513}$ Wenn wir in unserem Zusammenhang mit (spätantiker) Inschriftlichkeit von Präsenz sprechen, dann im Sinne der physischen Anwesenheit eines inschriftlichen Monuments, seiner körperlich erfahrbaren Gegenwart, seiner räumlichen Artikulation. Ähnlich wie im Fall der Materialität wohnt auch dem Konzept der Präsenz die Idee eines reziproken Verhältnisses zwischen der dinglichen Inschrift und dem menschlichen Akteur inne: Er hat sie bewusst erdacht, absichtsvoll geschaffen und mit einer bestimmten Intention zur Aufstellung gebracht. Sie ist Teil seiner Lebenswirklichkeit und gestaltet sein Umfeld. Ihre Gegenwart löst bei ihm bestimmte Gedanken, Emotionen und Reaktionen aus. Sie verleitet ihn womöglich zu konkreten Handlungen.

Vor diesem Hintergrund ist es sinnvoll, den Präsenz-Begriff in zweierlei Hinsicht zu erweitern, das eine Mal um den Begriff der ,Präsentifizierung und das andere Mal um denjenigen der ,Effektivität‘. Mit erstem ist das bewusste In-Szene-Setzen der Inschrift, also ihre öffentliche Zur-Schau-Stellung durch den Initiator, Produzenten oder Auftraggeber gemeint. Letzter hebt auf die Wirkmacht einer Inschrift auf den Betrachter und Leser ab. Und noch eine Idee spielt bei der Präsenz von Inschriftlichkeit eine Rolle, welche nunmehr von der spezifischen Funktion antiker Inschriften als Medien der Repräsentation und Kommemoration herrührt. Als solche waren sie dazu gedacht, eine Person, ein Ereignis oder eine Idee im Hier und Jetzt präsent zu machen. Sie waren also gleichsam so etwas wie ,Absenz-Überbrücker': Ehreninschriften mit dem Bildnis des Kaisers repräsentierten seine Person, wo er nicht zugegen sein

512 OLD 1440 s. v. praesentia.

513 LSJ 1343 s. v. $\pi \alpha \rho o v \sigma i ́ \alpha$.

Ә Open Access. () 2019 Katharina Bolle, publiziert von De Gruyter. (c) BY-NC-ND Dieses Werk ist lizenziert unter der Creative Commons Attribution-NonCommercial-NoDerivatives 4.0 Lizenz. 
konnte. Grabinschriften machten den Verstorbenen seinen Hinterbliebenen gegenwärtig. Und Inschriften historischer Denkmäler hielten die Erinnerung an Siege, Niederlagen und epochale Ereignisse wach.

Sich mit der Präsenz von Inschriften auseinanderzusetzen, erschöpft sich aber nicht nur in der Frage, ob diese zugegen waren und wessen Absenz sie zu überbrücken suchten. Unser Interesse an der Präsenz von Inschriftlichkeit in der Spätantike soll kein bloßer Selbstzweck sein, sondern ein forschungsperspektivisches Instrument, mit dessen Hilfe ein möglichst scharfes Bild der damaligen Lebenswirklichkeit gezeichnet und ein Verständnis für die Bedeutung von öffentlich präsentierten Inschriften entwickelt werden soll. Vor diesen Hintergrund ist es unerlässlich, möglichst viele Dimensionen der Präsenz in den Blick zu nehmen und nicht nur danach $\mathrm{zu}$ fragen, wo Inschriften aufgestellt wurden, sondern auch, warum ausgerechnet dieser Ort oder jenes Umfeld ausgewählt wurde, welche Monumente hier außerdem zugegen waren, wie man die Inschrift in Szene gesetzt hat und was dieses spezifische Setting für ihre Wirksamkeit und die Wahrnehmung durch den Betrachter bedeutete. Es sind dies Fragen, die sich letzten Endes zu einer topologischen Analyse bündeln und die darauf hinaus laufen, Inschriften in ihre räumlichen und kulturellen Kontexte einzuordnen und vor dieser Folie zu lesen und zu verstehen. ${ }^{514}$ Damit dies gelingen kann, sind auf der einen Seite eine möglichst detailreiche Kenntnis des archäologischen Befunds und auf der anderen Seite ein gewisses Verständnis für die Sitten und Gebräuche sowie für die Werte und Normen der jeweiligen Kultur und Gesellschaft unverzichtbar. Dazu drei Beispiele aus der griechischen-römischen Welt: Die im Zusammenhang mit der Materialität von Inschriften schon einmal zur Sprache gekommenen defixiones aus Blei ${ }^{515}$ erfuhren in der Regel eine besondere Präsentifizierung. Sie wurden zusammengefaltet, mit Nägeln durchbohrt und dann in der Erde vergraben, um die Wirkung der darauf eingeschriebenen Verfluchungen zu verstärken. Die ebenfalls schon angeführten Goldtäfelchen mit den orphischen Gedichten ${ }^{516}$ wurden dem Verstorbenen nicht einfach mit ins Grab gegeben, sondern ihm auf den Mund gelegt, sodass er die Worte gleichsam schon ,auf der Zunge‘ hatte und nur noch auszusprechen brauchte. Und bei zur öffentlichen Wahrnehmung bestimmten Dokumenten wie Gesetzestafeln oder Dekreten wählte man häufig Aufstellungsorte in der Nähe von Heiligtümern oder politischen Gebäuden, wodurch die Texte an Authentizität und Autorität gewannen.

Wie es diese Beispiele andeuten, vermögen sich topologische Analysen auf durchaus unterschiedlichen Ebenen abzuspielen: auf einer mikroskopischen und einer makroskopischen Ebene. Die erste betrifft den unmittelbaren räumlichen Kontext einer Inschrift und ihre Interaktion mit der sie direkt umgebenden Umwelt. Die

514 Zur Methode der topologischen Analyse, dem forschungspraktischen Vorgehen und ihrer Relevanz für die Altertumswissenschaften s. Dickmann/Witschel/Keil 2015.

515 S. o. S. 130.

516 S. o. S. 130 . 
meisten antiken Inschriften waren keine isolierten Texte, sondern integraler Bestandteil eines Monuments oder Denkmals, mit dem sie eng verbunden waren. Man denke zum Beispiel an Bauinschriften an den Fassaden von Tempeln und an Siegesdenkmälern, an Weihinschriften auf Altären oder an Ehreninschriften auf Statuenbasen, die ohne ein dazugehöriges Portätbild des Geehrten nicht vorstellbar waren. Makroskopische Analysen hingegen haben einen wesentlich breiteren Fokus und nehmen einen größeren topographischen Raum in den Blick, etwa eine Platzanlage, einen Gebäudekomplex oder ein ganzes Stadtareal. Solche Untersuchungen zielen weniger darauf ab, das Setting einzelner Inschriften und ihrer Monumente zu rekontextualisieren, sondern nach Orten verdichteter Inschriftlichkeit zu suchen und zu verstehen, warum bestimmte Räume und Kontexte anderen gegenüber bevorzugt wurden. Sowohl bei Mikro- als auch bei Makrostudien spielt jedoch nicht nur die spezifische Art und Weise der Präsentifizierung durch den Produzenten oder Auftraggeber eine Rolle. Wichtig ist auch die Frage nach der Wahrnehmung durch den Betrachter und Leser. Wer konnte die Inschriften zu welchem Zeitpunkt sehen? Wurde versucht, die Aufmerksamkeit des Betrachters auf bestimmte Details zu lenken, und wenn ja, wie und wozu? Welche Bedeutung spielte die Bewegung des Betrachters im Raum? Und inwiefern müssen wir ,Raum' nicht nur als eine physische, sondern auch als eine soziale Größe begreifen? ${ }^{517}$

So vielversprechend topologische Analysen zur Präsenz von Inschriftlichkeit im öffentlichen Raum auf den ersten Blick erscheinen, so schwierig sind sie in der Praxis umzusetzen. Denn häufig ist unsere Kenntnis des archäologischen Kontexts zu gering, als dass fundierte Aussagen möglich wären - weshalb wir über mehr oder weniger plausible Annahmen in vielen Fällen nicht hinaus kommen. Nur die wenigsten erhaltenen Inschriften der Antike befinden sich noch heute in situ. Viele wurden in späterer Zeit verschleppt, als Baumaterial wiederverwendet oder auf andere Art und Weise umgenutzt. Und selbst wenn der originale Standort einer Inschrift hinreichend bekannt ist, so ist damit wenig gewonnen, wenn wir uns kein Bild von der unmittelbaren und weiteren Umgebung machen können, wenn wir zum Beispiel nicht wissen, welche Gebäude und anderen Monumente dort einst zugegen waren. Noch komplizierter verhält es sich mit dem Aspekt der Wahrnehmung durch den Betrachter und Leser. Auch hier bleibt vieles Spekulation, da wir die Akteure selbst nicht mehr befragen können, sie ihre Eindrücke nicht überliefert haben und unsere eigenen Sehgewohnheiten und Vorstellungswelten nicht mehr die gleichen sind wie damals. Mit diesen Hindernissen vor Augen gilt es um so mehr, sich auf diejenigen (vergleichsweise seltenen) Befunde zu konzentrieren, die wir mit einiger Sicherheit für unsere Fragestellungen fruchtbar machen können - wobei wir auch hier um Hypothesenbildung nicht gänzlich herum kommen werden, sei es in Bezug auf den räumlichen

517 Zum weiten Spektrum des Raumbegriffs und seinen verschiedenen Ausprägungen s. die zusammenfassenden Erläuterungen bei Muth 2014, 285-294 mit umfangreichen Literaturverweisen zur Begriffs- und Diskursgeschichte. 
Kontext und das Setting oder auf die Intentionen des Auftraggebers und die Wirkung auf den Betrachter und Leser.

\subsection{Gewachsene und sich wandelnde Präsenz: Inschriftlichkeit im öffentlichen Stadtraum}

Die antike Stadt war ein ,beschriebener Raum‘. Wer durch die Straßen und über die Platzanlagen ging, sich in Marktbasiliken, Theatern, Thermen und anderen öffentlichen Bauten aufhielt, sah sich einer Vielzahl von allerlei Texten und Schriftzeugnissen gegenüber, die ihm in ganz unterschiedlichen Erscheinungsformen und Kontexten begegneten. Die zahlreich erhaltenen Bauinschriften von Gebäuden, die Ehreninschriften der Statuenbasen und die Weihinschriften der Altäre legen bis heute beredtes Zeugnis davon ab. Wegen ihres vergänglichen Materials weniger häufig erhalten, für jedes (in)schriftliche Stadtbild aber ebenso typisch, waren die auf Bronzetafeln eingeschriebenen und zur öffentlichen Kenntnisnahme ausgestellten instrumenta publica, also Senatsbeschlüsse, Gesetzestexte, Erlasse und Vereinsstatuten, ferner die für das gemeinschaftliche Leben in den Stadtgemeinden bedeutsamen Kalender und fasti sowie die tabulae patronatus und tesserae hospitales, mit denen persönliche Patronatsverhältnisse und Freundschaftsbeziehungen zu anderen Gemeinden öffentlich dokumentiert wurden. In nahezu jeder größeren Stadt markierten außerdem mit Inschriften versehene termini die Grenzen des pomerium und bestimmter Zonen innerhalb des Stadtgebiets. Wirte, Händler und Handwerker bewarben ihre Gaststätten, Läden und Betriebe mit großen Werbeschildern. Hauswände waren mit Spielankündigungen und Wahlaufrufen bemalt, und überall waren spontan hinterlassene Graffiti zu lesen. Viele dieser Texte waren der dauerhaften Präsenz angedacht, andere wiederum waren von eher ephemerem Charakter und wurden nach einiger Zeit entfernt, an einen anderen Ort verbracht oder durch neue ersetzt. Manche Schriftzeugnisse waren sogar nur zu bestimmten Gelegenheiten zu sehen, darunter zum Beispiel die bei Prozessionen mitgeführten Tafeln und Schilder, wie wir sie etwa von den Darstellungen des kaiserlichen Triumphzugs vom Titusbogen oder von einem Fragment aus Cherchel kennen. ${ }^{518}$ Der öffentliche Stadtraum war also voll von (In-)Schriften und inschriftlichen Monumenten unterschiedlichster Art und Gestalt, die gemeinsam eine sehr heterogene und fluide Inschriftenlandschaft ausbildeten, die ständig im Werden begriffen war und sich fortwährend veränderte. Inschriftliche Präsenz im öffentlichen Stadtraum bedeutete gewachsene und sich wandelnde Präsenz.

Diesen Umstand zu betonen, mag überflüssig erscheinen, ist aber durchaus notwendig. Denn wenn wir einen bestimmten Zeitraum - wie hier die Spätantike - untersuchen, so neigen wir häufig dazu, uns lediglich für jene Zeugnisse und Spuren zu

518 S. hierzu Corbier 2006, 56. 
interessieren, die eben diese Epoche hervorgebracht hat, und blenden alles zuvor Entstandene und bereits Existierende weitgehend aus. Dies mag aus forschungspraktischer Perspektive zulässig und in vielen Fällen sogar sinnvoll sein. Es führt aber dazu, dass wir uns den Blick auf die damalige Wirklichkeit noch stärker verstellen als es die oftmals lückenhaften Erhaltungszustände und Überlieferungssituationen ohnehin schon tun. ${ }^{519}$ Für die Spätantike und ihre Inschriftenkultur gesprochen, ist eine solche chronologische Fokussierung im Rahmen einer Studie zur Präsenz inschriftlicher Artefakte sogar besonders problematisch. Führt man sich allein die zwischen dem späten 3. und dem frühen 7.Jh. neu geschaffenen Inschriften vor Augen, so ist ihre Gesamtzahl gegenüber früheren Epochen geradezu dramatisch gering, beträgt in manchen Regionen des Reichs etwa $20 \%$, in anderen nicht einmal mehr $5 \% .{ }^{520}$ Dieser deutliche quantitative Rückgang mag für uns eklatant sein, wurde von den Zeitgenossen aber sicherlich nicht in so extremer Weise wahrgenommen. Denn nur weil weniger Inschriften neu angefertigt und öffentlich ausgestellt wurden, war Inschriftlichkeit ja nicht weniger präsent: Die epigraphischen Monumente und Denkmäler der Vergangenheit waren (zumindest teilweise) noch immer da. Sie gehörten zum gemeinsamen kulturellen Erbe, und einige wurden als solches auch erhalten und wertgeschätzt. Vor diesem Hintergrund wollen wir unseren Blick also gerade nicht auf die spätantiken Inschriften des öffentlichen Stadtraums, sondern auf den spätantiken Stadtraum und seine Inschriften richten. Im Mittelpunkt soll deshalb das Neben- und Miteinander von Alt und Neu, die Interaktion zwischen Bestehendem und Dazugekommenem und die Kombination verschiedener Bild- und Text-Medien, also: das epigraphische Gesamtbild stehen, das sich den Bewohnern und Besuchern einer spätantiken Stadt bot. ${ }^{521}$

Wie eingangs angedeutet, verlangt eine solche Betrachtung des städtischen Raums als Ort öffentlicher Inschriftlichkeit nach einer ebenso umfassenden wie detailreichen Kenntnis des zu untersuchenden Stadtbilds. Mit Blick auf den italischen Raum bieten sich hier die Gemeinden Aquileia und Ostia in besonderem Maße an. Denn zum einen verfügen sie über einen reichen, gut publizierten Inschriftenbestand, zum anderen sind sie archäologisch recht gut erschlossen, sodass sich die Aufstellungsorte und -gegebenheiten der Inschriften und ihrer Monumente vergleichsweise präzise nachvollziehen lassen.

519 Auf dieses Problem wies zuvor schon R. R. R. Smith in seinem Aufsatz zur Skulpturenausstattung der hadrianischen Bäder in Aphrodisias hin. Darin unterzieht er die fast 100 erhaltenen Statuen einer synchronen Betrachtung und liest sie als ein über fünf Jahrhunderte gewachsenes Ensemble: Smith 2007.

520 Vgl. hierzu Kap. 2.1.

521 Insbesondere die Kombination der Inschriften mit verschiedenen Monumenten und Denkmälern und das Zusammenwirken der unterschiedlichen Medien sind in dieser Hinsicht wichtig. Zum Verständnis des öffentlichen Raums als Produkt eines „plurimedialen“ Zusammenspiels s. Muth 2014 mit dem Beispiel des Forum Romanum. 


\subsubsection{Aquileia: Die Inschriftenlandschaft des Forums}

Aquileia liegt am nördlichen Adriabogen, in verkehrspolitisch günstiger Position im Hinterland der Lagune von Grado. ${ }^{522}$ Die erste Gründung der Gemeinde als Kolonie römischen Rechts erfolgte $181 \mathrm{v}$. Chr. und wurde im Zug einer zweiten Kolonisierung 169 v. Chr. noch einmal durch das Triumvirat von Titus Annius Luscus, Publius Decius Subulo und Marcus Cornelius Cethegus erneuert. ${ }^{523}$ Im Jahr 90 v. Chr. wurde sie zum municipium erhoben und ihren Bewohnern das römische Bürgerrecht verliehen. ${ }^{524} \mathrm{Als}$ militärischer Knotenpunkt und Legionsstandort war Aquileia wegen seiner Lage an den Grenzen zum Alpenraum und Illyrien seit jeher von großer Bedeutung und diente zuerst Caesar, später auch Augustus als wichtiger Stützpunkt für Militäroperationen. ${ }^{525}$ Während der frühen Kaiserzeit war Aquileia vor allem eine Stadt des Handels, die wirtschaftlich prosperierte und zunehmend wuchs. Über den einstigen Wehrmauern der republikanischen Zeit entstanden im Südosten ein weitläufiger Flusshafen, im Norden und Süden teils luxuriös ausgestattete Wohnhäuser und im Westen mit dem Theater ein imposanter Vergnügungsbau. Im 2. Jh. wurde auch das Terrain östlich des Flusses Natiso erschlossen. Im Stadtzentrum kam es zu mitunter aufwendigen Bauprojekten und Restaurierungsmaßnahmen, die - wie wir gleich sehen werden - unter anderem auch das Forum betrafen. In dem Konflikt zwischen dem römischen Senat und dem vom Donaulimes heimkehrenden Maximinus Thrax spielte Aquileia im Jahr 238 eine wichtige Rolle, als es dem zum Staatsfeind erklärten Kaiser Widerstand bot und sich hinter einem in aller Eile aus den Resten der republikanischen Stadtmauer und älterer Gebäude errichteten Schutzwall verschanzte. ${ }^{526}$ Unter der Regierung Diocletians stieg die Gemeinde schließlich zum Sitz des Statthalters der nunmehr neu eingerichteten Provinz Venetia et Histria auf. Sie erfreute sich als Residenzstadt des reisenden Kaisers großer Beliebtheit und erhielt eine eigene Münzprägestätte, die mit zwischenzeitlichen Unterbrechungen bis 425 in Betrieb war. ${ }^{527}$ Eine Blütezeit erlebte

522 Einen geschichtlichen Überblick zu Aquileia bieten die beiden reich bebilderten Bände Ghedini 2009 und Fozzati 2010, jeweils mit weiterführender Literatur zu einzelnen Epochen und Themengebieten; zur urbanistischen Entwicklung der Stadt mit einem Schwerpunkt auf die Zeit der Spätantike und den christlichen Kultbauten s. Jäggi 1990; ebenfalls mit Fokus auf die Zeit ab dem 3. Jh. s. Haug 2003, 86-106 mit dem ausführlichen Katalogteil auf S.325-367; zum Forum und seinen Inschriftenmonumenten des 4. Jhs. s. Witschel 2012/13 [2015], 31-35. Unverzichtbar für das Studium des antiken Aquileia sind die seit 1972 fortlaufende Reihe Antichità Altoadriatiche, Atti delle Settimane di studio aquileiesi (AAAd) sowie die seit 1930 erscheinende Zeitschrift Aquileia nostra (AN).

523 Zur ersten Gründung durch das Triumvirat Publius Cornelius Nasica, Gaius Flaminius und Lucius Manlius Acidinus Fulvianus: Liv. 39,22,6f.; 45,6f.; 54,1-55,6; 40,26,2; 34,2f.; CIL V 873. Zur zweiten Gründung: Liv. 43,1,5f.

524 Vitr. 20,3R.

525 Caes. Gall. 1,10,3; Tac. hist. 2,46; 85; 3,6; 8.

526 Herodian. 8,2-5.

527 Zur Münzprägung in Aquileia s. überblicksartig Gorini ${ }^{21986}$; Paolucci/Zub 2000. 
Aquileia im 4. und 5. Jh., eine Zeit, die vor allem durch eine intensive Christianisierung der Bevölkerung geprägt war und die einige der bedeutendsten Bauwerke des christlichen Kults in dieser Region hervorgebracht hat. ${ }^{528}$ Die große politische und kulturelle Stabilität dieser Epoche, die wohl nicht zuletzt auf die Rolle Aquileias als einflussreichem Bischofssitz zurückzuführen ist, wurde zu Beginn des 5. Jhs. und noch einmal 452 unterbrochen, als zunächst die Westgoten und dann Attila in die Stadt einfielen. ${ }^{29}$ War die Bevölkerung nach Abzug des Feinds jedes Mal zurückgekehrt und hatte sich um den Wiederaufbau bemüht, so blieb die Stadt nach einem erneuten Einfall im Jahr 568, dieses Mal durch die Langobarden, verlassen und zerfiel fortan zusehends. ${ }^{530}$

Wie für römische Koloniestädte üblich, lag das kaiserzeitliche Forum im Zentrum der Stadt, wo die beiden Hauptverkehrsachsen decumanus und cardo maximus aufeinanderstießen. ${ }^{531}$ Höchstvermutlich hatte sich hier auch schon das republikanische Forum befunden, das im Laufe der Zeit immer wieder erweitert und im 2. Jh. schließlich zu einer monumentalen Platzanlage ausgebaut wurde (Abb.61). ${ }^{532}$ Um eine weitläufige, mit Kalksteinplatten gepflasterte Freifläche von rund 140 mal 56 Metern erhob sich im Norden, Westen und Osten eine um drei Stufen erhöhte Portikus und im Süden eine dreischiffige Basilika mit zwei Apsiden an den Schmalseiten. Aus südlicher Richtung kommend, konnte man den Platz über die Basilika betreten. Weitere Eingänge befanden sich am Nordrand sowie an den Längsseiten, wo der decumanus in das Forum mündete.

Die Portikus beherbergte kleine Stuben und Verkaufsläden. Die Basilika diente wohl vornehmlich als Gerichtsstätte. Von anderen, für römische Fora typischen Gebäuden haben sich indes keine Spuren erhalten - dass es aber auch Tempel, Verwaltungsgebäude und Amtslokale gegeben haben muss, ist wahrscheinlich. ${ }^{53}$

528 Dazu zählen insbesondere die Kathedrale mit dem angrenzenden Bischofskomplex im Südosten (s. hierzu die Literaturverweise in Anm. 610 auf S. 230-232) sowie die kleine Kirche Sant'Ilario (s. Jäggi 1989) innerhalb der Stadtmauern. Unter den suburbanen Anlagen sind die sog. Beligna-Basilika auf dem Fondo Tullio (s. Brusin 1947; Cantino Wataghin 1989; dies. 2006; Zettler 2001, 180-183 mit Grundrissplan und Dokumentation der erhaltenen Mosaikinschriften im Boden), die Klosterkirche von S. Martino (Jäggi 1990, 181) und die sog. Monastero-Basilika zu nennen, deren Grundmauern heute als Teil des Frühchristlichen Museums in Aquileia zu besuchen sind (Bertacchi 1965; Forlati Tamaro 1965; Zettler 2001, 168-179 mit Grundrissplan und Dokumentation der erhaltenen Mosaikinschriften im Boden; Cantino Wataghin 2006).

529 Iord. Get. 42.

530 S. hierzu Jäggi 1990; Verzár-Bass 2003; Haug 2003, 100-106.

531 Zum kaiserzeitlichen Forum und seinen Bauten s. Brusin 1935; Bertacchi 1989; Ruaro Loseri 1961; Scavi ad Aquileia 1991 und 1994; Meng 1993; Maselli Scotti 1995; Mirabella Roberti 1995; Maselli Scotti et al. 1999; Haug 2003, 86-106 passim mit dem Katalogteil S. 329-331; Witschel 2007, 129-132; Maselli Scotti 2013.

532 Haug 2003, 329f.

533 Außerhalb des Forums, nördlich der vorbeilaufenden Straße, konnten zwei Gebäude freigelegt werden, bei denen es sich offenbar um die curia und das comitium der Gemeinde handelt; s. hierzu Maselli Scotti 1995; Haug 2003, 331. 


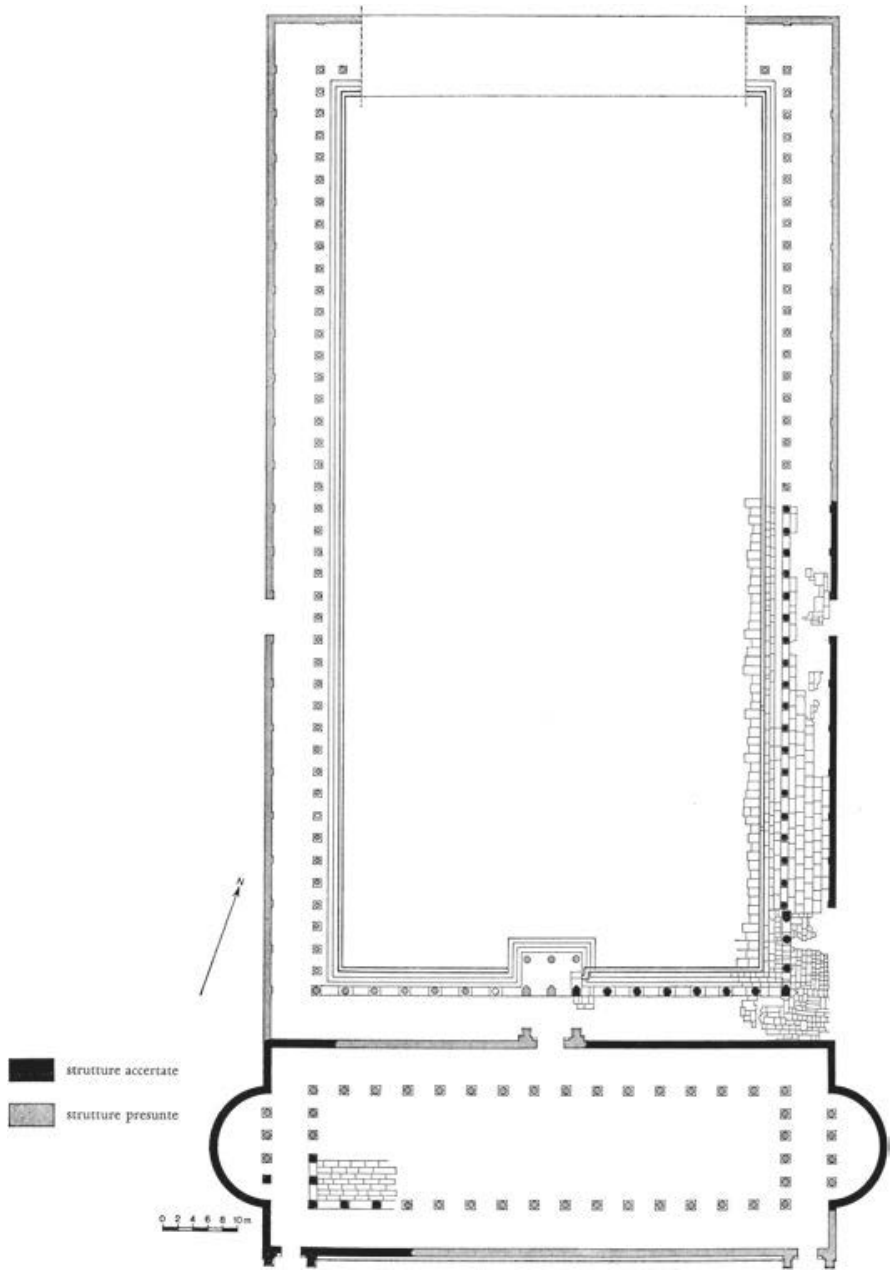

Abb. 61: Forum von Aquileia, Grundriss.

Gesichert ist indes die Existenz zweier Brunnen im Süden und Südosten der Freifläche, welche hier vermutlich schon in republikanischer Zeit angelegt worden waren. In ihnen fanden sich zahlreiche Gegenstände des Alltagslebens sowie des Kunsthandwerks, daneben auch eine hellenistische Bronzeapplik und ein vergoldeter Bronzekopf des 3. Jhs. ${ }^{534}$ Besondere Erwähnung verdient der Reliefschmuck der Portikusanlage. Auf den von korinthischen Kapitellen bekrönten Säulen aus lokalem weißem Marmor ruhte ein Dreifaszien-Architrav mit einem lesbischen Kyma und einem Girlandenfries. Darüber erhob sich eine hohe Attikazone, in der sich Reliefdarstellungen von Girlanden tragenden Eroten und Adlern mit Protomen des Iuppiter Amon und der Medusa abwechselten (Abb. 62, 63). Sie gehören stilistisch in severische Zeit und 


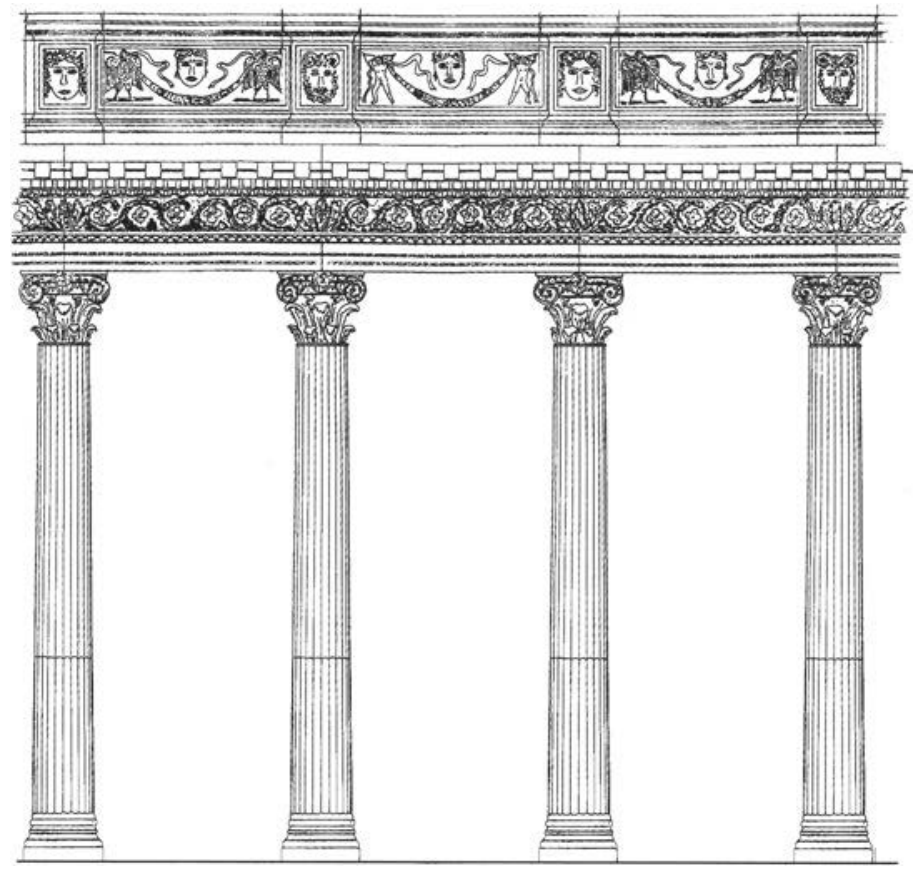

Abb. 62: Rekonstruktion der Portikus am Forum.

geben als solche einen vergleichsweise präzisen Anhaltspunkt für die Datierung der gesamten Forumsanlage in das späte 2. oder frühe $3 . \mathrm{Jh}^{535} \mathrm{Bis}$ zur Zerstörung Aquileias durch die Hunnen in der Mitte des 5. Jhs. sollte das Forum seine Bedeutung als gesellschaftliches Zentrum der Stadt beibehalten. Es wurde gepflegt und regelmäßig restauriert, teilweise auch mit neuen Bauten und Monumenten ausgestattet. ${ }^{536}$ Andererseits sind im Verlauf des 4. Jhs. aber auch Veränderungsprozesse in der Nutzung des Platzes wahrnehmbar, die seine Rolle als Ort öffentlicher Inschriftlichkeit betrafen.

Seit den ersten Grabungsarbeiten am Forum in den 1930er-Jahren und den systematisch durchgeführten Untersuchungen des Areals ab 1969 wurden mehrere Inschriften(fragmente) unterschiedlicher Zeitstellung entdeckt, einige davon noch immer in situ oder zumindest in unmittelbarer Nähe ihres einstigen Aufstellungsorts. Legen wir diese Funde für die Rekonstruktion des Forums als einem ,beschrifteten Raum zu-

535 S. Ruaro Loseri 1961 zur Rekonstruktion des Portikus-Gebälks; Casari 2004 und Verzár-Bass 2017 zum Motiv der Iuppiter-Amon- und Medusa-Köpfe, seiner Herkunft vom Augustus-Forum in Rom und seiner Verbreitung im nördlichen Adriaraum und der Cisalpina; zur Datierung s. Cavalieri Manasse 1983, 150-153.

536 So wurde der Platz im 4. Jh. stellenweise neu gepflastert, wozu man teilweise auf ältere Inschriftenplatten zurückgriff, darunter ein Exemplar mit einer Weihinschrift an Venus (Maselli Scotti/Zaccaria 1998, 155-157). Im Westen des Forums könnte in spätkonstantinischer Zeit ein neues Gebäude errichtet worden sein, worauf der Fund mehrerer Ziegel mit dem Stempel Constantini Victoris hindeuten (Tiussi/Villa/Novello 2013, 223 cat. 31). 

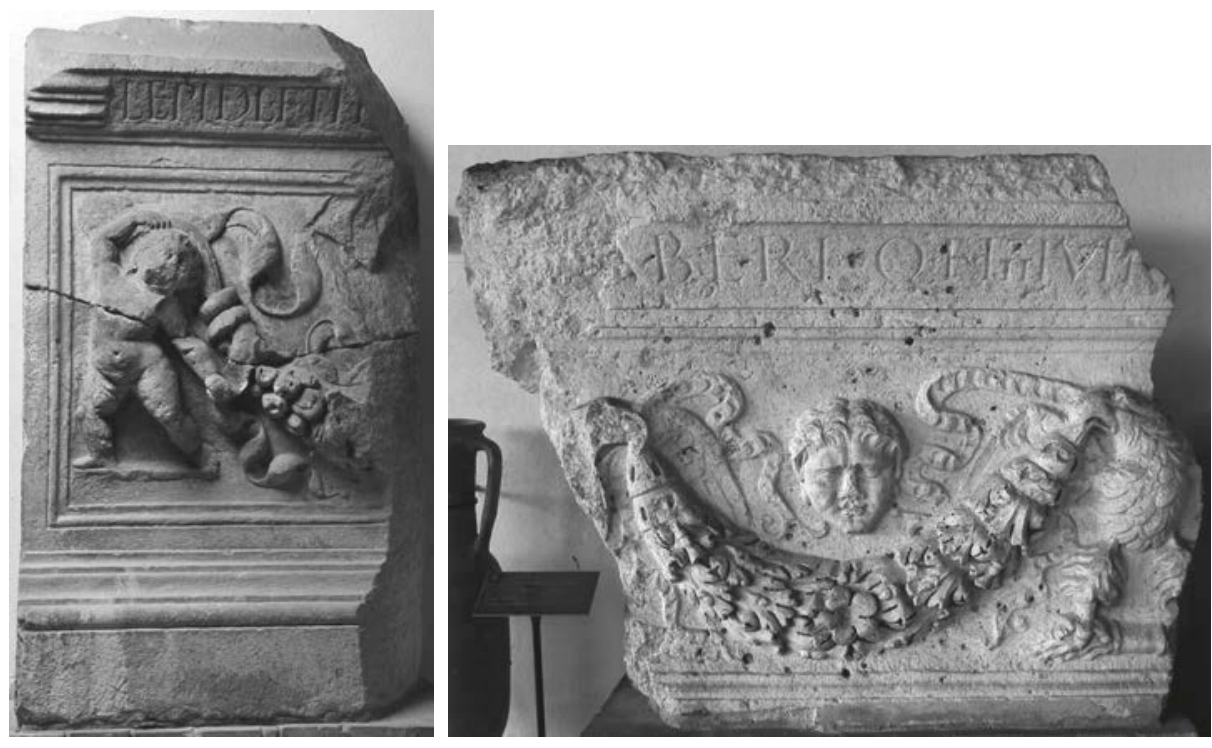

Abb. 63a-b: Gebälkteile der Forums-Portikus mit den nachträglich angebrachten Inschriften der summi viri.

grunde, wie er sich einem Besucher in der Mitte des 4. Jhs. darstellte, so kristallisiert sich das Bild eines Orts heraus, an dem sich die gemeinschaftliche städtische Identität ebenso Ausdruck verschaffte wie der Stolz auf die ruhmvolle Vergangenheit und das kulturelle Erbe Aquileias.

Betrat der Besucher das Forum von Norden her, so eröffnete sich ihm der Blick auf die umlaufende Portikus mit ihrer reichen ornamentalen Verzierung am Gebälk. Am oberen Rand der Attikazone, direkt über den Reliefdarstellungen und Protomen, waren Inschriften angebracht, bei denen es sich um Namensinschriften von verdienten und berühmten Männern der ferneren und jüngeren Vergangenheit handelte (Abb.63). Offenbar wurden die Inschriften nachträglich angebracht, indem man die Profilleiste an dieser Stelle abschlug, die Fläche glättete und dann die Inschriften anbrachte. Insgesamt haben sich 14 Fragmente dieser Inschriften erhalten, von denen sich einige mit bekannten Persönlichkeiten, Amtsträgern und patroni Aquileias in Verbindung bringen lassen. Darunter sind zum Beispiel L. Manlius Acidinus, einer der triumviri von der Gründung der Kolonie im Jahr 181 v. Chr., oder Laberius Quinti filius, einer der ersten quattorviri des municipium. ${ }^{537}$ Daneben waren offenbar auch ehemalige Kaiser in ihrer Funktion als Konsuln sowie Mitglieder des Herrscherhauses genannt. Eine

537 Von den 14 erhaltenen Stücken haben sich neun auf dem Gelände des Forums gefunden. Drei Fragmente waren offenbar schon im 19. Jh. bekannt, aber ohne Fundort dokumentiert worden. Die zwei übrigen stammen von einer Fundstelle etwas nördlich des Forums. Einige der Stücke sind publiziert bei IAq 649-654 und Lettich 2003, 25 Nr. 23; 32 Nr. 26, 27; s. außerdem: Maselli Scotti/Zacca- 
(sehr fragmentarisch) erhaltene Inschrift könnte Maximian (286-305) gegolten haben, mit der - sollte die Zuweisung an den Tetrarchenkaiser stimmen - im Übrigen auch eine Datierung der Inschriften zur Zeit seiner Regierung oder kurz danach angenommen werden kann. ${ }^{538}$ Sehr wahrscheinlich waren dazu passende Bildnisse der Männer direkt über den jeweiligen Namen als Bekrönung des Gebälks angebracht. Auch wenn dies am archäologischen Befund heute nicht mehr nachzuvollziehen ist, spricht vieles dafür: zum einen die Genitivkonstruktionen der Inschriften, die nach dazugehörigen Statuen der genannten Männer verlangen, zum anderen die Tatsache, dass derartige Inschriften ohne dazugehörige Bildnisse nur schwer vorstellbar sind, weil sich erst im Zusammenspiel der beiden Elemente ,Bild' und ,Schrift' die öffentliche Ehrung manifestierte. ${ }^{539}$ Nur in scheinbarem Widerspruch dazu steht der Umstand, dass die Inschriften mit einer Buchstabenhöhe von lediglich sieben bis knapp zehn Zentimetern erstaunlich klein sind und als solche in einer Höhe von mehr als neun Metern gewiss nur schwer zu erkennen waren - selbst wenn sie farbig ausgemalt waren, um so ihre Sichtbarkeit zu erhöhen. Wir begegnen hier dem Problem der eingeschränkten Sicht- und Lesbarkeit von Inschriften, ein Phänomen, das deren Bestimmung als zur öffentlichen Wahrnehmung ausgestellten Schriften zuwider zu laufen scheint: Wenn man die Namen ohnehin nicht hat lesen können, warum machte man sich dann die Mühe, diese - wohl unter nicht ganz einfachen Bedingungen - nachträglich an der Portikus anzubringen? Offenbar weil es den hierfür Verantwortlichen weniger um ihre Lesbarkeit als um ihre bloße Existenz an eben jener Stelle ging. Für die Würdigung der jeweiligen Person war die Rezeption der Inschrift durch den Betrachter weitgehend unerheblich - das leistete die Errichtung und die fortdauernde Existenz des entsprechenden Bild-Text-Ensembles. Für die Wirkung dieser Arrangements als Monument sorgte in erster Linie die optische Präsenz der Statuen, nicht aber die Tatsache, dass der Betrachter die Inschriften lesen konnte und dies auch tatsächlich tat. Dass er sie zur Kenntnis nehmen konnte, reichte aus. Man muss sich die Situation am Forum in Aquileia wohl ähnlich wie am Augustus-Forum in Rom vorstellen, wo den summi viri der Römischen Republik ein vergleichbares Denkmal gesetzt wurde und welches als Vorbild für Aquileia gedient haben könnte: eine effektvolle Würdigung für die ehrenwertesten Männer der Stadt und zugleich ein ausdrucksstarkes Sinnbild für die historische Größe und den Stolz auf die eigene Vergangenheit. ${ }^{540}$

In diesen Zusammenhang gehört ein weiteres statuarisches Denkmal, welches sich dem von Norden voranschreitenden Besucher des Forums alsbald zu seiner Rechten präsentierte: das Standbild des Publius Valerius Maro, des „Vaters“ des Vergil,

ria 1998, 125-130, insb. mit Anm. 56-58; Witschel 2012/13 [2015], 34; Tiussi/Villa/Novello 2013, $222 \mathrm{f}$. Nr. 30.

538 IAq 457 = 653: ---]i Maxi[---. Daneben werden vor allem paläographische Argumente für eine Datierung in das frühe 4. Jh. ins Feld geführt: Reiner 1991, 22; Zaccaria 2000, 93.

539 S. hierzu auch o. Kap. 2.2.4.

540 Vgl. Sotinel 2005, 38. 


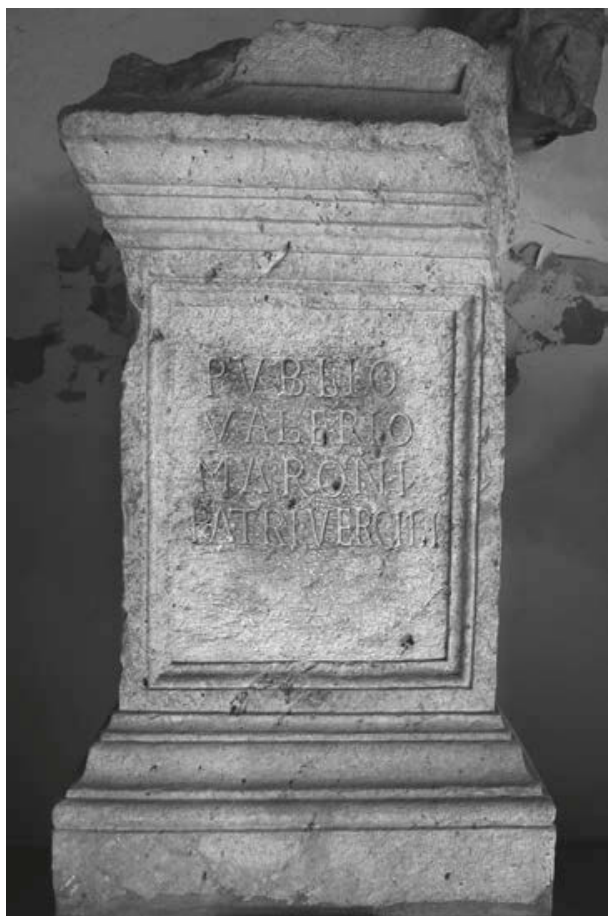

Abb. 64: Basis für eine Statue des Publius Valerius Maro, gefunden im östlichen Teil des Forums.

von dem sich allerdings nur die Basis mit der darauf angebrachten Namensinschrift mit den Worten Publio / Valerio / Maroni / patri Vergili erhalten hat (Abb. 64). ${ }^{541}$ Wie es die spezifische Gestaltung einiger Buchstaben der Inschrift - insbesondere des A mit gebrochener Querhaste und des gerundete $\mathrm{G}$ - verraten, war das Denkmal nicht in der Kaiserzeit, sondern um einige Zeit später, vermutlich im 4. Jh. entstanden. ${ }^{542}$ Dafür wurde auf eine ältere Basis (wohl aus dem 1. Jh.) zurückgegriffen, deren Inschrift abgeschlagen und durch die neue des Valerius Maro ersetzt wurde. Winzige Farbspuren in den Vertiefungen der Buchstaben zeigen, dass diese mit roter Farbe hervorgehoben waren. ${ }^{543}$ Wer das Bildnis zur Aufstellung gebracht hat, verschweigt die Inschrift seltsamerweise; da es auf dem Forum aufgestellt war, wird es aber wohl kaum eine

541 Die Basis wurde 1985 im östlichen Bereich des Forums gefunden, wahrscheinlich in unmittelbarer Nähe seines ursprünglichen Standorts; s. AE 1987, 425; Lettich 2003, 33 Nr.30; LSA 2660; außerdem Paci 1987; ders. 1989; di Stefano Manzella 1995, 164-172; Maselli-Scotti/Zaccaria 1998, 154-155; Sotinel 2005, 38f.; Witschel 2012/13 [2015], 34. Bei dem hier Geehrten kann es sich allerdings nicht um den leiblichen Vater des Vergil gehandelt haben, da dieser aus der gens Vergilia stammte. Da die dem Vergil-Kommentar des Aelius Donatus vorangestellte Vita Donatiana aus dem 4. Jh. einen Halbbruder des Vergil mit Namen Valerius Proculus erwähnt, liegt die Vermutung nahe, dass Maro den Dichter zu einem ungewissen Zeitpunkt adoptiert hatte (Vita Donati, Vitae Vergilianae antiquae, ed. C. Hardie, Oxford 1954, 14). Warum er das Cognomen Maro führte, bleibt unklar; vgl. hierzu Sotinel 2005, 39.

542 Vgl. Paci 1989.

543 Bertacchi 1986, 408, die die Basis damals allerdings noch als einen Altar des 2. Jhs. interpretierte. 
private, sondern eine von städtischen Institutionen verantwortete Ehrung gewesen sein.

Das Bildnis lässt sich schwerlich alleine vorstellen, weshalb überzeugend vorgeschlagen wurde, dass es zu einer größeren Statuengruppe gehörte, welche neben Valerius Maro auch Vergil selbst sowie Angehörige seiner Familie zeigte. ${ }^{544}$ Wahrscheinlich war diese im Rahmen der Erneuerung der Portikusanlage auf dem Forum zur Aufstellung gekommen und sollte die große Wertschätzung gegenüber dem Dichter der römischen Klassik bekunden. Insbesondere in der Spätantike erlebten die Werke Vergils noch einmal eine Renaissance, weshalb ein Denkmal zu seinen Ehren zu dieser Zeit keineswegs ungewöhnlich war. Dass weder Maro noch Vergil tatsächlich Söhne der Stadt waren und wohl auch sonst keine engen Beziehungen zu Aquileia gepflegt hatten, spielte dabei im Übrigen keine Rolle. Ihre Standbilder waren vielmehr Ausdruck eines ganz allgemein empfunden Stolzes auf die künstlerischen Leistungen der römischen Kultur überhaupt. ${ }^{545}$

Das auf dem Forum öffentlich inszenierte Erinnern an das politische und kulturelle Erbe Aquileias ging Hand in Hand mit einem Bekenntnis zu traditionellen römischen Werten. Am westlichen Rand des Forums, direkt an der Stelle, wo eine breite Querstraße in den Platz mündete, sah sich der Besucher gleich drei inschriftlichen Denkmälern gegenüber, die Gestalten der römischen Götterwelt zum Bildthema hatten. Aufgestellt wurden sie von Septimius Theodulus, der um 360 das Amt des Statthalters von Venetia et Histria bekleidete. ${ }^{546}$ In allen drei Fällen sind nur die Basen erhalten geblieben, bei denen es sich ausnahmslos um wiederverwendete Stücke aus dem 2. Jh. handelt. ${ }^{547}$ Die erste Statue zeigte wahrscheinlich Hercules, dessen Name auf der oberen Randleiste der Basis zu lesen war, während die eigentliche Inschrift auf dem zuvor geglätteten Inschriftenfeld stand: [Sept(imius)] Theodulus, / [v(ir) c(larissimus), c]orr[ector] ornavit (Abb.25a und b, s. o. S.116). ${ }^{548}$ Die zweite Basis trug nach Ausweis der Inschrift eine Statue der Concordia, der personifizierten Eintracht (Abb.26, s. o. S.116). Wie zuvor bereits dargelegt, wurde die alte Inschrift hier allerdings nicht komplett entfernt, sondern mit der neuen Inschrift des Theodulus kombiniert, indem diese einfach zwischen die Zeilen der bereits vorhandenen gesetzt wurde. ${ }^{549}$ Wessen Bild die dritte wiedererrichtete Statuenbasis zeigte, lässt sich angesichts der denkbar knappen Inschrift mit den Worten Septimius Theodulus, v(ir) c(larissimus) / [cor]rec(tor) ornavit nicht mehr ermitteln (Abb. 65). Dass es sich auch hier um eine Gestalt der römischen

544 So Witschel 2007, 129 und LSA 2660 (C. Machado u. U. Gehn); skeptischer Sotinel 2005, 39f., u. a. weil eine solche Statuengruppe für Aquileia nicht belegt ist.

545 Vgl. Mayer i Olivé 1993; Maselli Scotti/Zaccaria 1998, 154; Witschel 2007, $129 f$.

546 PLRE I Septimius Theodulus.

547 Zum Aspekt der Wiedererrichtung von älteren Denkmälern s. auch oben Kap. 3.4, S.115-117, wo die Basen im Zusammenhang mit der Praxis der Wiederverwendung besprochen werden.

548 S. o. S. $115-117$.

549 S. o. S. 117. 


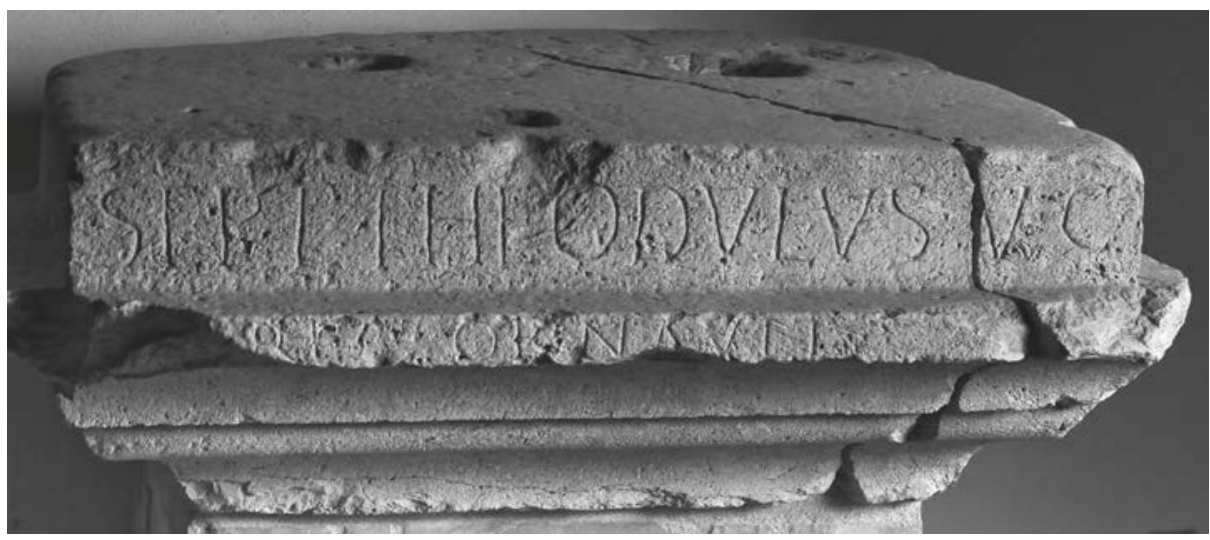

Abb. 65: Fragment einer Basis für eine wiedererrichtete Statue mit der Inschrift des Septimius Theodulus, gefunden am Westrand des Forums.

Götterwelt gehandelt hat, steht mit Blick auf die Sujets der anderen beiden Stücke aber mit gutem Grund zu vermuten. Diese Beobachtung ist insofern interessant, als dass es sich bei Theodulus mit Sicherheit um einen Christen handelte: In der sog. Allemannenbeute aus dem Rhein bei Straßburg fand sich ein liturgisches Bronzegefäß, das neben der Inschrift des Theodulus auch ein Alpha-Omega-Symbol aufweist. ${ }^{550}$ Die von ihm verantworteten Statuenumsetzungen auf dem Forum von Aquileia galten also in erster Linie der Pflege der opera publica und mithin der traditionellen kulturellen Werte - was aber offenbar zu keinem Konflikt mit seiner religiösen Überzeugung führte. Claudio Zaccaria interpretierte diese Form der Bewahrung paganer Götterbilder im öffentlichen Stadtraum überzeugend als Loyalitätsbekundung gegenüber den römischen Institutionen, die Theodulus in seiner Rolle als corrector der Provinz Venetia et Histria ja ohnehin vertrat. ${ }^{551}$

Es mag kein Zufall gewesen sein, dass sich Theodulus ausgerechnet den Bereich des Westzugangs zum Forum für die Aufstellung seiner Statuen wählte. Nicht nur, dass ihnen hier dank des regen Publikumsverkehrs große Aufmerksamkeit zuteil wurde. An eben dieser Stelle standen auch noch andere inschriftliche Denkmäler, deren Gesellschaft geeignet war, die eigenen Stücke aufzuwerten, denn es waren Denkmäler von hohem Alter und mit großer Bedeutung für die Identität der Bürgerschaft von Aquileia.

Bei einem dieser Stücke handelte es sich um das im 2. Jh. v. Chr. geschaffene Ehrenbildnis für Titus Annius, einer der triumviri, denen man die zweite Koloniegründung 169 v. Chr. zu verdanken hatte. Das Postament seines Ehrenbildnisses wurde bei Ausgrabungen 1995 ganz in der Nähe der Theodulus-Basen gefunden, unmittelbar vor

550 CIL XIII 10027, 69 = ILCV 84a-b.

551 Zaccaria 2008, 136. 


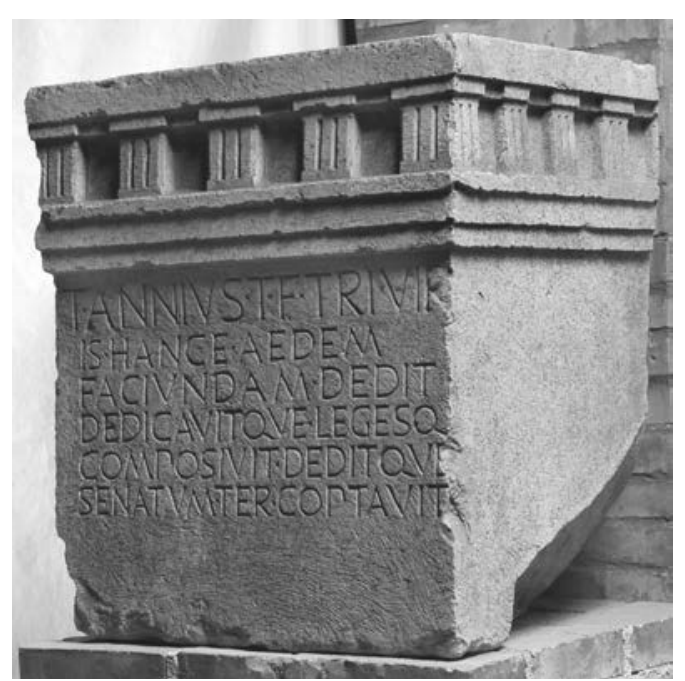

Abb. 66: Statuenbasis mit der Inschrift für den triumvir Titus Annius, gefunden am Westrand des Forums.

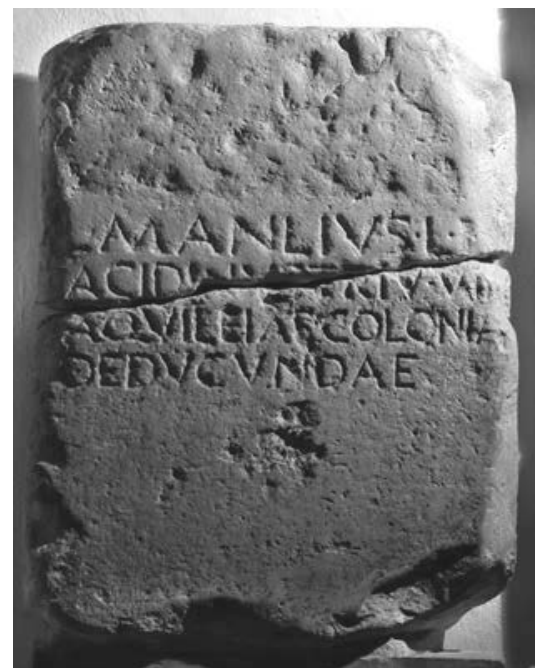

Abb.67: Tafel mit Ehreninschrift für den triumvir L. Manlius Acidinus, wahrscheinlich aufgestellt auf dem Forum.

den Stufen der Portikus (Abb. 66). ${ }^{552}$ Es trägt die Inschrift T(itus) Annius T(iti)f(ilius) tri(um)vir / is hance aedem / faciundam dedit / dedicavitque legesq(ue)/ composivit deditque / senatum ter co(o)ptavit, mit der man Annius als Stifter eines Tempels ehrte, welcher bislang allerdings nicht ausfindig gemacht werden konnte. Anlass für Fragen gibt auch die spezifische Gestaltung der Basis mit einem Drei-Faszien-Architrav und Metopen-Triglyphen-Fries am oberen Abschluss. Da dies für eine Statuenbasis äußert ungewöhnlich ist, schlug Christiano Tiussi zuletzt vor, das Stück als Altar eben jenes unbekannten Tempels zu interpretieren, von dem in der Inschrift die Rede ist ${ }^{553}$ - eine bedenkenswerte Idee, die sich allerdings nur schwer mit der Inschrift in Zusammenhang bringen lässt, die sich wie ein elogium, also eine postume Ehreninschrift, liest und folglich die Verbindung mit einem Standbild voraussetzt. ${ }^{54}$ Dieses muss von besonderer Bedeutung für die Bewohner Aquileias gewesen sein, denn den Fundumständen nach zu urteilen, war das Denkmal auch im 4.Jh. noch an Ort und Stelle zu sehen, um die Person des Annius in öffentlicher Erinnerung zu halten.

Angesichts fehlender Befunde zwar nicht zu beweisen, vor diesem Hintergrund aber gut vorstellbar, war Titus Annius nicht der einzige Gründervater, dem man auf dem Forum ein Denkmal gesetzt hatte. Wahrscheinlich waren auch seine beiden Amtskollegen sowie das Triumvirat der ersten Koloniegründung 181 v. Chr. mit einer Statu-

552 AE 1996, 685; Maselli Scotti/Zaccaria 1998, 130-143; Zaccaria 2000, 94; Lettich 2003, 34 Nr. 31; Zaccaria 2014.

553 Tiussi 2009.

554 Vgl. Zaccaria 2014, $524 \mathrm{f}$. 
engruppe vertreten - wenn auch nicht als Stifter eines Tempels, so doch als ehrenwerte Männer, welche die Geschichte der Stadt geprägt und gleichsam begründet hatten. ${ }^{555}$ Die heute im Museo Archeologico ausgestellte Basis mit einer Ehreninschrift für L. Manlius Acidinus, der dem Dreimännerkolleg von 181 v. Chr. angehörte, könnte zu einem solchen Ensemble auf dem Forum gehört haben (Abb. 67). ${ }^{556}$ Aus der Zeit der späten Republik stammt ein am Südende des Platzes gefundenes Fragment mit der Inschrift ---]i L(ucius) Tulliu[s ---], welches vermutlich ebenfalls zu einem Ehrendenkmal ähnlicher Art gehörte. ${ }^{557}$

Neben den alten Denkmälern vergangener Tage fehlte es aber nicht an Monumenten, welche die aktuelle Gegenwart reflektierten. Dazu zählen in erster Linie Ehreninschriften für Mitglieder des Kaiserhauses sowie für Mitglieder der Reichsverwaltung, wobei die Zeugnisse für letztere seit der Mitte des 3. Jhs. kaum noch zu fassen sind. ${ }^{558} \mathrm{Zu}$ den beiden spätesten Zeugnissen, die auf Denkmäler dieser Art hindeuten, gehören eine Inschrift zu Ehren des vir perfectissimus und magister sacrarum cognitionum Q. Axilius Urbicus aus dem späteren 3. oder frühen 4. Jh. (Inschrift Nr. A.II.1) ${ }^{559}$ sowie eine weitere, an der Ostseite des Forums entdeckte Marmortafel, bei der es sich wohl um die Ehreninschrift für ein Mitglied des konstantinischen consistorium handelt (Inschrift Nr. A.II.2). Bildnisse der Kaiser mit entsprechenden tituli scheinen hingegen noch häufiger aufgestellt worden zu sein, wie es etwa zwei spätantike Kaiserporträts ${ }^{560}$ sowie Ehreninschriften für die Söhne Konstantins I. von der Westseite des Forums bezeugen (Inschrift Nr. A.I.5).

Ungeachtet dieser auf dem Platz selbst zu Tage gekommenen Stücke ist aus Aquileia noch eine ganze Reihe weiterer Ehreninschriften bekannt, die sich ursprünglich ebenfalls auf dem Forum befunden haben müssen, zu einem späteren Zeitpunkt aber als Baumaterial weggeschafft wurden. Dies gilt zum Beispiel für eine Ehreninschrift der Kaiser Diocletian und Maximian, die in der Kathedrale von Aquileia verbaut wurde (Inschrift Nr.A.I.7), sowie für die vielen im Fundament der Monastero-Kirche

555 Mit dieser Annahme zuvor auch schon Maselli Scotti/Zaccaria 1998, 143.

556 IAq 27 = AE 1990, 388. Der Fundort des Stücks ist unbekannt. Die Statue muss allerdings nicht direkt nach der Gründung im Jahr 181 v. Chr. aufgestellt worden sein, eine Datierung in spätere Zeit ist ebenfalls vorstellbar; s. hierzu Wachter 1987, 277 Anm. 687.

557 AE 1996, 688; Mainardis/Zaccaria 1993, 77; Bertacchi 1995, 147. Die gens Tullia taucht in mehreren Inschriften aus Aquileia auf und zählte während der republikanischen Zeit offenbar zu den einflussreichsten Familien der Stadt; s. hierzu Bertacchi 1989, 72.

558 S. hierzu o. S. 33 .

559 Das Stück wurde nicht auf dem Forum, sondern in der Klosterkirche Monastero verbaut gefunden. Da die Inschrift aber davon spricht, die Bürger der Stadt hätten die Statue ihrem Patron an einem öffentlichen Ort errichtet, kann es sich hierbei wohl nur um das Forum handeln.

560 Museo Archeologico, Aquileia, Inv. 161336; L'Orange 1984, 128; und Museo Archeologico, Aquileia, Inv. 261; Santa Maria Scrinari 1972, 68f. Nr.202; LSA 1015; die Zuweisung dieses Kopfs zu der Darstellung eines Kaisers ist allerdings unsicher; möglicherweise handelt es sich um die Darstellung eines hohen Beamten. 
zum Vorschein gekommenen Statuenbasen. Darunter sind etwa das mächtige, im Jahr 105 n. Chr. errichtete Postament für eine Reiterstatue des Ritters C. Minicius Italus ${ }^{561}$ und mehrere Basen mit Inschriften für Kaiser des 3. Jhs. ${ }^{562}$ Wann sie vom Forum weggeschafft wurden, ist schwer zu beurteilen. Womöglich war es im früheren 4. Jh. zu einer umfassenden Neukonzeption des Platzes gekommen, in dessen Zug nicht nur die Portikus mit den Bildnissen und Inschriften der summi viri ausgestattet, sondern auch die Platzanlage als repräsentativer Ort städtischer Identität neu gestaltet wurde. Alte Bildwerke und Denkmäler, welche die gemeinsame Vergangenheit versinnbildlichten und für die Geschichte der Stadt von Bedeutung waren, blieben an Ort und Stelle. Andere, denen diese Wertschätzung nicht zuteil wurde und die vornehmlich der individuellen Ehrung städtischer Beamter und Wohltäter gedient hatten, wurden hingegen abgeräumt und als Baumaterial wiederverwendet. Ersetzt wurden sie durch neu geschaffene Monumente, darunter solchen mit Gegenwartsbezug, wie etwa Porträts der regierenden Herrscher, vor allem aber durch retrospektive Denkmäler, in denen sich ein ausgeprägtes Geschichtsbewusstsein Ausdruck verschaffte, wie etwa die Standbilder der summi viri oder die Statuengruppe des Vergil und seiner Familie.

Angefangen bei den Bildnissen aus dem 2. Jh. v. Chr. über die erneut zur Aufstellung gekommenen Denkmäler der Kaiserzeit bis hin zu denjenigen der aktuellen Gegenwart präsentierte sich dem Besucher so eine ganze Vielzahl unterschiedlichster Inschriften, die im Laufe der Jahrhunderte zu einer vielfältigen und facettenreichen ,Landschaft‘ zusammengewachsen waren.

\subsubsection{Ostia: Die Inschriftenlandschaft des Stadtraums}

Livius zufolge soll es der vierte König von Rom, Ancus Marcius, gewesen sein, der den an der Mündung des Tiber gelegenen Ort im 7. Jh. v. Chr. gründete (Abb. 68). ${ }^{563}$ Die frühesten Spuren der zunächst als castrum angelegten Siedlung sind für die Mitte des 4. Jhs. v. Chr. nachgewiesen, als Ostia vor allem für die Kontrolle der Flussschifffahrt in dieser Region eine bedeutende Rolle spielte. Mit der Einrichtung der provincia quaestoria Ostiensis im Jahr 267 v. Chr. wurde es zum Sitz des quaestor classicus ernannt und war fortan ein wichtiger Flottenstützpunkt für Rom. ${ }^{564}$ Besondere Bedeutung kam dem Hafenort auch als Umschlagsplatz für Getreidelieferungen aus Sizilien und Sardinien zu, wovon die noch heute sichtbaren Reste großer Speicherbauten im Hafengebiet zeugen. Zunächst sorgte ein quaestor von Rom aus für die Verwaltung Ostias, bis in der Mitte des 1. Jhs. v. Chr. das für Kolonien übliche System mit unabhängigen decu-

561 CIL V 875 = ILS 1274; Pflaum 1960/61, 141-143 Nr. 59,1; Alföldy 1984, 98f. Nr. 87.

562 Zum Beispiel CIL V 865 (Gallienus); 857 (Salonina); s. hierzu auch Mainardis/Zaccaria 1993, 67 mit weiteren Befunden in Anm.19.

563 Liv. 1,33,9.

564 Cic. Sest. 39; Cic. Mur. 18 


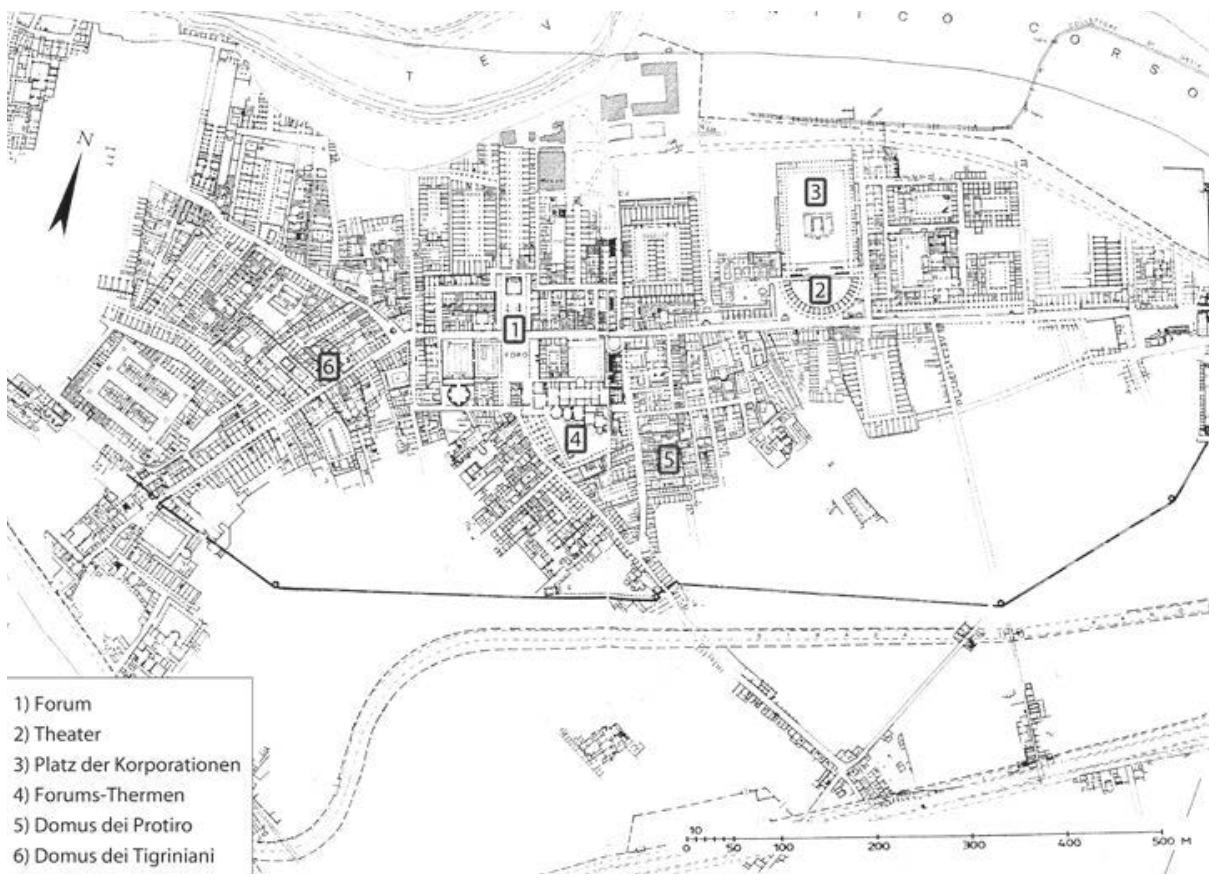

Abb. 68: Ostia, Gesamtplan der Stadt in der Spätantike.

riones und duumviri eingeführt wurde, wodurch die Einflussnahme Roms allerdings nie wirklich geschmälert wurde. ${ }^{565}$ Aus dieser Zeit sind vor allem Wirtschafts- und Lagerbauten bekannt sowie einige Heiligtümer (zum Beispiel für Hercules, Vulcanus und die Bona Dea) und private Wohnhäuser. ${ }^{566}$ Will man Cicero Glauben schenken, war das spätrepublikanische Ostia kein Ort, an dem man sich gerne aufhielt: non tam gratiosam et illustrem quam negotiosam et molestam. ${ }^{567}$ Das änderte sich allerdings in der Kaiserzeit, als sich die ehemals hektische Handelsstadt $\mathrm{zu}$ einer amoenissima civitas entwickelte und schon bald zu einem beliebten Zweitwohnsitz römischer Aristokraten wurde. Diese ließen hier ihre mitunter großzügig angelegten und luxuriös ausgestatteten domus errichten, welche ihren stadtrömischen Vorbildern in kaum etwas nachstanden. ${ }^{568}$ Mit dem nördlich des decumanus maximus gelegenen Theater war schon im Jahr 17 v. Chr. ein imposanter Vergnügungsbau entstanden. Im Laufe der Zeit folgten mehrere Thermen und kleinere Bäder, die sowohl von öffentlicher Hand

565 S. hierzu die fragmentarisch erhalten gebliebenen Fasti Ostienses ab 46 v. Chr.: Vidman ${ }^{2} 1982$; Grosso/Bargagli 1997.

$566 \mathrm{Zu}$ den Kulten und zum religiösen Leben Ostias s. Rieger 2004.

567 Cic. Mur. 8,18.

568 Zum privaten Wohnen in Ostia s. Boersma 1985; Danner 2017. 
als auch von Privatleuten betrieben wurden. ${ }^{569}$ Vom wirtschaftlichen Wohlstand der Stadt zeugten auch die zahlreichen Vereinshäuser und die Sitze verschiedener collegia, wie etwa der sog. Platz der Korporationen. ${ }^{570}$ Die größte Blüte erlebte Ostia im 2. Jh., als mehrere aufwendige Bauprojekte zu einer Monumentalisierung des Stadtbilds führten und Ostia ein imposantes architektonisches Antlitz verliehen. An öffentlichen Plätzen und entlang den Straßen wurden stattliche Hallen und Basiliken mit reichem Baudekor errichtet. Brunnenanlagen und Nymphäen sorgten für ein angenehmes Ambiente. Unter Hadrian errichtete man nördlich des Forums im Herzen der Stadt ein gewaltiges Capitolium, etwas später ließ Antoninus Pius eine große Thermenanlage bauen. In severischer Zeit bemühte man sich vor allem um den Erhalt und Ausbau des bestehenden Baubestands und sorgte zum Beispiel für den Ausbau und die Vergrößerung des Theaters. Ein großer Rundtempel westlich des Forums war eines der letzten großen öffentlichen Neubauprojekte, das vermutlich unter Severus Alexander realisiert wurde. ${ }^{571}$

Im Verlauf des 3. Jhs. verlor Ostia seine Bedeutung als Wirtschaftszentrum zunehmend an das nur wenige Kilometer nördlich gelegene Portus, das schon unter Claudius und Trajan zu einem großen Seehafen ausgebaut worden war. ${ }^{572}$ In der Folge gingen auch die Bevölkerungszahlen in Ostia zurück und einige einst belebte Stadtgebiete verödeten angesichts des schwindenden Bedarfs an Wohnraum und Gewerbebauten. Überregionaler Handel spielte keine zentrale Rolle mehr, und Ostia scheint sich spätestens im 4. Jh. zu einer recht beschaulichen Wohnsiedlung entwickelt zu haben. Das öffentliche Leben konzentrierte sich auf bestimmte Zonen in der Innenstadt, um deren Instandhaltung und Attraktivität man sich sehr bemühte und die nach wie vor gepflegt und rege besucht wurden. Das galt insbesondere für den decumanus maximus, der zu einer repräsentativen Promenade mit schmucken Fassaden, Zierbauten und Brunnen umgestaltet wurde, ebenso wie für das Theater und die großen Thermenanlagen.

Dank intensiver archäologischer Untersuchungen konnten in den letzten Jahren sehr detaillierte Erkenntnisse gewonnen werden, wie wir uns das spätantike Stadtbild Ostias im 4. und 5. Jh. vorzustellen haben. ${ }^{573}$ Entgegen dem in der Forschung lange Zeit vorherrschenden Bild einer im ökonomischen und kulturellen Niedergang begriffenen Stadt, in der sich jeglicher baulicher Gestaltungswille auf den Bereich des privaten Wohnens konzentrierte, während man dem öffentlichen Stadtraum nur wenig Aufmerksamkeit schenkte und sich auf den notdürftigen Erhalt einiger weniger

569 Zum Theater s. Calza 1927; Battistelli/Greco 2002; zu den Thermen und Badehäusern s. Poccardi 2006.

$570 \mathrm{Zu}$ den Vereinen und ihren Bauten s. Zevi 2008.

571 S. hierzu Descœudres 2001, 254-259 (A.-K. Rieger).

572 Zur spätantiken Stadtgeschichte Ostias s. Pavolini 1986; Boin 2013 mit Schwerpunkt auf dem christlichen Ostia; zu Portus s. Keay et al. 2005.

573 S. hierzu besonders die Arbeiten von Axel Gering und Luke Lavan: Gering 2004; ders. 2010; ders. 2011a; ders. 2011b; Lavan 2012. 
gemeinschaftlich genutzter Anlagen beschränkte, erlebte Ostia im 4. Jh. eine intensive urbanistische Renaissance: Der bereits bestehende Baubestand wurde aufwendig renoviert und aufgewertet und durch mehrere Neubauten, wie Thermen, Portiken und Nymphäen, ergänzt. Inschriftliche Denkmäler spielten dabei ebenfalls Rolle und waren elementarer Bestandteil vieler Bau- und Umgestaltungsinitiativen dieser Zeit. Wo immer Alt und Neu in Beziehung zueinander traten, aneinander anknüpften und miteinander interagierten, so waren hiervon auch Inschriften und epigraphische Monumente betroffen, die Ostia in großer Zahl aufzuweisen hatte.

Wie sich die über Jahrhunderte gewachsene Inschriftenlandschaft Ostias im späten 4. und frühen 5. Jh. präsentierte und inwiefern sie auch jetzt noch in einem ständigen Wandel begriffen war, führt der Platz der Korporationen besonders anschaulich vor Augen (Abb. 69). Die monumentale Platzanlage von rund 107 mal 78 Metern schloss sich direkt an das Bühnenhaus des Theaters nach Norden hin an und war zusammen mit diesem in augusteischer Zeit errichten worden. ${ }^{574}$ In der Mitte des Platzes ragte ein kleiner Podiumstempel empor, der den Komplex als sakralen Raum auswies und auch für Versammlungen genutzt werden konnte. ${ }^{575}$ Nach ersten Umbaumaßnahmen unter Claudius wurde das Gelände im 2. Jh. auf das heutige Niveau aufgeschüttet und die den Platz umlaufende Portikus um eine zweite Säulenreihe erweitert. Im Inneren wurden mit Hilfe von Trennwänden insgesamt 61 kleine Kammern angelegt, in welchen die zahlreichen in Ostia beheimateten Vereine und Handelsorganisationen ihre Büros und Geschäftsräume (stationes) unterhielten. Um welche es sich dabei handelte - Schiffsreeder, Holzhändler, Gerber, Seiler, Kalfaterer und andere mehr -, konnte der Besucher großen Inschriften in dem mit Mosaiken ausgelegten Fußböden entnehmen, die vor den jeweiligen Eingängen in einer tabula ansata zu lesen waren (Abb. 70). ${ }^{576}$

Daneben gab es auch Inschriften auf Marmortafeln, wie diejenige mit dem Schriftzug NAVICULARI AFRICANI, die wohl für die Anbringung an der Außenwand des entsprechenden Raums gedacht waren (Abb.71). ${ }^{577}$ Das weitläufige Areal des Platzes wurde indes für die Errichtung statuarischer Denkmäler genutzt, von denen neben einigen Standbildern auch die beschrifteten Postamente erhalten geblieben sind. ${ }^{578}$ Dabei handelte es sich um Bildnisse von Magistraten, Geschäftsleuten und Vereinsfunktionären Ostias, die sich besondere Verdienste für die Stadt erworben und hier öffentliche Würdigung für ihre Leistungen erfahren hatten. Im Laufe der Zeit muss ihre Zahl stetig angewachsen sein, bis der Platz im frühen 3. Jh. regelrecht mit Statuen-

574 Zum Platz der Korporationen s. SdOstia I, 1953, 116f. (G. Becatti); Pavolini 1983, 67-69; Steuernagel 2005; Cébeillac-Gervasoni/Caldelli/Zevi 2006, 225-227.

$575 \mathrm{Zu}$ dem Tempel und seiner Bedeutung für das Vereinswesen in Ostia s. Steuernagel 2005, 78.

576 Aufgelistet bei: SdOstia IV, 1961, 64-85 (G. Becatti); Cébeillac-Gervasoni/Caldelli/Zevi 2006, 225-230; van der Meer 2012, 32-37.

577 NSc 1953, 285 Nr. 44.

578 Aufgelistet bei Laird 2002, 261-264; van der Meer 2012, $39 f$. 


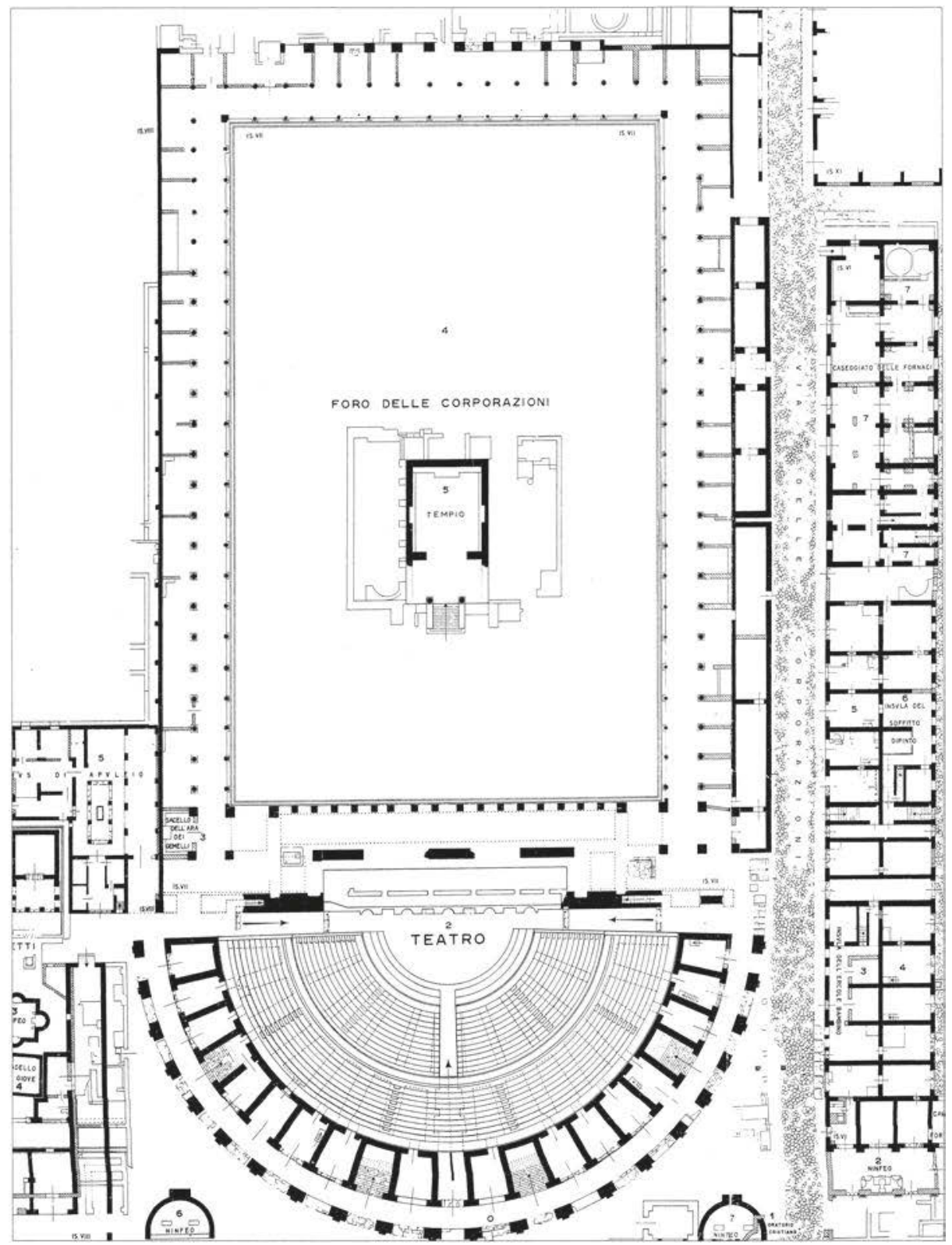

Abb. 69: Platz der Korporationen hinter dem Theater, Grundriss.

denkmälern gefüllt war. Lange Zeit scheint sich an dieser Situation nichts geändert zu haben. Erst als der Platz im 4. Jh. seine Funktion als Sitz der Vereine und Handelstreibenden einbüßte und nunmehr vor allem in Rahmen von Veranstaltungen im Theater genutzt wurde, veränderte sich auch die seit der Mitte des 2. Jhs. stetig gewachsene 


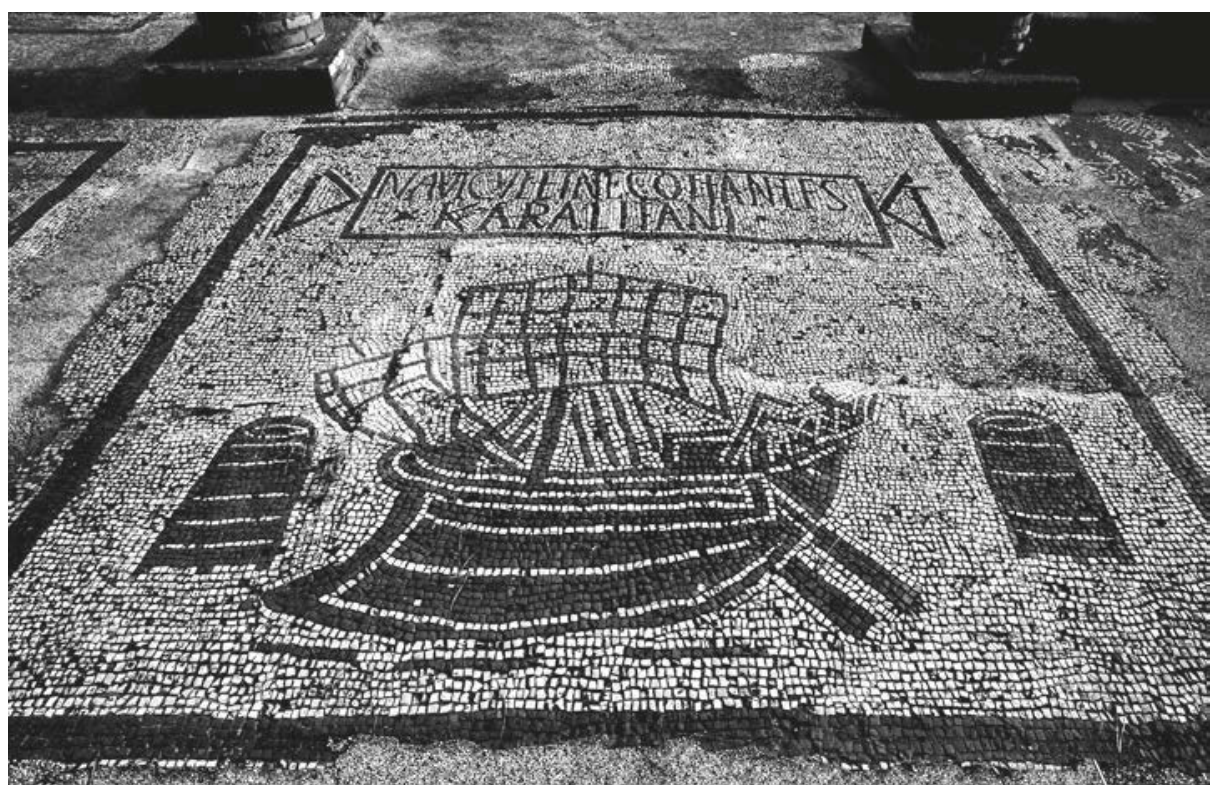

Abb.70: Platz der Korporationen, Bodenmosaik der umlaufenden Portikus vor der Kammer der navicularii karalitani.

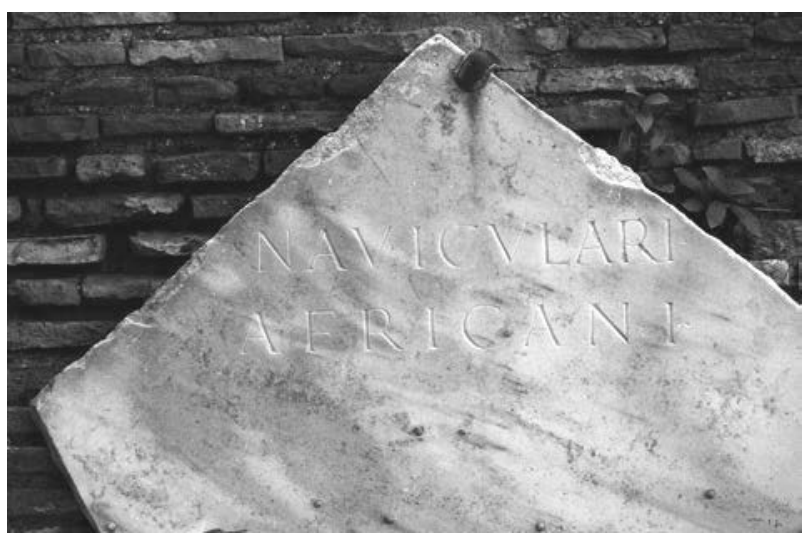

Abb. 71: Inschriftentafel der naviculari africani vom Platz der Korporationen.

Inschriftenlandschaft des Platzes: Die Standbilder und ihre Basen wurden entfernt und für den Ausbau des Theaters benutzt. Diese Praxis der Wiederverwendung war ein nicht nur in Ostia durchaus üblicher Umgang mit älteren Monumenten und Denkmälern, der in der Spätantike besonders intensiv und auffallend häufig gepflegt wurde. ${ }^{579}$ Vor allem im Bereich des neu angelegten zentralen Korridors des Theaters waren viele

579 Zum Aspekt der Wiederverwendung von Statuenbasen als Baumaterial in der Spätantike s. o. Kap.3.3. 


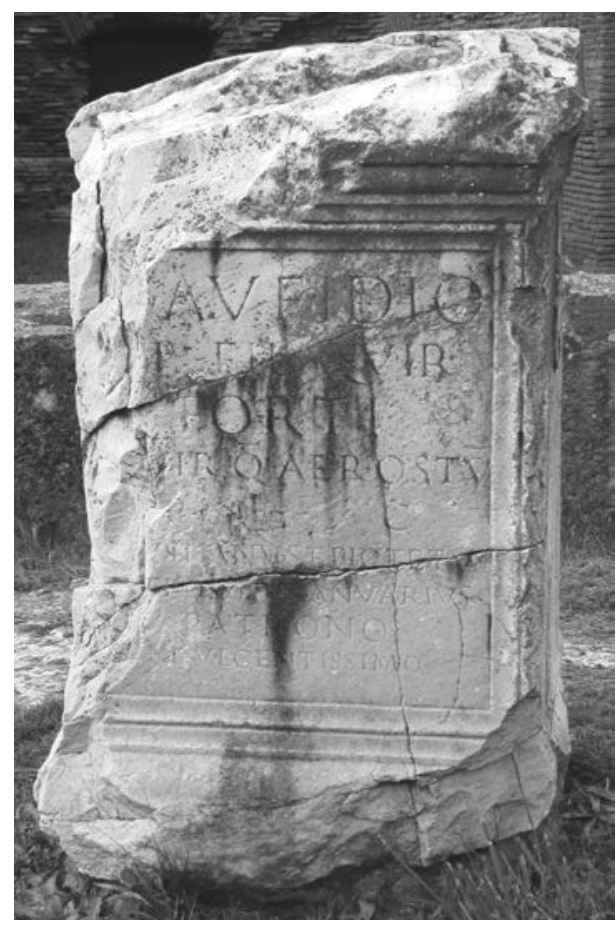

Abb.72a: Statuenbasis vom Platz der Korporationen mit der kaiserzeitlichen Inschrift des P. Aufidius Fortis (CIL XIV 4621).

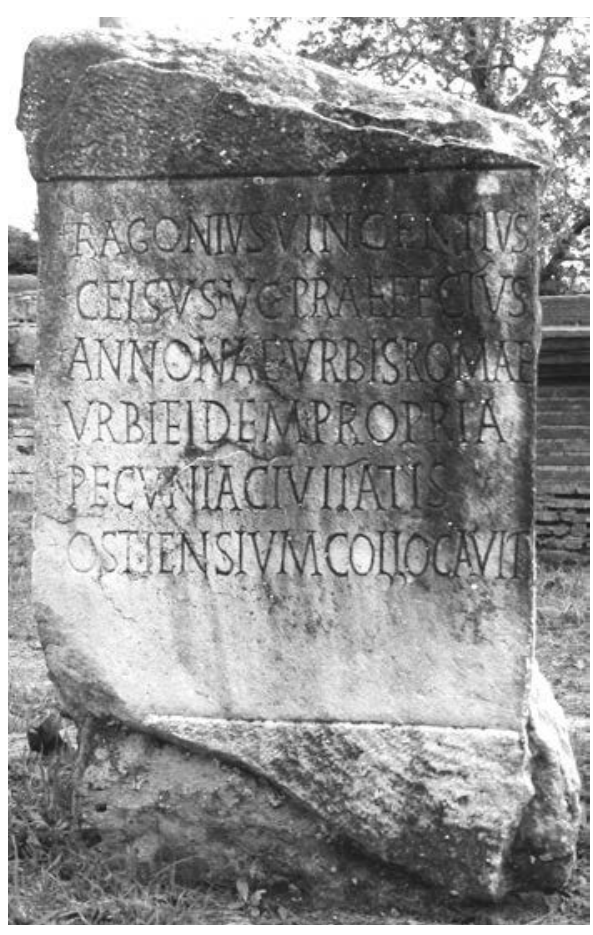

Abb. 72b: Spätantike Inschrift des Ragonius Vincentius Celsus auf der ehemaligen Rückseite (CIL XIV 4716).

der Postamente als bequem zu beschaffendes und gleichsam sofort gebrauchsfertiges Baumaterial zum Einsatz gekommen. ${ }^{580}$ Wo Inschriftlichkeit also einstmals sehr präsent war, war sie nun (zumindest in Form der beschrifteten Statuenbasen) verschwunden - oder hatte sich an andere Orte verlagert. So wurde etwa die in der Mitte des 2. Jhs. auf dem Platz der Korporationen errichtete Basis für ein Standbild eines gewissen P. Aufidius Fortis (Abb. 72a) wiederverwendet und anderswo erneut zur Aufstellung gebracht. Ragonius Vincentius Celsus, im späten 4. Jh. praefectus annonae von Rom und als solcher auch für den Umbau des Theaters verantwortlich, hatte sich die Basis zu eigen gemacht, um eine Statue der Göttin Roma darauf zu errichten. Dazu wurde die alte Inschrift des Fortis stehen gelassen, die Basis kurzerhand umgedreht und sodann auf der (ehemaligen) Rückseite mit dem neuen Widmungstext des Celsus versehen (Abb.72b):

580 Paschetto 1912, 335. S. hierzu auch die Angaben bei den entsprechenden CIL-Einträgen, zum Beispiel rep. in theatro (CIL XIV 390), ex parietinis theatri Ostiensis (CIL XIV 4140), basis extracta ex theatro Ostiensis (CIL XIV 4142). Viele der im Theater vermauerten Basen wurden im Zuge moderner Restaurierungsarbeiten wieder auf dem Platz der Korporationen aufgestellt, wo sie heute zu sehen sind. 
Ragonius Vincentius / Celsus v(ir) c(larissimus) praefectus / annonae urbis Romae / urbi eidem propria / pecunia civitatis / Ostiensium collocavit. ${ }^{581}$

Ragonius Vincentius Celsus, vir clarissimus, praefectus annonae urbis Romae, stellte dies eben dieser Stadt [d. h. eine Statue der Roma] auf, aus dem eigenen Geld der Gemeinde von Ostia.

Ihren neuen Platz hatte die Basis nun direkt vor dem Theater und präsentierte sich dem auf dem decumanus entlangschreitenden Besucher $\mathrm{zu}$ dessen Rechten. Und dies war nicht der einzige Fall dieser Art. Während des 4. Jhs. wurden auch anderswo in Ostia bereits bestehende Bildwerke und Denkmäler von verlassenen Stadtteilen fortgeholt, mit neuen Inschriften ausgestattet und an noch immer belebten Plätzen erneut errichtet. Das im Zentrum des ehemaligen castrum gelegene Forum etwa war ein solcher Ort (Abb.73).

An der Westseite des Platzes, direkt südlich des vorbeilaufenden decumanus steht noch heute eine Basis in situ, deren Inschrift berichtet, die Statue sei auf Geheiß des im späteren 4. Jh. amtierenden praefectus annonae P. Attius Clementinus von einem unansehnlichen Ort auf das Forum gebracht worden, um dieses zu verschönern (Abb. 74):

Translatam ex sor/dentibus locis / ad ornatum fori / et ad faciem publicam / curante P(ublio) Attio / Clementino v(iro) c(larissimo) / praef(ecto) ann(onae). ${ }^{582}$

Versetzt aus verächtlicher Gegend zum Schmuck des Forums und zum öffentlichen Anblick, unter der Fürsorge des P. Attius Clementinus, vir clarissimus, praefectus annonae.

Am östlichen Rand, zwischen Portikus und Thermenanlage, standen zwei weitere Statuendenkmäler des 4. Jhs., dieses Mal errichtet von Ragonius Vincentius Celsus, dem uns schon durch seine Romastatue vom Theater bekannten Stadtpräfekten (Abb. 87, 88, s. u. S. 265). ${ }^{583}$ Auch sie stammten ursprünglich aus dem 2. Jh. und waren nunmehr mit der gleichlautenden Inschrift Curavit Ragonius Vincentius Celsus, v(ir) c(larissimus), praefectus annonae urbis Romae, et civitas fecit memorata de proprio versehen - wiederverwendet worden. Einander als Paar ergänzend, flankierten sie den Eingang zur Via della Forica, einer Parallelstraße des decumanus, die das Forum mit dem östlich gelegenen sog. Foro della Statua Eroica verband.

Weniger der ästhetischen Aufwertung des Platzes als vielmehr der öffentlichen Ehrung zugedacht war ein weiteres inschriftliches Denkmal des Forums, welches zu Beginn des 4. Jhs. in der Nähe des Roma-Augustus-Tempels im Süden des Platzes

581 CIL XIV 4716 = AE 1910, 196 = LSA 1662; Witschel 2007, 139; Inschrift des 2. Jhs.: CIL XIV 4621. 582 CIL XIV 4721 = LSA 329; Witschel 2007, 139. Hier, wie auch bei der Basis des P. Aufidius Fortis, zeugen Reliefs an den Nebenseiten noch von der ersten Nutzung der Basis. Die alte Inschrift wurde allerdings vollständig entfernt.

583 CIL XIV 4717 = AE 1928, 131 = LSA 2582; Witschel 2007, 139 und CIL XIV 139 = LSA 1651. Das Sujet der zugehörigen Bildwerke ist nicht mehr zu ermitteln. Vermutlich handelte es sich um Götterbildnisse. 
1: Statuenbasis P. Attius Clementinus

2: Statuenbasis Ragonius Vincentius Celsus

3: Statuenbasis Ragonius Vincentius Celsus

4: Reiterstatuenbasis Manlius Rusticianus

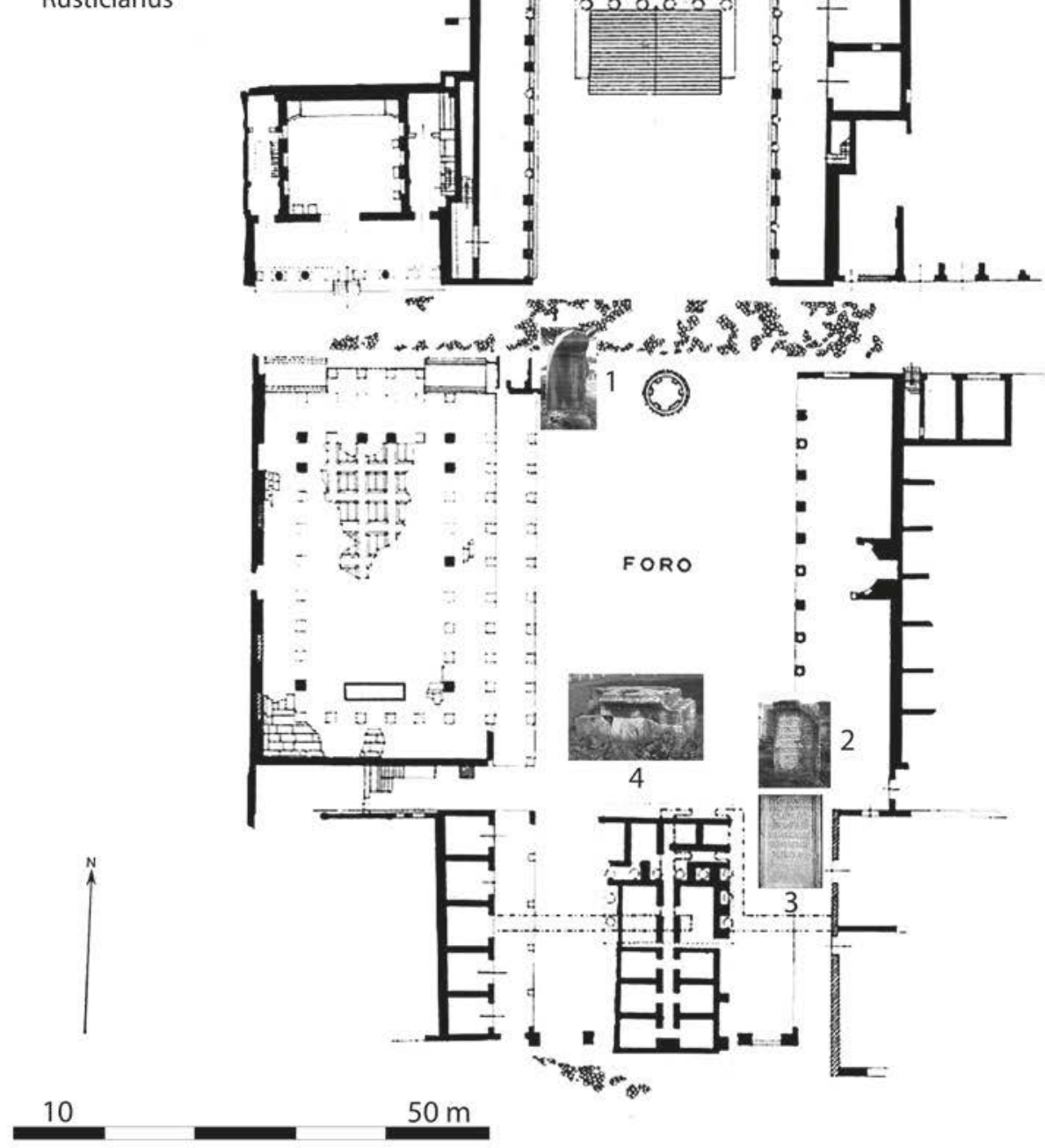

Abb.73: Plan des spätantiken Forums von Ostia mit darin eingetragenen Inschriftenzeugnissen. 


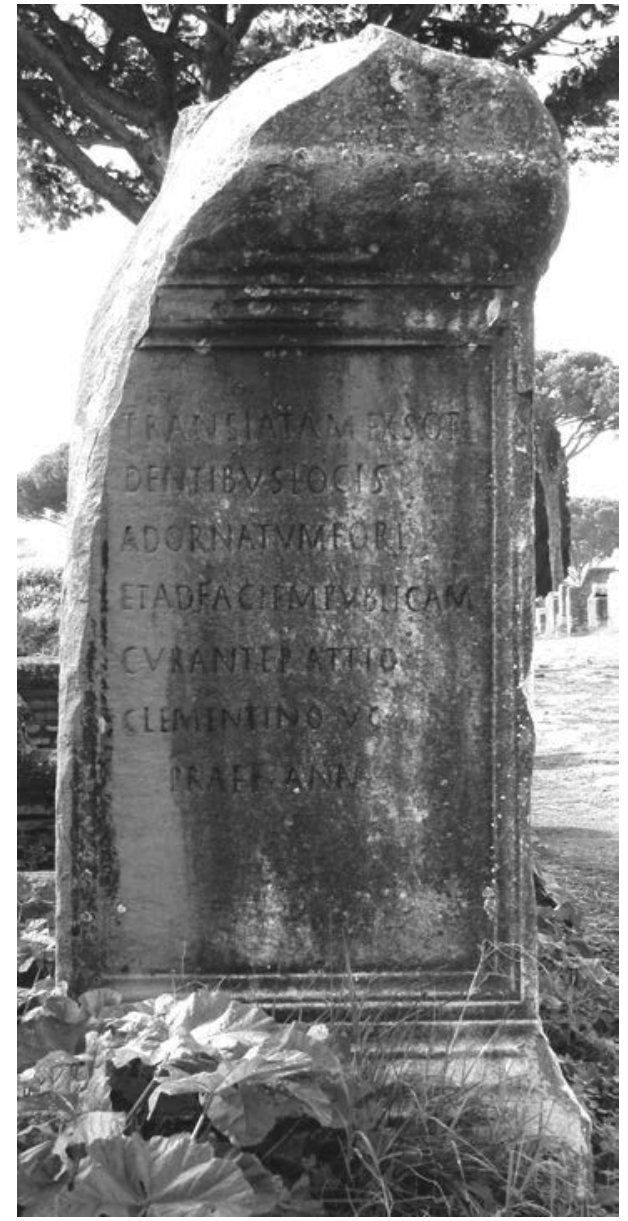

Abb.74: Basis für ein wiedererrichtetes Standbild mit der Inschrift des P. Attius Clementinus.

errichtet wurde und sich auch heute noch dort befindet. Dabei handelt es sich um das Postament für eine Reiterstatue des Manlius Rusticianus, ebenfalls praefectus annonae (Abb. 75). ${ }^{584}$ Den von Rom aus agierenden Beamten, die seit dem späten 3. Jh. für die Verwaltung Ostias zuständig waren, oblag auch die Sorge um das öffentliche Bauwesen, weswegen sie häufig als Bauherren auftraten und für die skulpturale Ausstattung öffentlicher Plätze und Gebäude sorgten. Ihr Engagement dankte man ihnen im Gegenzug mit der Errichtung einer Ehrenstatue.

Neben diesen heute noch in situ befindlichen Stücken muss es auf dem Forum aber noch weitere Ehrenstatuen aus früheren Epochen gegeben haben, deren Spuren heute allerdings verloren sind. So berichten mehrere Grab- und Ehreninschriften lokaler Magistrate und Aristokraten aus Ostia, dass diese zu Lebzeiten mit einer Statue - 


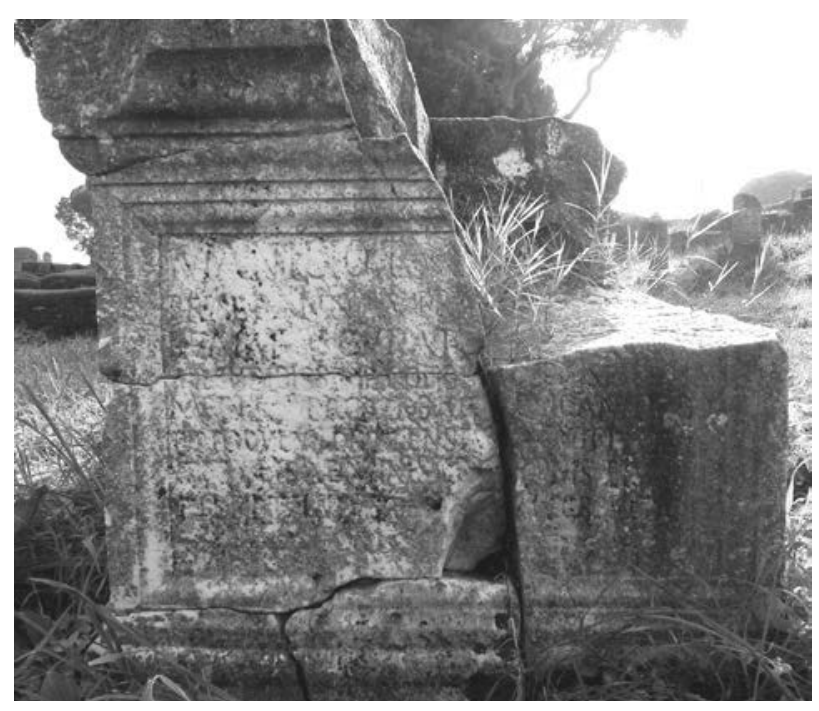

Abb.75: Wiederverwendete Basis für eine Reiterstatue des Manlius Rusticianus vom Südrand des Forums.

mitsamt dazugehöriger Inschrift - auf dem Forum geehrt worden waren. ${ }^{55}$ Und den Grabungsunterlagen des frühen 19. Jhs. ist zu entnehmen, dass man während der ersten systematischen Untersuchungen des Forums zwischen 1802 und 1804 Denkmäler dieser Art in großer Zahl geborgen habe, um sie anschließend in private und öffentliche Sammlungen zu überführen. ${ }^{586}$ Darunter waren womöglich auch Denkmäler von historischer Bedeutung, wie wir sie bereits vom Forum aus Aquileia kennen. In einem Abwasserkanal der Via dei Molini wurde eine Marmortafel gefunden, deren Inschrift dem mythischen Gründer Ostias, dem römischen König Ancus Marcius, galt:

A[nco] / Mar[cio] / reg[i Rom(ano)] / quart[o a R]omul[o] / qui ab u[rbe c]ondit[a] / [pri]mum colon[iam] / [c(ivium) Rom(anorum)] dedux[it]. ${ }^{587}$

585 So zum Beispiel die Inschrift des Fabius Hermogenes: CIL XIV 353: Fabio Hermog[eni] / equo publ(ico) scribae aedil[i] / dec(urioni) adl(ecto) flam(ini) divi Hadri[ani] / in cuius sacerdotio solus ac p[rimus ludos] / scaenicos sua pecunia fecit [---] / hunc splendidissimus ordo dec[urionum f(unere) $p$ (ublico)] / honoravit eique statuam equestre[m cum in]/scriptione ob amorem et industria [m] / in foro ponendam pecun(iam) publ(icam) decr[evit] / inque locum eius aedil(i) substituendum [---] / putavit in solacium fabi pat[ris] / qui ob honores ei habitos HS L m(ilia) n(ummum) / dedit ex quorum usuris quincunci[bus] / [quot]annis XIII Kal(endas) Aug(ustas) die natali eius dec[urionibus] / [si]ngulis / (denarii) V dentur et decuri[alibus] / [ce]raris / (denarii) XXXVII s(emis) libraris / (denarii) [XXXVIIS] / li[ctor]ibus / (denarii) XXV[---] // In aede Romae et Augusti placu[it] / ordini decurionum praesente / Fabio patre uti sportulas / die natal(i) Hermogenis fili(i) / eius praesentibus in foro ante / statuas ipsius dividi / stipulatione interposita.

586 Paschetto 1912, 485-565; vgl. Gering 2011a, 474.

587 CIL XIV 4338 = AE 1919, 63 = AE 2000, 266; Cébeillac-Gervasoni/Caldelli/Zevi 2006, 73f. Nr.1; Dat.: wohl Mitte 2.Jh. 


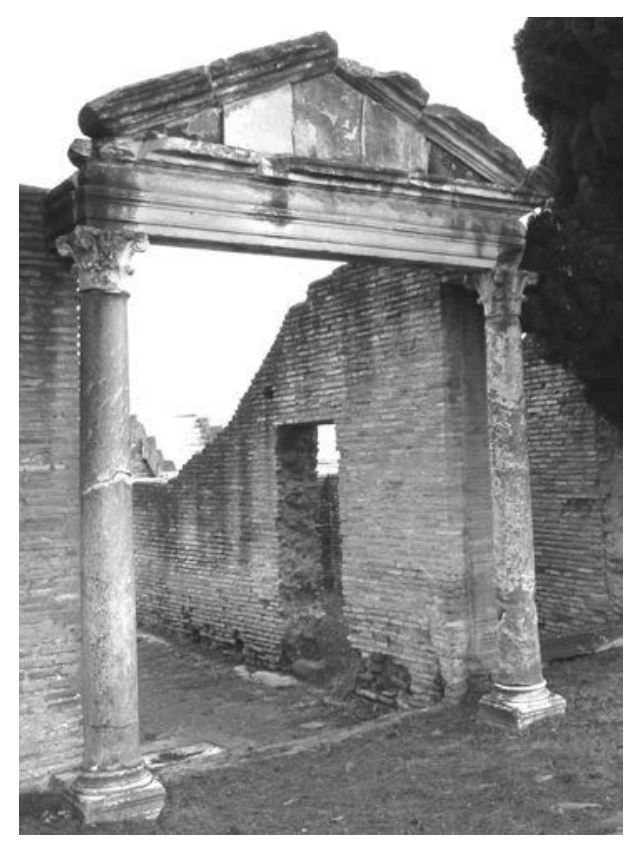

Abb.76a: Sog. Domus del Protiro, Eingangsportal.

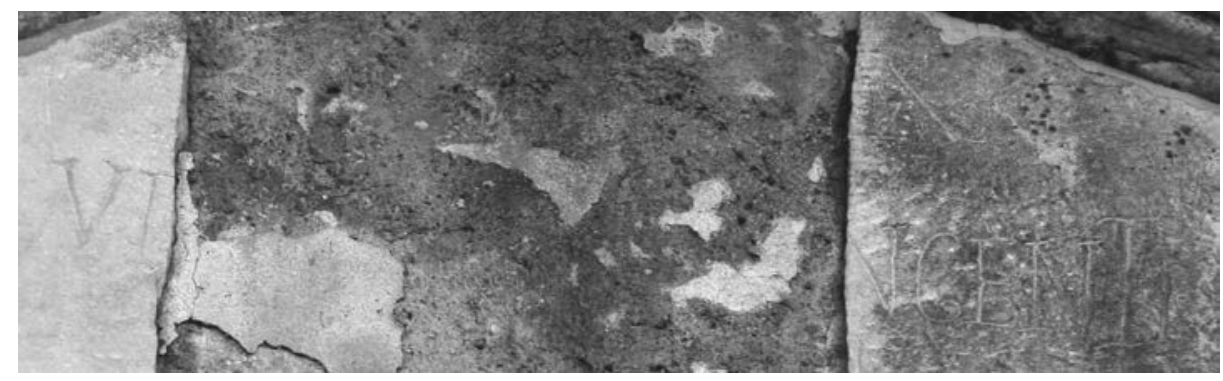

Abb.76b: Detail der Inschrift im Tympanon.

Mit großer Wahrscheinlichkeit war das entsprechende Denkmal einst auf dem Forum aufgestellt und dort auch noch in der Spätantike zu sehen, als das Forum nach wie vor der wichtigste Ort der gemeinschaftlichen Identität, Schauplatz öffentlicher Erinnerung und nicht zuletzt das repräsentative Aushängeschild der Stadt war.

Jenseits der frei zugänglichen Platzanlagen waren Inschriften auch in anderen Kontexten präsent, wie zum Beispiel an den Fassaden privater Wohnhäuser. Eine solche Inschrift hat sich etwa im Tympanon der sog. Domus del Protiro erhalten, wo allem Anschein nach der Name des Besitzers in großen Buchstaben zu lesen war (Abb. 76)..$^{58}$

588 Boersma 1985, 74. 

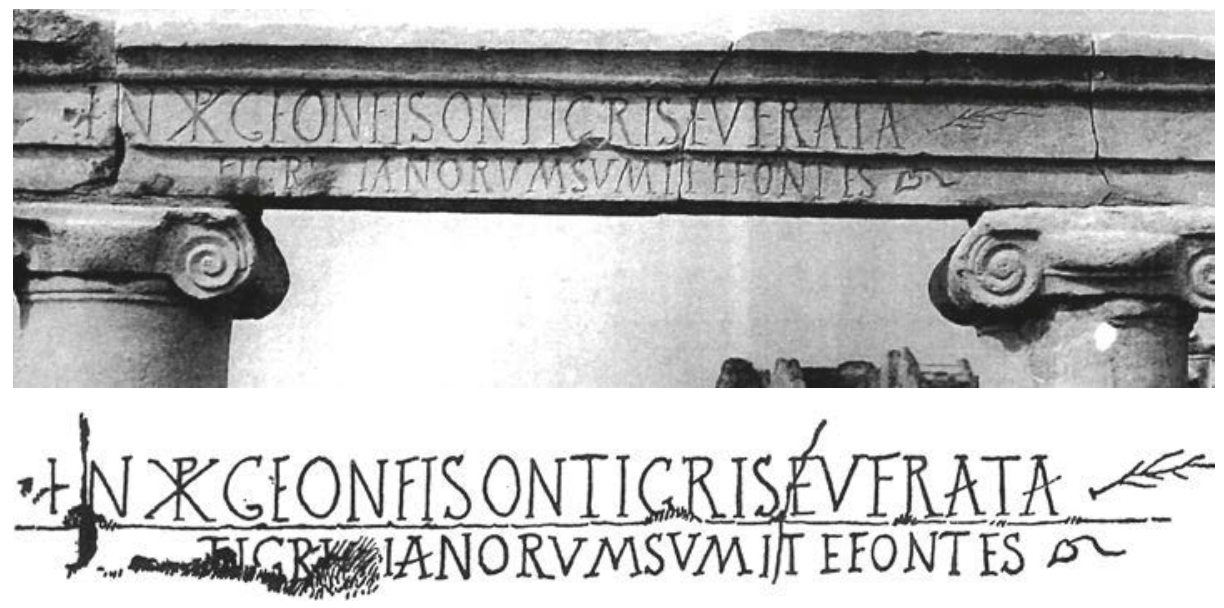

Abb.77: Architravinschrift der sog. Domus dei Tigriniani am Gebälk des Nymphäums (oben) und Umzeichnung (unten).

Obgleich auf private Initiative hin entstanden, waren auch Inschriften dieser Art von einem gleichsam öffentlichen Charakter, da sie nicht nur der Wahrnehmung des Eigentümers und Hausgastes angedacht waren, sondern sich auch an vorbeikommende Passanten richteten. Einen in dieser Hinsicht sehr interessanten Befund bietet die am westlichen decumanus gelegene sog. Domus dei Tigriniani. ${ }^{589}$ Das Wohnhaus aus dem 2. Jh. wurde im Laufe der Zeit mehrfach umgebaut und erweitert, bis es sich im 4. Jh. schließlich als ein weitläufiger Komplex von überdachten Wohn- und Arbeitsräumen und offenen Hofanlagen präsentierte. Über zwei schmale langgestreckte Eingänge erreichte man zwei repräsentative Säle mit apsidialem Abschluss und luxuriöser Marmorausstattung, von denen der eine als Empfangsraum, der andere als Nymphäum diente. Auf dem Architrav dieses Nymphäums hatte der zur christlichen Familie der Tigriniani gehörende Hausherr eine Inschrift anbringen lassen. In dieser wurde Jesus Christus als Quell der vier Paradiesflüsse Gihon, Physon, Tigris und Euphrat gepriesen: In XP Geon Fison Tigris Eufrata (Abb. 77).

Die zweite Zeile richtet sich direkt an Leser und forderte diesen dazu auf, das Nymphäum der Tigriniani aufzusuchen und die dortigen Annehmlichkeiten des reichlich fließenden Wassers zu genießen: Tigri[n]ianorum sumite fontes. ${ }^{590}$ Auf diese Weise

589 Zu dem Bau s. Gobbi 1998; Brenk/Pensabene 1999; Boin 2013, 76-78.

590 Die Lesung und Deutung der zu Beginn der zweiten Zeile unvollständig erhaltenen Inschrift war lange Zeit umstritten und wurde kontrovers diskutiert. G. Calza las Cristianorum (Calza 1940). R. Egger

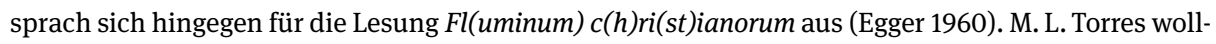
te die ersten beiden Buchstaben als das Zahlzeichen IV interpretieren: $I V c(h) r i(s t) i a n o r u m$ (Torres 2008, 76-78). Zuletzt setzte sich aber die bereits von M. Burzachechi sowie später noch einmal von B. Brenk und P. Pensabene vorgeschlagene Ergänzung zu Tigri[n]ianorum durch (Burzachechi 1957; ders. 1964; Brenk/Pensabene 1999), womit auch die Interpretation des Gebäudekomplexes als luxu- 
entstand die Illusion einer direkten Kommunikation zwischen dem Hausherren und den Besuchern der Anlage, bei denen es sich offenbar um einen bestimmten Kreis von Gästen gehandelt hat, denen die Tigriniani die „paradiesischen Genüsse“ ihres Nymphäums zu besonderen Anlässen gewährten. Vor diesem Hintergrund illustriert die Inschrift also nicht nur, wie fließend die Grenzen zwischen der Sphäre des Öffentlichen und des Privaten in der römischen Kultur tatsächlich waren. Sie ist auch ein anschauliches Beispiel für die Verschmelzung alter römischer Traditionen mit neuen christlichen Inhalten und offenbart, dass pagane und christliche Ideen und Werte nicht nur nebeneinander bestanden, sondern Teil ein und derselben Lebenswelt waren und diese gemeinsam prägten.

\subsection{Geplante und konzeptuelle Präsenz: Inschriftlichkeit im Kirchenraum}

Anders als die Inschriftenlandschaft des öffentlichen Stadtraums mit seinen weiten Plätzen und belebten Straßen war diejenige des in sich abgeschlossenen Kirchenraums nicht über einen langen Zeitraum hinweg gewachsen, sondern im Wesentlichen geplant. ${ }^{591}$ Inschriftliche Präsenz im Kirchenraum bedeutete somit konzeptuelle, zuweilen programmatische Präsenz. Spätestens seit dem frühen 5. Jh. gehörten Inschriften zur Innenausstattung christlicher Kultbauten unbedingt dazu, sei es in Gestalt monumentaler Bautituli an den Wänden, musivischer Stifterinschriften in den Fußböden, steinerner Epitaphe mit Grabinschriften oder bischöflicher Monogramme an den Kapitellen. Auch wenn die Inschriftenlandschaft eines Kirchengebäudes nicht unveränderlich war und im Laufe der Zeit einige Inschriften entfernt und andere hinzugefügt wurden, so hatte sie ihren Ursprung doch in einer anfänglichen, den Bau als einen in sich geschlossenen Raum begreifenden Idee genommen, und Anzahl, Ausführung und Anbringung der Inschriften waren einem konkreten Konzept gefolgt. In aller Deutlichkeit zeigt sich dies am Beispiel der nach ihrem bischöflichen Stifter benannten Eufrasius-Basilika in Parentium (Poreč). Hier war man bei der Präsentifizierung der einzelnen Inschriften absichtsvoll vorgegangen und hatte - wie wir später noch sehen werden - besonderes Augenmerk sowohl auf die optische Interaktion der Inschriften untereinander als auch auf deren visuelles Zusammenspiel mit der architektonischen Gestaltung und bildlichen Ausschmückung des Innenraums gelegt.

riöses Wohnhaus bestätigt wurde. Zuvor war der Bau u. a. als Bibliothek oder Xenodochium und das Nymphäum als christlicher Kultraum gedeutet worden; s. hierzu die Zusammenfassung der Kontoverse bei Brenk/Pensabene 1999.

591 S. hierzu auch die Datenpublikation „Mosaikinschriften auf den Fußböden von Kirchenräumen in der spätantiken Provinz Venetia et Histria“ des Sonderforschungsbereichs 933 „Materiale Textkulturen“ an der Universität Heidelberg mit Grundrissplänen und Bildmaterial der hier diskutierten Kirchenanlagen: http://mosaikinschriften.materiale-textkulturen.de/index.php (Stand: 3.5.2019). 
Leider sind nur die wenigsten frühchristlichen Kirchenanlagen so gut erhalten wie diejenige in Parentium, und nur in den seltensten Fällen ist sowohl die bauliche Gestalt wie auch die epigraphische Ausstattung so hinreichend bekannt wie dort. Zumeist ist unser Wissen in dieser Hinsicht sehr beschränkt, sodass topologische Analysen, die nicht nur die unmittelbare Umgebung einer Inschrift, sondern den größeren Kontext des gesamten Kirchenraums berücksichtigen könnten, zumindest in unserem Untersuchungsgebiet des spätantiken Italiens, nur in Ausnahmefällen möglich sind. Immerhin können wir aber einen speziellen Typus bzw. einen bestimmten Ort inschriftlicher Präsenz im Kirchenraum sehr gut fassen: den mit Mosaiken ausgelegten Fußboden mit den hierin integrierten Bau- und Stifterinschriften. Insbesondere die frühchristlichen Kirchenanlagen des nördlichen Adriabogens haben eine große Anzahl solcher Inschriften überliefert, von denen sich viele noch heute in situ befinden und vor Ort in Augenschein genommen werden können. Ihre spezifische Präsenz war einem planvollen Vorgehen geschuldet - und dies nicht nur, weil die Inschriften als integraler Bestandteil der musivischen Gesamtkomposition nicht ohne vorhergehende Planung hätten realisiert werden können; vielmehr auch deshalb, weil ihre Verortung im Kirchenraum symbolisch bedeutsam war.

Sich des Bodens für die Anbringung einer Inschrift zu bedienen, war in der Spätantike weder neu noch ungewöhnlich. In Mosaikböden eingebettete Inschriften hat es seit hellenistischer Zeit im gesamten Mittelmeerraum gegeben. Bei figürlichen und szenischen Bildkompositionen in repräsentativen Räumen etwa waren es vor allem Beischriften und Bezeichnungen. In Banketträumen konnte man Sprüche wie ,Zum Wohl` oder ,Guten Appetit‘ lesen. Im Eingangsbereich privater Wohnhäuser wurde der Besucher häufig mit dem Namen des Hausherren vertraut gemacht oder mit einem Grußwort willkommen geheißen. Und in öffentlichen Gebäuden wie Basiliken oder Thermen hat sich der Bauherr nicht selten mit einer eindrucksvollen Inschrift verewigt. ${ }^{592}$ Dass aber die an der Errichtung eines gemeinschaftlich genutzten Baus beteiligten Stifter ihr finanzielles Engagement für die Nachwelt festhielten, indem sie ihren Namen und die gespendete Summe in Form einer Inschrift in den Boden einschrieben, und dies im Kollektiv und in einer gleichsam konzertierten Aktion, war durchaus etwas Neues. Die Wurzeln dieser speziellen Form des inschriftlichen Erinnerns führen zum einen auf die jahrhundertealte Tradition der griechisch-römischen Welt zurück, die eigene Wohltätigkeit gegenüber der Gemeinschaft durch eine öffentlich dargebrachte Inschrift zu kommemorieren. Zum anderen rührte diese epigraphische Praxis vom Wertesystem des christlichen Glaubens her, wo die Gemeinschaft der Gläubigen untereinander eine sehr viel größere Rolle spielte als in den polytheistischen Religionen der Antike. ${ }^{593}$ So ist nicht verwunderlich, dass sich insbesondere im Kirchenraum

592 Vgl. Zettler 2001, 29-36 mit konkreten Beispielen.

593 Zur Genese und Deutung der musivischen Stifterinschriften s. Zettler 2001, bes. 145-164. 
Inschriften zu einer absichtsvoll inszenierten Inschriftenlandschaft verdichteten und konzeptuelle Präsenz entfalteten.

Was dies konkret bedeutete, wollen wir uns anhand einer Reihe von Beispielen solcher Bodeninschriften vor Augen führen. Dabei richten wir den Blick insbesondere auf die frühchristlichen Kirchenanlagen Norditaliens, und hier speziell der Provinz Venetia et Histria, wo die reichhaltigsten Zeugnisse erhalten geblieben sind. Besondere Erwähnung verdient die Gemeinde Aquileia, die seit dem 4. Jh. nicht nur eine große Bischofskirche und einen herrschaftlichen Bischofssitz beherbergte, sondern auch mehrere kleinere Basiliken beheimatete. Darunter waren die Kirche auf dem Fondo Tullio (sog. Beligna-Kirche) aus dem späten 4. oder frühen 5. Jh. und die um die Mitte des 5. Jhs. erbaute sog. Monastero-Kirche. Zum Patriarchat Aquileias zählte ferner die frühchristliche Anlage in S. Canzian d'Isonzo aus dem späten 5. Jh., die einem der wichtigsten Märtyrer Aquileias geweiht war, sowie der unter der ehemaligen Kathedrale S. Maria gelegene frühchristliche Komplex in Equilium (Iesolo). Nur weniger Kilometer südlich von Aquileia lag der ehemalige Seehafen Grado mit der unter Bischof Nicetas (571-586) zu einer großen dreischiffigen Anlage ausgebauten Kirche Sant'Eufemia, der kleineren Kirche S. Maria delle Grazie und der Basilika auf der Piazza della Corte. Jenseits der Grenzen des Patriarchats von Aquileia wollen wir uns den im 5. und 6. Jh. entstandenen Kirchenanlagen in Iulia Concordia (Concordia Sagittaria), Verona, Vicetia (Vicenza) und Tergeste (Triest) ausführlicher widmen. Aus der Provinz Tuscia et Umbria soll uns außerdem die Kirche S. Reparata in Florentia (Florenz) als ein Beispiel epigraphischer Präsenz im Kirchenraum dienen.

Alle diese zwölf Kirchen wurden entweder bei ihrer Errichtung oder in einer späteren Umbauphase mit einem Tessellatboden ausgestattet, in den das eine Mal nur wenige, das andere Mal eine ganze Reihe von Inschriften integriert wurden. So zeigte etwa das Mosaik der Kirche in Iulia Concordia (Taf.12, 13) und dasjenige der Basilika auf der Piazza della Corte in Grado (Taf. 26, 27) wohl insgesamt nicht mehr als zehn Inschriften, während im Boden der Monastero-Kirche in Aquileia wenigstens 35 (Taf. 8-11) und in demjenigen der Basilika Sant'Eufemia in Grado sogar mehr als 50 Inschriften zu lesen waren (Taf.14-21). ${ }^{594}$ Dabei handelte es sich in den meisten Fällen um sog. Stifterinschriften, mit denen sich die an der Finanzierung des Mosaikbodens beteiligten Gemeindemitglieder mit ihrem Namen und der gespendeten Summe an römischen Fuß verewigt hatten. Die Inschriften folgten in der Regel dem Formular ille/ illa/illi fecit/fecerunt pedes tot oder ille/illa/illi votum solvit/solverunt. War der Stifter ein hoher kirchlicher Würdenträger oder gar der Bischof selbst, konnte der Text auch ausführlicher ausfallen und den Charakter einer Bau- oder Weihinschrift annehmen,

594 Aufgrund des unvollständigen Erhaltungszustands der Tessellate ist die jeweils genaue Zahl nicht zu ermitteln. Auflistungen der Inschriften aus der Kirche in Iulia Concordia: Caillet 1993, 113123; Zettler 2001, 190-192; aus der Kirche von der Piazza della Corte in Grado: Caillet 1993, 192-200; Zettler 2001, 210-211; aus der Monastero-Kirche in Aquileia: Caillet 1993, 158-192; Zettler 2001, 168179; aus der Basilika Sant’Eufemia in Grado: Caillet 1993, 218-257; Zettler 2001, 194-207. 
wie zum Beispiel im Fall der Inschrift des Bischofs Elias in der Basilika Sant'Eufemia in Grado. ${ }^{595}$

Anders als im Osten des Römischen Reichs, wo viele Böden frühchristlicher Kirchenanlagen mit figürlichen Mosaikbildern ausgekleidet waren und gelegentlich sehr komplexe narrative Bildprogramme biblischer oder christologischer Thematik aufwiesen, herrschten in den Kirchen des italischen Raums meist flächendeckende geometrische Kompositionen vor. ${ }^{596}$ Oftmals setzten sich die Tessellate aus mehreren rechteckigen Segmenten zusammen, von denen jedes einzelne ein eigenes, mitunter sehr komplexes Dekorationssystem mit unterschiedlich geformten Feldern ausbildete. Diese waren ihrerseits mit ornamentalen, seltener auch mit figürlichen Motiven ausgefüllt - dienten darüber hinaus aber auch als Rahmungen für Inschriften. Bei dem Mosaik des Hauptschiffs der Basilika in Iulia Concordia etwa bildeten aneinandergereihte Swastiken einen Teppich von rautenartigen Feldern aus, in deren Mitte sich die Inschriften mit unterschiedlichen Füllmotiven (darunter Kreuze, salomonische Knoten und stilisierte Blüten) in unregelmäßigen Abständen abwechselten (Taf.12, 13). In der Basilika Via Madonna del Mare in Tergeste waren es große, von sich überschneidenden Flechtbändern gerahmte Oktogone sowie von einem raffinierten Schlingband gebildete Kreise, in welchen die Namen der Stifter in großen Buchstaben prangten (Taf.41-43). Und in der Gradenser Kirche auf der Piazza della Corte hatten sich die wohltätigen Gemeindemitglieder in die Achtecke eines Dekors aus alternierenden Flechtkreuzen, Hexagonen und Oktogonen eingeschrieben (Taf. 26, 27). Am variantenreichsten und interessantesten aber präsentierte sich der Mosaikboden der hallenförmigen Monastero-Kirche in Aquileia. Er wies nicht weniger als zehn, von einer schmalen Solea in fünf nördliche und fünf südliche geschiedene Segmente mit sehr detailreichen Dekorationsschemata auf. Wenigstens acht - vermutlich aber jedes einzelne - davon zeigten kunstvoll gestaltete Inschriftenfelder: Kreise, Quadrate, Oktogone und Hexagone, das eine Mal einfach und rahmenlos, das andere Mal sehr aufwendig gerahmt, ornamental verziert oder mit einer tabula ansata als Schriftgrund gestaltet (Taf. 8-10).

Während die Inschriftenfelder hier integraler Bestandteil des jeweiligen Dekorationssystems waren, kam es anderswo auch vor, dass sie von diesem losgelöst waren. In solchen Fällen wirkten sie wie kurzerhand darüber platziert, ohne dass auf Unterbrechungen oder Beschneidungen einzelner Motive und des Rapports Rücksicht genommen wurde; so geschehen zum Beispiel im Fall des früheren Mosaikbodens der Basilika Via Madonna del Mare in Tergeste. Bei diesem wurde ein aus alternierenden Kreuzen und Oktogonen zusammengesetztes Segment an seinem westlichen Rand durch drei doppelt gerahmte rechteckige Inschriftenfelder nachgerade überdeckt (Taf.40). Ähn-

595 CIL V S. 149 = Caillet 1993, 226f. Nr. 7 = Zettler 2001, 196 Nr. 7.

596 Eine Ausnahme bildet das Mosaik in der Südhalle des Theodorischen Komplexes in Aquileia, das neben embelmartigen figürlichen Darstellungen von Menschen und Tieren auch eine große szenische Darstellung mit der Jonas-Geschichte zeigte; s.hierzu u. S. 230-232 Anm.611. 
liches ist auch in der Basilika S. Reparata in Florentia zu beobachten. Hier stachen zwei großen Inschriftenfelder emblemata-gleich inmitten der geometrisch gestalteten Mosaikteppiche des Mittelgangs hervor (Taf. 28, 29). Ob solche Zeugnisse das Resultat einer später erfolgten Einfügung sind, lässt sich nur schwer entscheiden. Korrekturen und Ergänzungen in Mosaiken waren oftmals so sorgfältig durchgeführt, dass sie archäologisch kaum nachzuweisen sind. Da es sich in Tergeste wie in Florentia um klassische Stifterinschriften handelt, die sich angesichts der pedes-Angabe am Ende nur im Zusammenhang mit der Finanzierung des jeweiligen Bodentessellats lesen lassen, fällt es allerdings schwer zu glauben, die Inschriften seien erst nachträglich eingesetzt worden. Warum sollten wir hingegen nicht annehmen, dass man den sichtbaren Umbruch zwischen Dekorationssystem und Inschrift als besonders reizvoll empfand, und es absichtlich auf diesen visuellen Effekt anlegte?

Denkbar ist dies allemal, zumal sich bei eingehender Betrachtung der Inschriften abzeichnet, dass einige Stifter sichtlich darum bemüht waren, ihre eigene Inschrift visuell hervorzuheben und ihr eine individuelle Gestalt zu verleihen. Das war zwar nicht immer der Fall und wir kennen ausreichend Beispiele, bei denen die Inschriften (wenigstens innerhalb eines Segments) gestalterisch kaum voneinander abwichen. So etwa in Iulia Concordia (Taf.12, 13) oder Equilium (Taf. 30), wo der Gleichheitsgedanke unter den Gemeindemitgliedern vielleicht besonders ausgeprägt war und sich in der einheitlichen Ausführung sämtlicher Inschriften Ausdruck verschaffte. Anderswo ist das Bedürfnis nach einer gesteigerten individuellen Gestaltung des eigenen Stücks aber kaum zu übersehen. Da der Textinhalt in dieser Hinsicht nur wenig Spielraum für Kreativität zuließ, konzentrierte man sich vor allem auf die Form und Ausgestaltung der Rahmung sowie auf eine auffällige Farbgebung. Ein anschauliches Beispiel dafür liefert die kleine Hallenkirche SS. Felice e Fortunato in Vicetia aus dem 4. Jh. ${ }^{597}$ Ihre Inschriften zeichnen sich durch besonders charakteristische Gestaltungsmerkmale aus (Taf. 46, 47). Am auffälligsten ist die große, inmitten eines Rapports aus Oktogonen und Quadraten sitzende Inschrift des Felix, des Toribius und der Immola (Taf. 47 Abb. 184). ${ }^{598}$ Sie steht in das Innere eines aus einem zweisträhnigen Flechtband gebildeten Kreises geschrieben, der wiederum von einem quadratischen Feld eingefasst wird. In dessen Ecken sitzen kleine, aus einem Schachbrettmuster gebildete Dreiecke. Für die Schrift selbst wurden schwarze tesserae gewählt, die sich sehr deutlich von dem in Hellbraun gehaltenen Schriftgrund absetzen. Die restliche Kreisfläche und das Quadrat hat man mit rötlichen Steinchen gefüllt. Die Ziermotive in den Ecken sind polychrom in Schwarz, Weiß und Rot gestaltet. Das Flechtband setzt sich auf schwarzem Hintergrund aus einer roten und einer hellbraunen Strähne zusammen. In den gleichen Farben, allerdings etwas kleiner und ohne das rahmende Flechtband, präsentieren sich auch drei andere Inschriften, die ihrerseits in verschiedenen Seg-

$597 \mathrm{Zu}$ dem Bau s. Carraro 2010.

598 Caillet 1993, 90f. Nr. 4 = Zettler 2001, 251 Nr. 7. 
menten mit einem Halbkreismuster, einem Dekor aus sich überschneidenden Kreisen sowie einem Rapport aus alternierenden Kreisen und Rauten eingelassen sind. ${ }^{599}$ In einem weiteren Feld hat sich ein gewisser Mauricius mit seiner Frau Macriana und den Seinigen verewigt. ${ }^{600}$ Ihre Inschrift zeichnet sich weniger durch eine besonders kunstvolle Rahmung aus - man gab sich mit einem doppelt gefassten Ring zufrieden -, als vielmehr durch eine ungewöhnliche Schriftgestaltung, die sich in einer auffälligen Ligatur des C und U im cum der letzten Zeile niederschlägt (Taf. 46). Unverwechselbar ist schließlich die Inschrift des Splendonius und seiner Familie, die von einem ausladenden, polychromen Stern eingefasst wird. Zwischen den vier breiten Zacken sitzen Dreieckmotive mit Schachbrett- und Halbkreismuster, auch diese aus verschiedenfarbigen tesserae zusammengesetzt (Taf.47 Abb.185). ${ }^{601}$ Mit seinen exzentrisch gestalteten Inschriften ist der Kirchenboden in Vicetia ohne vergleichbare Parallelen, was womöglich auf seine frühe Entstehungszeit im 4. Jh. zurückführen ist. Damals waren gemeinschaftliche Kirchenstiftungen noch selten, und die Praxis der Darbringung von Stifterinschriften im Mosaikboden hatte noch keine Tradition ausgebildet. ${ }^{602}$ Womöglich hatte sogar jeder Stifter seine Inschrift selbst entworfen oder entwerfen lassen.

In den im 5. und 6. Jh. entstandenen Bauten äußerte sich der persönliche Gestaltungswille subtiler, wenngleich nicht weniger wirkungsvoll. So zum Beispiel bei den Inschriften der frühchristlichen Basilika in Verona, die sich durch individuelle Rahmungen mit bunten Flechtbändern, Wellenlinien und Zahnschnitten oder durch die Hinzufügung kleiner Bilder von Vögeln und Fischen voneinander abzusetzen suchten (Taf. 44, 45); ${ }^{603}$ oder in der kleinen Basilika S. Maria delle Grazie in Grado, wo sich die Inschrift des Paares Johannes und Afrodites dem Betrachter ebenfalls zusammen mit einer Vögel-Darstellungen präsentierte (Taf. 23 Abb.144). ${ }^{604}$ Figürliche Motive wie diese weckten besondere Aufmerksamkeit, denn sie waren in den vornehmlich aus geometrischen Elementen zusammengesetzten Dekorationssystemen eher ungewöhnlich und nur selten mit einer Inschrift direkt kombiniert.

Auffällig gestaltete Exemplare sind auch unter den Inschriften der MonasteroKirche in Aquileia zu entdecken. Dort wurde sowohl mit auffälligen Einfassungen

599 Caillet 1993, 88f. Nr. 1 = Zettler 2001, 250 Nr. 3; Caillet 1993, 89 Nr. 2 = Zettler 2001, 251 Nr. 4; Caillet 1993, 92 Nr. 6.

600 Caillet 1993, 91f. Nr. 5 = Zettler 2001, 251 Nr. 5, allerdings mit der falschen Lesung ex v[oto] statt cum suis am Ende.

601 Caillet 1993, 89 Nr. 3 = Zettler 2001, 251 Nr. 6.

602 Zur Frühgeschichte von SS. Felice e Fortunato s. Pavolini 1986; Carraro 2010. Zu der frühen Entstehungszeit der Inschriften im 4. Jh. passt auch, dass diese noch keine Pedaturangabe machen. Vielleicht wurden die einzelnen, von den jeweiligen Stiftern finanzierten Mosaiksegmente individuell gefertigt und dann vor Ort aneinandergelegt; vgl. hierzu Zettler 2001, 249f.

603 Auflistung der erhaltenen Inschriften: Caillet 1993, 71-85 und Zettler 2001, 246-248; zu den Mosaiken der Kirche s. Rinaldi 2007, 608-613 Tav. LXXXIII-LXXXVIII.

604 Caillet 1993, 204f. Nr.3 = Zettler 2001, 207f. Nr. 3. 
als auch mit dem Einsatz von verschiedenen Farben gearbeitet (Taf. 8-10) ${ }^{605}$ Besondere Erwähnung verdient auch die Inschrift des Obsequentius in der Basilika von Florentia, die mit der Darstellung eines farbenprächtigen Pfaus aufwartete (Taf. 29 Abb.154). ${ }^{606}$ Der Inschrift muss gesteigerte Aufmerksamkeit zuteil geworden sein, und dies um so mehr, da sich die zweite - und zugleich letzte - Inschrift des Bodenmosaiks der Florentiner Kirche nicht nur wesentlich unauffälliger, sondern in einem nachgerade diametralen Gegensatz präsentierte. Bei ihr handelt es sich nicht um die Inschrift eines Einzelnen, sondern um eine Auflistung von insgesamt 15 Stiftern mit deren Namen und der von ihnen gespendeten Summe an römischen Fuß (Taf. 29 Abb.155). ${ }^{607}$ Auf eine dekorative Rahmung und eine bildliche Illustrationen wie bei der Inschrift des Obsequentius wurde hierbei ebenso verzichtet wie auf den Einsatz farbiger tesserae. Die Schrift erscheint in schwarzen Buchstaben auf hellem Grund, und eine einfache schwarze Rahmenlinie dient als schlichte Einfassung. Insbesondere im Vergleich mit der durch die bildliche Darstellung des Pfaus in Szene gesetzten Inschrift des Obsequentius war die nüchterne Aufzählung von dezentem, nachgerade ostentativ bescheidenem Charakter. Dass man alle Stifter in Form einer Liste nannte, ohne dabei einzelne Namen visuell besonders hervorzuheben, war vielleicht dem Wunsch geschuldet, der Inschrift einen egalitären Anstrich zu verleihen: Alle Beteiligten sollten als Mitglieder einer eng verbundenen Gemeinschaft erscheinen, und die Finanzierung des Bodens sollte als eine von der Kirchengemeinde gemeinschaftlich getragene Anstrengung ausgewiesen werden. ${ }^{608}$ Doch so wenig der Einzelne auf den ersten Blick herausstach - die Liste war keineswegs eine bloße Reihen- als vielmehr eine hierarchisch angeordnete Rangfolge. Die bedeutendsten und freigiebigsten Stifter, namentlich der Diakon Marinianus, wurden als erste genannt. Die übrigen folgten gemäß der Höhe ihrer Spende. An welcher Stelle der eigene Name innerhalb der Inschrift erschien, war also nicht vollkommen gleichgültig, sondern Spiegelbild sozialer Hierarchien und Gradmesser der Opferbereitschaft gegenüber der Kirchengemeinde.

Was hier im Kleinen, gewissermaßen auf der mikroskopischen Ebene einer einzelnen Inschrift zum Ausdruck kommt, gilt genauso im größeren Kontext des gesamten Kirchenbodens. Auch hier war die Position der Inschrift von großer Wichtigkeit, und

605 Caillet 1993, 158-192; Zettler 2001, 168-179.

606 Caillet 1993, 28 Nr. 2 = Zettler 2001, 194 Nr. 15.

607 Caillet 1993, 27 Nr.1.

608 Welche Rolle Obsequentius bei der Errichtung der Kirche und der Finanzierung des Mosaikbodens spielte, ist besonders vor diesem Hintergrund nicht leicht einzuschätzen. Eigentlich würde man eine derart prominente Inschrift von einem hohen Kleriker, am ehesten von einem Bischof erwarten. Im Text erscheint Obsequentius aber als einfacher Laie ohne kirchliches Würdenamt. Rätselhaft bleibt auch, warum gerade er eine vergleichsweise kleine Summe von ,nur' XX pedes beisteuerte. Die in der Liste aufgeführten Spender waren wesentlich großzügiger und gaben (soweit es der unvollständige Erhaltungszustand feststellen lässt) zwischen $L X V$ und CCC pedes. Zur Person des Obsequentius s. PCBE II 1546 s. v. Obsequentius. 
der jeweilige Anbringungsort konnte sowohl ihre Effektivität als auch ihre Bedeutsamkeit maßgeblich bestimmen. Ebenso entscheidend wie die materiale Präsenz einer Inschrift war also ihre topologische Präsenz, also ihre Lage und Positionierung im Kirchenboden. Es war dies eine für die Wirkung der Inschriften auf den Betrachter und für ihr Funktionieren als Medien der Kommemoration wesentliche Variable und ein in unserem Zusammenhang zentraler Aspekt, mit dem wir uns nun eingehender auseinandersetzen wollen.

Was man sich unter dem Begriff der ,topologischen Präsenz‘ konkret vorzustellen hat, verdeutlicht ein Überblick über die Anbringungsorte und die Verteilung der Inschriften im Boden. Führt man sich die jeweiligen Befunde in den entsprechenden farblich markierten Grundrissplänen vor Augen (s. Tafelteil), so ergibt sich auf den ersten Blick ein heterogenes Gesamtbild, sowohl was die Anzahl der Inschriften als auch ihre Verteilung auf dem Fußboden angeht. Dieser Eindruck wird noch in dreierlei Hinsicht verschärft: erstens durch den unvollständigen Erhaltungszustand der meisten Tessellate; zweitens durch den Umstand, dass wir es mit verschieden großen Mosaikflächen und unterschiedlichen Bautypen (Hallenkirchen, ein- und dreischiffige Basiliken) mit jeweils anderen Funktionen (Bischofskirche, Gemeindekirche, Märtyrer-Kirche) zu tun haben; und drittens durch die Tatsache, dass einige der Anlagen während des 5. und 6. Jhs. architektonisch umgestaltet wurden und in diesem Zuge auch neue Mosaikpavimente erhielten, wie es zum Beispiel in der MonasteroKirche in Aquileia, in der Basilika S. Maria delle Grazie in Grado, in Tergeste und in Verona geschehen war, wo wir mehrere Phasen voneinander zu unterscheiden haben. Aller forschungspraktischer Unwägbarkeiten zum Trotz, erlaubt es die vergleichende Betrachtung der markierten Grundrisspläne aber immerhin, drei Erkenntnisse von allgemeingültigem Anspruch zu formulieren. Die erste scheint nicht mehr als trivial zu sein: Wie viele Inschriften in einem Kirchenboden zu lesen waren und an welchen Stellen sie sich befanden, war von Fall zu Fall unterschiedlich und offenbar weder von der Größe des Baus noch von seiner architektonischen Gestalt oder seiner speziellen Funktion abhängig. Wäre es tatsächlich nach diesen Kriterien gegangen, müsste man in der Basilika von Iulia Concordia - ein stattlicher Komplex des frühen 5. Jhs. und womöglich Bischofskirche der Gemeinde - wesentlich mehr Inschriften erwarten, während die Ausstattung der vergleichsweise kleinen Kirchen von Aquileia und Grado sowohl in ihrer Zahl als auch in ihrer qualitätsvollen Gestaltung überrascht. Diese recht oberflächliche Beobachtung verliert aber an Banalität, wenn man nach strukturellen Berührungspunkten zwischen den vermeintlich individuellen Einzelfällen sucht. Solche gibt es nämlich sehr wohl, und sie führen uns zu zwei weiteren Erkenntnissen: Die Inschriften waren stets nach Osten bzw. in Richtung der Apsis hin ausgerichtet, also für den Betrachter von Westen her lesbar. Und: Für ihre Anbringung kamen nahezu alle architektonischen und liturgischen Bereiche des Kirchenraums in Frage, wobei einige häufiger in Anspruch genommen wurden als andere. So weisen die Tessellate des Naos überall die mit Abstand zahlreichsten Inschriften auf, und das sowohl im Fall der Saalkirchen mit rechtwinkligem Grundriss als auch 
im Fall der mehrschiffigen Basiliken. Der Narthex und der Bereich direkt hinter dem Eingangsportal im Kircheninneren waren offenbar weniger beliebt, denn hier angebrachte Inschriften können wir lediglich in Equilium (Taf.30 Abb.156), in der Basilika Sant'Eufemia in Grado (Taf. 14 Abb. 126) und in der Märtyrer-Kirche in S. Canzian d'Isonzo (Taf.11 Abb.121) nachweisen. Einzig in diesen beiden zuletzt genannten Kirchen war im Übrigen auch die Solea, der Prozessionsweg für den Ein- und Auszug des Klerus, als Inschriftenträger in Anspruch genommen worden. In der MonasteroKirche in Aquileia (Taf. 8 Abb.113) und der Bischofskirche von Verona (Taf.44 Abb.180) war (soweit es der jeweilige Erhaltungszustand zu erkennen gibt) die Solea hingegen von Inschriften frei gehalten worden. In einigen Fällen, wie in der Kirche Via Madonna del Mare in Tergeste, rückten die Inschriften sehr nahe an das Presbyterium heran (Taf. 41 Abb.173). In der Kirche S. Maria delle Grazie in Grado finden sie sich auch in den direkt an die Apsis angrenzenden Seitenräumen (Taf. 24 Abb.145). Und in Iulia Concordia war eine Inschrift sogar im Umgang dahinter angebracht (Taf. 12 Abb.122; Taf. 13 Abb. 125). Der einzige Bereich, in dem Inschriften vollkommen fehlen, ist das Presbyterium. ${ }^{609}$ Die Verteilung der Inschriften auf die verschiedenen Bereiche führt Tabelle 3 im Einzelnen noch einmal vor Augen.

Was können wir diesen Befunden für die Frage nach der topologischen Präsenz der Inschriften abgewinnen? Dass sich die Inschriften nach der Apsis - das heißt in der Regel nach Osten - hin ausrichteten, ist wenig überraschend. Die Apsis war sowohl architektonischer Fluchtpunkt des Kirchenraums als auch Platz des Altars sowie das liturgische Zentrum, wo der Ablauf des Zeremoniells mit der Eucharistiefeier seinen Höhepunkt fand. Dementsprechend orientierte sich auch der Kirchenbesucher - und mithin der potentielle Betrachter und Leser der Inschriften - in eben diese Richtung, sobald er den Bau an der gegenüberliegenden Seite des Eingangsportals betrat. An dieser Ausrichtung der Inschriften änderte sich im Übrigen auch dann nichts, wenn andere, den Text umgebende Dekor- und Bildmotive des Tessellats anderweitig arrangiert waren, wie es etwa in einem Mosaiksegment in der Kirche von Verona oder im sog. Theodorischen Komplex in Aquileia (Taf. 4 Abb. 103) zu beobachten ist. Stets blieben die Inschriften nach dem Altarraum bzw. nach Osten hin orientiert, und stets war mithin auch der Leser dem Allerheiligsten zugewandt, wenn er sich ihrer Betrachtung widmete. ${ }^{610}$ Einen in dieser Hinsicht interessanten Sonderfall

609 Dieser Befund bedeutet allerdings nicht, dass das Presbyterium niemals als Ort einer Inschriftensetzung benutzt wurde. Gegenbeispiele finden sich vor allem in der östlichen Reichshälfte und gelegentlich auch in unserem Untersuchungsgebiet des spätantiken Italiens, wie zum Beispiel in der Basilika S. Pietro Maggiore in Ravenna mit einem Mosaikboden aus dem 5. Jh. (Caillet 1993, 43-47) oder in der kleinen Kirche S. Micheli in Salemi (Caillet 1993, 35-41). Doch handelt es sich bei beiden um stark von griechischen bzw. östlichen Traditionen beeinflusste Bauten, die sich als solche nur bedingt als Vergleichsbeispiele anbieten und daher nicht in die Untersuchung miteinbezogen wurden. 610 Der Fall des Bodenmosaiks im sog. Theodorischen Komplex in Aquileia ist allerdings komplexer. Bei dem von Bischof Theodoros um 310 mit Mosaikböden ausgestalteten Bau handelt es sich nicht wie etwa in Verona um einen Längsbau mit abschließender Apsis im Osten, sondern um einen 
Tab.3: Verteilung der Bodeninschriften in den einzelnen Zonen des Kirchenraums.

\begin{tabular}{ll}
\hline Zone & Kirche \\
\hline Narthex & Equilium, Kirche unter der ehem. Kathedrale S. Maria \\
\hline Eingangsbereich & Grado, Basilika Sant'Eufemia \\
& S. Canzian d'Isonzo, Märtyrer-Kirche \\
\hline & Aquileia, Beligna-Kirche \\
& lulia Concordia, Bischofskirche \\
& Equilium, Kirche unter der ehem. Kathedrale S. Maria \\
& Florentia, Kirche S. Reparata \\
Naos. Hauptschiff und Seiten- & Grado, Basilika Sant'Eufemia \\
schiffe bei Basiliken & Grado, Kirche S. Maria delle Grazie, ältere Phase \\
& Grado, Kirche auf der Piazza della Corte \\
& Tergeste, Kirche Via Madonna del Mare, jüngere Phase \\
& Verona, Bischofskirche, ältere Phase \\
& Verona, Bischofskirche, jüngere Phase \\
\hline Naos. Hauptraum bei Aulen- und & Aquileia Monastero-Kirche, ältere Phase \\
Hallenbauten & S. Canzian d'Isonzo, Märtyrer-Kirche \\
& Tergeste, Kirche Via Madonna del Mare, ältere Phase \\
& Vicetia, Kirche Santi Felice e Fortunato \\
\hline Solea & Grado, Basilika Sant'Eufemia \\
\hline Bereich um das Presbyterium & S. Canzian d'Isonzo, Märtyrer-Kirche \\
\hline \multirow{2}{*}{ Apsisnebenräume } & Aquileia Monastero-Kirche, jüngere Phase \\
& Equilium, Kirche unter der ehem. Kathedrale S. Maria \\
& Tergeste, Kirche Via Madonna del Mare, jüngere Phase \\
\hline & lulia Concordia, Bischofskirche \\
& Grado, Basilika Sant'Eufemia \\
& Grado, S. Maria delle Grazie, jüngere Phase \\
\hline
\end{tabular}

in zwei große Hallen und mehrere kleine Räume gegliederten Komplex mit rechteckigem Grundriss (Taf.1 Abb.99). Der Boden der südlichen Halle ist mit einer Mosaikkomposition aus verschiedenen geometrischen Dekorsystemen mit figürlichen und symbolischen Motiven (darunter Tiere, Personifikationen und christliche Sinnbilder), Portätbildnissen (vielleicht der Stifter) und einer großflächigen Darstellung der Jonas-Geschichte ausgestattet (Taf.3 Abb.101). Das ebenfalls in mehrere Felder eingeteilte Mosaik der Nordhalle zeigt ebenso anspruchsvolle Dekorationssysteme mit geometrischen und figürlichen Füll- und Ziermotiven, auch diese aus dem Bereich der christlichen Symbolsprache (Taf. 2 Abb.100). Während sich die Bildmotive des östlichen Teils dieser Halle nach Osten, diejenigen des westlichen Teils nach Westen ausrichten, sind sämtliche hier angebrachten Inschriften konsequent nach Osten hin orientiert, und dies, obgleich sie den benachbarten Bildmotiven so visuell entgegenstehen und die natürliche Bewegungsrichtung des Betrachters ignorieren. Um die Inschriften lesen zu können, muss sich dieser erst zu ihnen hinwenden. Offenbar spielte auch hier die Hinwendung beim Lesen nach Osten eine wichtige Rolle und fand ihre Parallele in der Hinwendung in Richtung der aufgehenden Sonne beim Beten. Zur Genese und Bedeutung dieser Sitte und zur Ostung von Kirchengebäuden s. Gamber 1976, 7-27; RAC XXII, 2008, 278-281 (S. de Blaauw) mit weiteren Literaturverweisen; 
bildet einmal mehr das oben schon zur Sprache gebrachte Bodentessellat aus Vicetia. Dessen Inschriften besaßen keine gemeinsame Ausrichtung, sondern folgten ganz unterschiedlichen Leserichtungen (Taf. 46 Abb.183). Doch was auf den ersten Blick als Ausnahme von der Regel erscheinen mag, ist in Wahrheit nichts anderes als deren Bestätigung: Denn bei dem kleinen Bau handelte es sich nicht etwa um eine Basilika, sondern um eine frühe, bereits im 4. Jh. errichtete Saalkirche mit rechteckigem Grundriss ohne Apsis, in welcher der seinerzeit noch mobile Altar schlichtweg in der Mitte des Saals aufgestellt wurde. Ein eindeutiger baulicher Fluchtpunkt, an dem man sich bei der Ausrichtung der Inschriften hätte orientieren können, fehlte also. So war es in der Folge zu unterschiedlichen Positionierungen der Inschriften gekommen.

Was die Verteilung der Inschriften auf dem Boden des Kirchenraums angeht, scheinen vor allem die liturgische Funktion und die sakrale Bedeutung der jeweiligen Raumbereiche eine Rolle gespielt zu haben. Der Raum der Kirche war ein Raum voller Symbolik, und nicht alle Bereiche waren gleichermaßen wert- und bedeutungsvoll. Es herrschte eine komplexe Hierarchie, die von der architektonischen Ausrichtung des Baus, der Platzierung der liturgischen Hauptelemente (Altar, Priestersitze und Leseplatz) sowie von der räumlichen Gliederung mittels Schranken, Barrieren und Niveauunterschieden bestimmt wurde. ${ }^{611}$ Dementsprechend erfuhren auch die in den verschiedenen Raumbereichen präsenten Inschriften unterschiedliche Wertschätzung. Die größte Bedeutung kam dem Bereich des Presbyteriums in und unmittelbar vor der Apsis zu, denn es war dies der Ort des Allerheiligsten, wo der Altar seinen Platz hatte und das Messopfer zelebriert wurde. Die Apsis war gleichsam Brennpunkt des Kirchenbaus und Blickpunkt der Raumerfahrung. An ihren Wänden befanden sich große Bilder mit der Darstellung Christi und der Heiligen. Hier standen die Sitze des Klerus und der bischöfliche Thron. Laien war der Zugang untersagt. Sie hatten sich im Naos aufzuhalten, wo sie - womöglich nach Männern und Frauen getrennt - dem Gottesdienst stehend beiwohnten. Nach der Predigt versammelte sich die Gemeinde in der Nähe des Altars, um gemeinsam die Eucharistie zu feiern.

Ein zweiter für den liturgischen Ablauf bedeutungsvoller Ort war die Solea, der schmale Bodenstreifen in der Mittelachse des Hauptschiffes, über den der Bischof mit seinem Gefolge zu Beginn der Zeremonie in den Kirchenraum einzog und ihn am Ende wieder verließ. Die Solea war gestalterisch oftmals besonders hervorgehoben und gelegentlich sogar durch Balustraden abgeschrankt, wodurch ihre sakrale Geltung

Heid 2006. - Zum sog. Theodorischen Komplex und dem viel diskutierten und in seiner Deutung noch immer umstrittenen Mosaikboden s. Brusin 1957; Kähler 1962; Mirabella Roberti 1996; Zettler 2001, 117-144; ders. 2010; Duval 2000; Lehmann 2010.

$611 \mathrm{Zu}$ den einzelnen Komponenten des Kirchengebäudes, ihrer liturgischen Funktion und sakralen Bedeutung s. RAC XXII, 2008, 353-373 (S. de Blaauw); speziell zum Zusammenhang von Liturgie und Architektur s. Gamber 1976; Brandenburg 1995; Doig 2008; Verstegen 2009; sowie den Sammelband Altripp 2006 mit Beiträgen zum spätantiken und frühmittelalterlichen Kirchenbau im Westen und im Osten; zum Ablauf des liturgischen Zeremoniells s. Metzger 1998. 
verstärkt wurde. Ähnlich verhielt es sich mit den die Apsis flankierenden Seitenräumen, deren Zutritt ebenfalls dem Klerus vorbehalten war. Sie dienten als Aufenthaltsund Ankleideräume der Priester sowie der Aufbewahrung liturgischer Utensilien.

Liest man die markierten Grundrisspläne vor der Folie dieser Überlegungen noch einmal, so wird klar, dass es den Stiftern nicht gleichgültig gewesen sein konnte, in welchem Bereich des Kirchenraums sie ihre Inschrift anbrachten. Es gab bestimmte Orte, derer man nur durch besondere Privilegien habhaft werden konnte und deren Stellenwert sich nicht unbedingt darin ermaß, ob sie von möglichst vielen Kirchenbesuchern eingesehen oder betreten wurden, sondern ob diese Orte von hoher symbolischer und liturgischer Bedeutung waren. In diesem Sinn war es wohl kein Zufall, dass die Böden im Eingangsbereich vergleichsweise selten mit Stifterinschriften ausgestattet waren, während sich ihre Präsenz in Richtung des Altarraums verdichtete. Und wohl nicht ohne Grund waren es vor allem die ranghohen Kleriker und Bischöfe, welche die bedeutungsvollsten Orte des Kirchenbodens - allen voran die Solea und den Bereich rund um das Presbyterium - mit ihren Inschriften besetzten. Je näher sich eine Inschrift am Altarraum befand, als desto wertvoller durfte sie gelten. ${ }^{612}$

Am Beispiel der Basilika Sant'Eufemia in Grado, deren Inschriften offenbar nach genau diesem Prinzip im Boden verteilt wurden, lässt sich dies besonders gut illustrieren (Taf.14-21). Die Kirche im Patriarchat Aquileia wurde im späten 4. oder frühen 5. Jh. zunächst als einschiffige Saalkirche erbaut und im späten 5. Jh. unter Bischof Nicetas (454-485?) zu einer großen Basilika mit drei Schiffen erweitert. Unter Bischof Elias (571-586) erhielt sie im späten 6. Jh. ihre heutige Gestalt und wurde schließlich im November 579 eingeweiht. ${ }^{613}$ Elias war es auch, der sie mit dem heute noch in Teilen erhaltenen Mosaikfußboden ausstatten ließ. Dieser erstreckte sich (inklusive der Nebenräume) auf rund 900 Quadratmeter und stellt und das wohl organischste

612 Die Höhe der Spende hatte hingegen nicht überall und nur bedingt Auswirkung auf die Positionierung der Inschrift, wie es das Beispiel der Monastero-Kirche in Aquileia vor Augen führt, wo sich keinerlei Regelhaftigkeit in dieser Hinsicht erkennen lässt. Großzügigere und bescheidenere Stifter wurden nebeneinander in ein und demselben Mosaiksegment verewigt. Anderswo, beispielsweise in der kleinen Basilika S. Maria delle Grazie in Grado, lässt sich ein solches Schema hingegen durchaus erkennen: Bei den im südlichen Seitenschiff erhaltenen Inschriften aus dem frühen 6. Jh. nimmt die Höhe der Spende in Richtung des Altarraums zu, angefangen bei $X X$ pedes über $X X V$ bis hin zu $L X$ pedes; gänzlich konsequent war man allerdings auch hier nicht, denn die am östlichsten gelegene Inschrift verzeichnet XXXXV pedes; vgl. hierzu die jeweiligen Angaben bei Caillet 1993 und Zettler 2001. 613 Anlass zur Weihung am 3. November 579 gab eine von Bischof Elias einberufene Diözesansynode. Dass man die Kirche ausgerechnet der Heiligen Eufemia weihte, war wohl eine bewusst gesetzte polemische Spitze im Streit um die Frage nach der wahren Natur Christi. Die Märtyrerin war die Schutzpatronin des Konzils von Chalkedon 451, zu dessen orthodoxen Beschlüssen sich Elias bekannt hatte. - Bei dem ersten Bau handelte es sich um eine kleine, rechteckige Kirche, die später durch eine vieleckige Apsis im Osten ergänzt wurde. Wegen des an der Nordwand angebrachten Grabmosaiks für einen gewissen Petrus, einen bekehrten Juden (Abb.5, s. o. S. 79), wird der Bau in seiner Frühphase zuweilen auch als ,Petrus-Aula، bezeichnet; zur Geschichte und den einzelnen Bauphasen der Basilika s. Zovatto 1952; ders. 1971, 15-22; Brusin 1957, 453-500; Bovini 1973. 
und interessanteste Werk seiner Art im Raum des nördlichen Adriabogens dar. ${ }^{614}$ Jedes Schiff und jeder Nebenraum war mit einem eigenen, in mehrere Segmente gegliederten Mosaikteppich ausgelegt, dessen verschiedene geometrische und ornamentale Muster von großer Schönheit und Raffinesse waren. Kunstvolle Schlingbänder und Efeuranken durchwirkten die einzelnen Abschnitte und formten unterschiedliche Rahmen in Form von Kreisen, Quadraten oder Rauten aus. In deren Mitte saßen Schmuckmotive, in einigen wenigen Fällen auch Vogeldarstellungen, am häufigsten aber die Inschriften der damaligen Stifter. Einen besonderen visuellen Akzent hatte man durch die auffällige Gestaltung der sehr breit angelegten Solea gesetzt. Sie zeigte ein elegantes, in vielen Farben ausgeführtes Halbkreismuster, aus welchem originell gestaltete Inschriftenfelder hervorstachen. Angesichts der gleichsam wie Korridore angelegten Mosaikteppiche musste sich der eintretende Besucher gleichsam in das Innere des Baus hingezogen gefühlt und sich unwillkürlich nach Osten in Richtung der Apsis hin orientiert haben (Taf. 21 Abb. 142). Suchte sein Blick den Boden, so waren es die aus schwarzen und roten tesserae zusammengesetzten Inschriften, die seine gesteigerte Aufmerksamkeit auf sich zogen. Nicht zuletzt wegen des äußerst zurückhaltenden Einsatzes figürlicher Motive entwickelten die Inschriften ein besonders starkes Gewicht innerhalb der Komposition und stachen dem Betrachter schnell ins Auge.

Welche Wirkung die Tessellate entfalteten, können wir heute nur noch erahnen, denn der Boden ist lediglich in Teilen erhalten und ganze Segmente sind im Laufe der Jahrhunderte verloren gegangen. Der farblich markierte Grundrissplan (Taf. 14 Abb.126) verzeichnet daher nur einen Teil der damals vorhandenen Inschriften, und zwar insgesamt 46 von insgesamt 56 bekannten Stücken. ${ }^{615}$ Insbesondere im südwestlichen Segment des Hauptschiffs und in weiten Teilen der Seitenschiffe muss es aber noch weitere Inschriften gegeben haben, die in ihrer Gestaltung und Anordnung den erhaltenen Stücken vermutlich sehr ähnlich waren. Insgesamt belief sich ihre Summe wohl auf nicht weniger als 80 Stück. Dem lückenhaften Gesamtbild zum Trotz lässt sich die planvolle Anordnung der Inschriften bzw. ihre konzeptuelle Präsenz im Kirchenboden aber gut nachvollziehen, angefangen bei den vergleichsweise schlichten Zeugnissen einfacher Laien und Angehöriger des niederen Klerus im Naos bis hin zu den aufwendigen Stücken privilegierter Stifter in den bedeutungsvollsten Zonen des Kirchenraums. Während erstere ihren Platz in den Seitenschiffen und Randzonen des Mittelschiffs hatten, fanden sich letztere im exklusiven Bereich der Solea, nahe dem Presbyterium sowie im sog. Salutatorium südlich der Apsis wieder, wo sich neben dem Bischof selbst auch ranghohe Kleriker und besonders spendable Gemeindemitglieder mit ihrem Namen verewigt hatten. Es war dies eine von konzeptuellen Überlegungen getragene topologische Anordnung, die auf der einen Seite soziale Hierarchien abbil-

614 Speziell zu dem Mosaikboden s. Caillet 1993, 218-257 mit weiteren Literaturhinweisen. 615 Bei zehn Inschriften ist der Anbringungsort unbekannt. 
dete, die sich auf der anderen Seite aber auch als ein Sinnbild der Kirchengemeinde und ihrer inneren Struktur lesen ließ: Der Bischof als Oberhirte der Gemeinde, um den sich die einzelnen Mitglieder wie die Schafe einer Herde versammeln.

Ganz im Westen des Kirchenraums, gleich hinter dem Haupteingang hat sich eine vergleichsweise große Fläche des Mosaikbodens mit mehreren Inschriften erhalten, an deren spezifischer Anordnung sich diese Idee verdeutlichen lässt. Dabei geht es um das Tessellat des Mittelschiffes und die auf der Solea und in den angrenzenden Segmenten angebrachten Inschriften. Der Mittelstreifen wird beherrscht von einem Ensemble aus vier (ursprünglich vermutlich fünf) hierarchisch aufeinander folgenden Inschriften. Es beginnt mit derjenigen des lector Amara und seiner Familie, ${ }^{616}$ worauf diejenige der sehr freigiebigen Laien Nonnus, Eusebia, Petrus und Iohannes folgt. Den Worten der Inschrift nach waren sie famuli sanctae martyris Eufemiae und brachten gemeinsam eine Spende von 100 Fuß auf. ${ }^{617}$ Beide Inschriften stehen in einen rechteckigen, am oberen Rand je durch ein in Schwarz und Rot gehaltenes Dreieckband abgesetzten Rahmen eingeschrieben (Taf.15 Abb.127). Gleich darüber prangt der Name des diaconus Laurentius in einem auffällig gestalteten Medaillon mit schwarzem Hintergrund, weißer Schrift und der Darstellung zweier sich gegenüberstehender Tauben und eines Weinstocks (Taf. 16 Abb. 129). ${ }^{618}$ An der Spitze des Ensembles ,thronte، schließlich Bischof Elias, repräsentiert durch eine lange, in Hexametern abgefasste Inschrift. Diese sprach den Leser direkt an und wies Elias als Bauherren der Kirche aus (Taf.16 Abb. 128):

Atria quae cernis vario formata decore / squalida sub picto c\{a\}elatur marmore tellus / longa vetustatis senio fuscaverat aetas / prisca en cesserunt magno novitatis honori / praesulis Haeliae studio praestante beati / haec sunt tecta pio semper devota timori. ${ }^{619}$

Die Halle, die du mit bunter Zier ausgestaltet siehst - die schmutzige Erde wird durch bunten Marmor versteckt -, hatte ihre lange Lebenszeit durch den Verfall des Alters getrübt. Sieh! Das Alte ist der großen Pracht des Neuen gewichen, durch das hervorragende Bemühen des seligen Bischofs Elias. Dieses Haus ist für immer geweiht der frommen Gottesfurcht.

In dem direkt nördlich anschließenden Mosaiksegment an den Rändern des Mittelschiffs hatten sich wiederum weniger privilegierte und bescheidenere Stifter aus dem niederen Klerus und aus der Laiengemeinde mit ihren Inschriften eingetragen (Taf. 19 Abb.135-139). Darunter waren die beiden notarii Paulus und Thomas, der lector Iohannes, zwei Soldaten mit dem gleichen Namen und der Schiffsbauer Stefanus, die

616 Caillet 1993, 223f. Nr. 4 = Zettler 2001, 195f. Nr. 4.

617 Caillet 1993, 224f. Nr. 5 = Zettler 2001, 196 Nr. 5.

618 Caillet 1993, 225 Nr. 6 = Zettler 2001, 196 Nr. 6.

619 Caillet 1993, 226 Nr. 7 = Zettler 2001, 196 Nr. 7. 
sich alle jeweils mit einer Spende von 25 oder 30 Fuß beteiligt hatten. ${ }^{620}$ Das andere, südlich an die Solea angrenzende Segment war wohl sehr ähnlich gestaltet. Auch hier müssen sich dem Betrachter eine ganze Reihe vergleichbarer Inschriften einfacher Stifter aus der Kirchengemeinde und -beamtenschaft präsentiert haben. Die Botschaft dieser Komposition war unmissverständlich: Der Bischof war zugleich Kopf und Herz der Kirchengemeinde, die ranghohen, ihm eng verbundenen Kleriker waren seine Stütze und die Laienmitglieder die sprichwörtlichen Schafe seiner Herde, die sich um ihn herum gruppierten. Diese Lesart drängt sich auch bei einem zweiten, in seiner materialen Präsenz vergleichbaren Inschriften-Ensemble auf, bei dem wieder Elias die Hauptrolle spielt (Taf. 20 Abb. 140). Es kleidet den Boden des kleinen rechtwinkligen Anbaus am südlichen Seitenschiff aus, der wegen seiner reichen dekorativen Ausstattung als ,Salutatorium“ bezeichnet und als Empfangs- oder Repräsentationsraum des Bischofs gedeutet wird. Eingebettet in einen großen Rundschild und umrahmt von einer Inschrift prangt ein aus vergoldeten tesserae zusammengesetztes Monogramm des Elias inmitten einer Krone aus acht weiteren Medaillons, die in fünf Fällen die Inschriften von Klerikern (ein lector, ein diaconus und drei notarii) aufweisen. ${ }^{621}$ Wieder bildet der Bischof das Herzstück der Komposition und wieder scharen sich die Mitglieder seiner Gemeinde, hier offenbar die engsten Vertrauten aus dem Kreise der hohen Kirchenbeamten, um seine Person herum.

Bestätigung findet die Idee einer planvollen, symbolträchtigen Präsenz der Inschriften von Sant'Eufemia auch an anderen Stellen im Kirchenboden, dieses Mal allerdings weniger im Hinblick auf die sinnbildliche Abbildung der Gemeindestruktur als vielmehr im Hinblick auf den Zusammenhang zwischen dem Anbringungsort der Inschrift und der sozialen Rolle des Stifters. Dass vor allem ranghohe Kleriker die liturgisch wichtigsten und prominentesten Räume des Kirchenbaus besetzten, haben die gerade genannten Beispiele vor Augen geführt. Davon abgesehen konnte es aber auch für Laien möglich gewesen sein, ihre Inschrift an bedeutungsvollen Stellen zu platzieren, vor allem in der Nähe des Presbyteriums. So geschah es jedenfalls in Gestalt von vier sternförmig angeordneten Inschriften im südöstlichen Segment des Mittelschiffs, unmittelbar vor dem Altarraum. ${ }^{622}$ Wohl kaum zufällig hatten hier ausgerechnet Martinianus und Simplicia das prominenteste, der Apsis am nächsten gelegene Feld für sich in Anspruch nehmen dürfen, betrug ihre Spende doch nicht weniger als $100 \mathrm{Fuß,}$ während die übrigen Stifter für lediglich 25 Fuß aufgekommen waren. Auf der gegenüberliegenden Seite des nordöstlichen Segments hatte indes weniger das großzügige

620 Caillet 1993, 237-242 Nr.20-30 = Zettler 2001, 200-202 Nr.20-30. Die Anordnung der Inschriften in den Feldern folgte offenbar einem bestimmten Rhythmus: Während in der rechten Reihe jedes Feld eine Inschrift trug, war es auf der linken Seite nur jedes zweite. Wenigstens bis zur Höhe der Stiftungsinschrift des Elias auf der Solea herrschte außerdem ein inhaltliches Wechselspiel zwischen Inschriften mit votum-Formular und solchen mit pedatur-Angabe.

621 Caillet 199, 248-250 Nr. 42-47 = Zettler 2001, 205 Nr. 43-48.

622 Caillet 1993, 234-236 Nr.16-19 = Zettler 2001, 199 Nr.16-19. 
finanzielle Engagement des Stifters den Ausschlag für den privilegierten Anbringungsort seiner Inschrift gegeben als dessen Bescheidenheit. Denn anstatt seinen tatsächlichen Namen zu nennen, spricht die Inschrift - womöglich als Ausdruck christlicher Demut - schlicht von demjenigen, nomen quius Deus scit. ${ }^{623}$

Zwar lässt sich die systematische, einem programmatischen Konzept unterliegende Anordnung der Stifterinschriften nur in Sant'Eufemia so eindrücklich nachzeichnen. Und ebenso gibt es Kirchen, für die sich keine vergleichbaren Prinzipien feststellen lassen - was in vielen Fällen allerdings nicht zuletzt mit dem oftmals unvollständigen Erhaltungszustand des Bodens zusammenhängt, der uns keine verlässlichen Aussagen über die jeweils gespendete Summe an römischen Fuß oder die Identität des in der Inschrift Genannten erlaubt. An der sich in Sant'Eufemia herauskristallisierenden Tendenz von einer konzeptuellen Verteilung der Inschriften, bei der die liturgische und symbolische Bedeutung des Anbringungsorts sowie die soziale Rolle und kirchenhierarchische Position des Stifters eine entscheidende Rolle spielten, kann aber kaum gezweifelt werden. Die Befunde der Märtyrerkirche in S. Canzian d'Isonzo, diejenigen der Basilika Via Madonna del Mare in Tergeste oder auch die gut erhaltene Situation in der Kirche S. Maria delle Grazie in Grado deuten jedenfalls in diese Richtung. ${ }^{624}$

Dessen ungeachtet zeigt das Beispiel Sant'Eufemia aber in jedem Fall, in welchem Maß sich der Bischof des Mediums der Inschrift bediente und dieses für die eigene Selbstdarstellung als Bauherr und Oberhirte der Gemeinde nutzte. Was wir in Grado lediglich anhand der in den Mosaikboden integrierten Inschriften fassen können, spielte sich anderswo in größeren Dimensionen und auf weiteren Ebenen ab: Neben den Bodentessellaten boten auch die Wandverkleidungen, Apsismosaiken und Architekturelemente beste Bedingungen der repräsentativen Selbstdarstellung. Inwiefern der gesamte Kirchenraum zum Schriftträger gemacht werden konnte und inwiefern ihn der Bischof für die Repräsentation seiner Person nutzte, zeigt das Beispiel der Eufrasius-Basilika im heutigen Poreč, welcher das folgende Fallbeispiel gewidmet ist.

623 Caillet 1993, 242f. Nr. 32 = Zettler 2001, 202 Nr. 32. Inschriften dieser Art sind in den Kirchen unseres Untersuchungsgebiets wie auch in anderen Teilen des westlichen Reichs selten belegt. Ein ähnlicher Fall liegt bei einer Inschrift aus Parentium (Poreč) vor: Cuius num/en D(eu)s nuvet / pro voto s/uo $f(e) c(i t) p(e) d(e s)$ XIII (Taf. 35 Abb. 163; Caillet 1993, 311 Nr. 9 = Zettler 2001, 225 Nr. 2).

624 S. dazu die einzelnen Einträge bei Caillet 1993 und Zettler 2001 zu den betreffenden Kirchenbauten sowie die neuere Studie von J.-P. Caillet, in der er sich stärker als in seiner 1993 vorgelegten Arbeit für eine systematische Anordnung der Inschriften auf den Kirchenböden ausspricht und dies am Beispiel der Kirchen von Aquileia und Grado zu verdeutlichen sucht: Caillet 2006. 


\subsection{Fallbeispiel 2: Die Eufrasius-Basilika in Parentium - der Kirchenraum als Schriftträger}

Die Geschichte der heutigen Eufrasius-Basilika begann im 3. Jh. mit einem kleinen Oratorium am nördlichen Stadtrand von Parentium, das im Zuge der fortschreitenden Christianisierung im darauffolgenden Jahrhundert $\mathrm{zu}$ einem größeren Kirchenkomplex ausgebaut wurde. ${ }^{625}$ Dieser bestand aus zwei einander angelehnten Hallenbauten und war mit einem flächendeckenden Mosaikboden ausgestattet, von dem sich einige Reste im Nordwesten der heutigen Basilika erhalten haben (Taf.32, 33). Das Tessellat war in mehrere Felder untergliedert, die neben verschiedenen geometrischen und ornamentalen Dekorationsschemata auch Stifterinschriften zeigten. Zu den herausragenden Stücken zählen zwei große emblemata-artige Inschriften in der Nordhalle. Die eine ist in einen aus Laub- und Wellenkranz gebildeten Kreisrahmen integriert (Taf. 33 Abb.159), die andere mit der Darstellung eines von Weinranken umspielten Kantharos kombiniert (Taf. 33 Abb. 160). ${ }^{626}$ Im 5. Jh. erfuhr der Komplex, nunmehr Aufbewahrungsort der Gebeine des lokalen Märtyrers Maurus und Bischofssitz, eine bauliche Umgestaltung. Auf dem Gelände der kleinen Doppelkirche wurde eine stattliche Basilika mit drei Schiffen errichtet. Auch dieser, als ,Basilika Preeufrasiana bezeichnete Bau, hatte einen Mosaikboden erhalten, und abermals waren die an der Finanzierung beteiligten Stifter mit ihrem Namen darin verewigt (Taf.34-35). Ähnlich wie wir es bereits bei den Kirchen des Patriarchats Aquileia und dessen Umgebung kennen gelernt haben, folgte die Anordnung dieser Inschriften im Kirchenraum bestimmten Prinzipien: Kleriker und besonders großzügige Stifter besetzten die auffälligsten Stellen und bedeutungsvollsten Orte: Den diaconi und lectores war der prominente Bereich direkt hinter dem Haupteingang im Mittelschiff sowie das Feld unmittelbar vor der Apsis des nördlichen Seitenschiffs vorbehalten, während sich die Inschriften der Laien in den Seitenschiffen und in einem schmalen, von einer ganzen Reihe von verschiedenen Stiftern geteilten Streifen im Zentrum des Mittelschiffs befanden.

Als Eufrasius um das Jahr 530 Bischof von Parentium wurde, ${ }^{627}$ ließ er an gleicher Stelle einen neuen weitläufigen Gebäudekomplex mit einem Episkopium, einem großem Atrium, einem oktogonalen Baptisterium und einer Gedenkkapelle zur Aufbewahrung der wichtigsten Reliquien errichten (Taf. 36 Abb. 165). Das Herzstück bildete die dreischiffige Basilika, die Eufrasius der Gottesmutter Maria sowie dem lokalen Märtyrer und erstem Bischof von Parentium, Maurus, weihte. Sie ist heute unter der Bezeichnung ,Eufrasiana‘ bekannt. Der Bau stand ganz im Zeichen byzantinischer Bautradition und schloss im Osten mit drei Apsiden ab. Dass nicht nur das Mittel-

$625 \mathrm{Zu}$ den baulichen Ursprüngen der Eufrasius-Basilika sowie zu ihrer weiteren Geschichte s. Molajoli 1940; Terry 1984; Prelog 1986, 7-16; Caillet 1993, 293-331.

626 Caillet 1993, 297-299 Nr. 1-2 = Zettler 2001, 222-224 Nr.1-4.

$627 \mathrm{Zu}$ seiner Person s. PCBE II 671f. s. v. Eufrasius. 
schiff, sondern auch die Seitenschiffe in halbrunden Nischen ausliefen, kam bis dahin vor allem im östlichen Mittelmeerraum vor, wo der dreiapsidiale Abschluss seinen Ursprung und weite Verbreitung gefunden hat. Im Westen war ein solcher Architekturtypus hingegen unüblich, wurde in der Folgezeit auch nur sehr vereinzelt aufgegriffen und konnte sich niemals tatsächlich durchsetzen. ${ }^{628}$ Doch nicht nur im Hinblick auf die außergewöhnliche bauliche Gestaltung stach die Eufrasiana unter den Kirchenbauten der Region hervor. Beachtenswert war auch ihre Innenarchitektur und die aufwendige Innenausstattung mit Mosaikbildern, Inkrustationen aus Marmor und Perlmutt, bunten Stuckaturen und kostbarem Mobiliar, womit sich Eufrasius ebenfalls an östliche Vorbilder anlehnte und seine Stiftung in die Riege ähnlicher Anlagen in Salona und Ravenna einreihte - gleichfalls von Byzanz beeinflusste Bauten. ${ }^{629}$

Während die dekorative Ausgestaltung des aufgehenden inneren Mauerwerks sehr gut erhalten blieb, ist der mit Mosaiken ausgelegte Boden fast vollständig verloren. Weite Teile wurden schon im 14 . Jh. beschädigt, als man ihn immer wieder für die Anlage von Gräbern öffnete und die Tessellate dabei unwiederbringlich zerstörte. Bei Restaurierungsarbeiten im späten 19. Jh. wurden weitere Partien vernichtet. Wenigstens was die Mosaiken der Seitenschiffe angeht, vermitteln zuvor angefertigte Zeichnungen einen vagen Eindruck des einstigen Zustands (Taf. 37 Abb. 166). Demnach war der Boden in jeweils drei langgezogene Segmente untergliedert, von denen jedes einzelne ein individuelles geometrisches Dekorationssystem aufwies. Das Mosaik der kleinen südlichen Konche zeigte ein Muschelmotiv mit äußerem Wellenband und einer herabfliegenden Taube, das bei Ausgrabungen in den 1930er-Jahren fast unbeschadet freigelegt werden konnte. Auch hier wurde nicht auf die Anbringung von Stifterinschriften verzichtet, deren genaue Zahl aufgrund des schlechten Erhaltungszustands allerdings nicht mehr zu ermitteln ist. Gewissheit besteht bei lediglich zwei Stücken, die in Fragmenten erhalten geblieben sind und die wohl ganz im Osten des südlichen Seitenschiffs, unmittelbar vor der Apsis, angebracht gewesen sein müssen. Bei dem einen handelt sich um die Inschrift des archidiaconus Dominicus, bei dem anderen um diejenige des vir clarissimus Iohannes. ${ }^{630}$ Eine weitere, offenbar gleich mehrere Stifter auflistende Inschrift kennen wir indes nur aus einer Aufzeichnung durch den reisenden Humanisten Ciriacus von Ancona. Er besuchte den Bau im 15. Jh.

\footnotetext{
628 Vgl. Prelog 1986, 14.

629 Insbesondere die Ähnlichkeiten zu den ravennatinischen Kirchenbauten S. Vitale und S. Apollinare in Classe sind bemerkenswert. Architektonische Parallelen lassen sich beispielsweise in der mehrfach gebrochenen Hauptapsis, der Gestaltung der Fassade, der Gliederung des Eingangsbereichs in drei Portale, der dreiteiligen Fensterfront im Giebel sowie im Verhältnis von Arkaden und Fenstern in den Seitenschiffen feststellen. Darüber hinaus bestehen große Ähnlichkeiten im Bildprogramm und in der Ausführung der Wandmosaiken. Zur architektonischen Verwandtschaft zwischen der Eufrasius-Basilika und den Bauten Ravennas s. Terry 1986; zur Abhängigkeit der Wandmosaiken s. Terry/Maguire 2007, 59-69.
}

630 Caillet 1993, 329 Nr. 24-25 = Zettler 2001, 229f. Nr.1-2. 
und will sie in der Nähe des Altars für die Heiligen Maurus und Eleutherius gesehen haben, also vermutlich im nördlichen Seitenschiff, etwa auf der Höhe des fünften Interkolumniums. ${ }^{631}$ Ferner erwähnen die Ausgrabungsberichte des 19. Jhs. noch zwei Inschriften mit den Namen Claudia und Honoria, deren Gestaltung aber ebenso ungewiss ist wie ihr Anbringungsort. ${ }^{632}$

Dass dies die einzigen Inschriften des Mosaikbodens gewesen sind, fällt angesichts unserer bisherigen Erfahrungen schwer zu glauben. Stattdessen steht es zu vermuten, dass insbesondere in die (vollständig verlorenen) Mosaiken des Hauptschiffs noch weitere Inschriften integriert waren. Mit dem Bild der Basilika Sant'Eufemia in Grado vor Augen - ebenfalls eine bischöfliche Stiftung des 6. Jhs., wie auch die ,Eufrasiana، von byzantinischen Einflüssen geprägt und kaum weniger aufwendig ausgestattet als diese - liegt der Gedanke nahe, dass es vor allem Bischof Eufrasius selbst war, der sich mit einer Inschrift im Boden verewigt hatte. Und dies umso mehr, da er offenbar großen Wert darauf legte, seine Person im Raum präsent werden zu lassen und dem Bau seinen Namen gleichsam ,einzuschreiben‘. Ob in seiner Darstellung im Mosaikbild der Apsis, der Stiftungsinschrift oder der zahlreichen vorhandenen Monogramme repräsentiert - Eufrasius war in Schrift- und Bildform allgegenwärtig.

Am offensichtlichsten war dies im Mosaikbild in der Kuppel der Hauptapsis (Abb.11, s. o. S. 82). Das Werk zeigt im Zentrum die thronende Gottesmutter mit dem Jesuskind im Arm. Rechts und links daneben führen ihr zwei Engel auf der einen Seite drei heilige Märtyrer, auf der anderen Seite den Heiligen Maurus, Bischof Eufrasius, den Diakonus Claudius und dessen kleinen, ebenfalls Eufrasius genannten Sohn zu. ${ }^{63}$ Claudius trägt das Evangelium, Eufrasius hält als Bauherr der Kirche ein Modell seiner Basilika in den verhüllten Händen. Im Gegensatz zu den Heiligen am rechten Bildrand zeigen ihre Gesichter individuelle Merkmale wie tiefe Stirnfalten, ausgeprägte Krähenfüße und dunkle Tränensäcke und verschweigen das fortgeschrittene Alter der beiden Kleriker nicht. Vor allem bei der Abbildung des bischöflichen Stifters Eufrasius hat man sich um eine besonders veristische Wiedergabe des Antlitzes bemüht, womöglich um seiner Person spezielle Aufmerksamkeit zuteil werden zu lassen. ${ }^{634}$

Das Bildwerk war für Eufrasius mehr als dekorative Zierde. Es war symbolträchtiger Bedeutungsträger und nicht zuletzt Ausdruck seines persönlichen Selbstdarstellungsbedürfnisses, das sich vor dem historischen Hintergrund seiner Entstehungszeit

631 Caillet 1993, 327 Nr. 23 = Zettler 2001, 230 Nr. 3-5.

632 Prelog 1986, 18.

$633 \mathrm{Zu}$ dem Bildwerk und den daran ausgeführten Restaurationsarbeiten s. Terry/Maguire 2007.

634 Die gesteigerte Betonung seiner Person erschöpft sich nicht allein in der veristsichen Darstellungsweise. Eufrasius ist neben der Gottesmutter auch als einziger in ein dunkles Gewand gekleidet. Offenbar um seinem Bildnis einen außergewöhnlichen Glanz zu verleihen, hat man außerdem sehr kleine und besonders viele opake tesserae für sein Gesicht verwendet. Zur gezielten Verwendung von tesserae aus bestimmten Materialen und den gewünschten Effekten auf den Betrachter s. Terry/Maguire 2007, 149-152. 
in der Mitte des 6. Jhs. als ein subtiles, aber gleichwohl unmissverständliches Zeichen und kirchenpolitisches Bekenntnis lesen ließ: Im sog. Dreikapitelstreit um die Frage nach der göttlichen und menschlichen Natur Christi hatte sich Eufrasius zusammen mit anderen Bischöfen seiner Provinz zunächst der monophysitischen Position Kaiser Justinians und der Haltung Papsts Pelagius I. entgegengestellt und sich schließlich von der römischen Kirche abgewandt. ${ }^{635}$ Im hierauf folgenden ,Schisma von Istrien` übernahm er die Rolle des Wortführers und lieferte sich heftige Auseinandersetzungen mit Papst Pelagius I., der ihn als Spalter, Ehebrecher und Geschwistermörder beschimpfte und zu exkommunizieren drohte. ${ }^{636}$ Angesichts dieses Konflikts war das Mosaikbild in der Kirche von Parentium wohl eine trotzige Antwort des Eufrasius auf die Verunglimpfungen seines Widersachers, vermochte er sich hier doch in ganz anderem Licht zu präsentieren als es Pelagius getan hatte. Eufrasius erscheint als treuer Diener Gottes und Verehrer Marias, dem die Gesellschaft von Engel und Heiligen zuteil wird und dem es wie diesen gebührt, in ,himmlischen Sphären' zu wandeln. ${ }^{637}$

Neben seinem Bildnis in der Apsis waren es vor allem die Inschriften mit seinem Namen und die vielen Monogramme, die dem Besucher der Kirche unmissverständlich zu verstehen gaben, wem der Ruhm des Bauherrn gebührte. Die Stiftungsinschrift befindet sich gleich unterhalb des Apsisbilds und erstreckt sich in hell leuchtenden Lettern auf blauem Grund über die gesamte Breite des Apsisrunds. Das in Distichen abgefasste Epigramm hat den Charakter einer Lobpreisung auf Eufrasius. Dieser, so die Inschrift, habe die Kirche als verfallene, schmucklose Ruine vorgefunden und sie unter Erfüllung eines Gelöbnisses als goldglänzenden Prachtbau wiedererrichtet (Taf. 38, Abb. 167):

Hoc fuit in primis templum quassante ruina / terribilis labsu nec certo robore firmum, / exiguum magnoque carens tunc furma metallo, / sed meritis tantum pendebat putria tecta. / Ut vidit subito labsuram pondere sedem, / providus et fidei fervens ardore sacerdus /Eufrasius $s(a n) c(t)$ a precessit mente ruinam. / Labente melius sedituras deruit aedes; / fundamenta locans erexit culmina templi. / Quas cernis nuper vario fulgere metallo, / perficiens coeptum decoravit munere magno, / aecclesiam vocitans signavit nomine (Christi). / Congaudens operi sic felix vota peregit. ${ }^{638}$

635 Zum Dreikapitelstreit und seine Bedeutung für das sog. Istrische Schisma s. Schieffer 1976.

636 Pelagius Epist. 53, 7-8.

637 Zur Deutung des Mosaiks vor dem kirchenpolitischen Hintergrund des Dreikapitelstreits s. Pre$\log$ 1986, 14; Terry/Maguire 2007, 127-147.

638 InscrIt X2, 81. Übersetzung nach Prelog 1986, 21. Die Beschreibung des Vorgängerbaus als verfallene Ruine ist als ein typisch (spätantiker) Topos zu verstehen, wonach die Herrlichkeit des Neubaus durch die Konstruktionen eines scharfen Kontrasts noch zu steigern gesucht wurde. Dass die sog. Preeufrasiana alles andere als eine bescheidene, schmucklose kleine Kirche war, widerlegen allein die erhaltenen Überreste ihres Mosaikbodens sowie die Tatsache, dass der Neubau der ,Eufrasiana“ auf eben den gleichen Grundmauern errichtet und mit Architekturelementen ihres Vorgängerbaus ausgestattet wurde. Zur Errichtung der Eufrasiana auf den Grundmauern des Vorgängerbaus aus dem 5. Jh. s. Deperis 1898. 


\begin{abstract}
Dies war anfangs ein erschütterter und baufälliger Tempel, der zusammenzustürzen drohte und nicht mit sicherer Stärke gefestigt war, der eng war und nicht mit Gold geschmückt, und dessen schadhaftes Dach allein durch die Gnade gestützt wurde. Als der vorsorgliche und dem Glauben ergebene Priester Eufrasius sah, dass seinem Sitz die Gefahr droht, unter der Last zusammenzustürzen, kam er in heiliger Absicht dem Einsturz zuvor, und um das baufällige Gebäude besser zu befestigen, riss er es ab und nachdem er die Fundamente gelegt hatte, errichtete er den Giebel des Tempels. Was du bald in Gold glänzen siehst, (hat er) geschmückt, indem er das Angefangene vollendet und in seiner Größe mit Geschenken beschenkt hat. Den Namen Christi anrufend bezeichnete der die Kirche, sich freuend über das Werk und erfüllte so glücklich sein Gelöbnis.
\end{abstract}

Zu dieser gesellte sich noch eine zweite Inschrift ähnlichen Inhalts. Sie war zwar unauffälliger gestaltet und nicht so prominent angebracht, deswegen aber kaum weniger bedeutungsvoll. Es ist die Inschrift auf dem Unterbau (stipes) eines Marmoraltars mit den darauf eingemeißelten Worten Famul(us) D(e)i Eufrasius antis(tes) temporib(us) suis ag(ens) an(num) XI a fondamen(tis) d(e)o iobant(e) s(an)c(t)e aecl(esie) catholec(e) hunc loc(um) cond(idit) (Taf. 39 Abb. 169). ${ }^{639}$ Wo der Altar einst stand, ist unklar. Angesichts des kunstvollen Flachreliefs auf der Vorderseite und der handwerklichen Qualität des Stücks aus weißem griechischen Marmor handelt es sich wahrscheinlich um den Hauptaltar des Presbyteriums, zumal sich einzelne Motive des Reliefs Muschel und Delphin - auch in der Wandverkleidung der Apsis sowie an der hier aufgestellten Priesterbank wiederfinden (Taf.39 Abb.170). Das Relief des Altars zeigt einen von zwei Säulen getragenen Bogen, der ein von einem Giebel bekröntes Portal überspannt. In dem breiten Halbrund sitzt eine große Muschel, darunter winden sich zwei Delphine. Im Tympanon des Giebels ist die Abbildung eines großen Kreuzes und zweier sich gegenüberstehender Tauben zu sehen, wie auch die Delphine typische Elemente der christlichen Symbolsprache und bevorzugt verwendete Bildmotive. Die Inschrift wiederum steht in eleganten Majuskeln auf dem Bogen geschrieben, gleichsam so, als habe man hier eine wirkliche Bauinschrift abbilden wollen.

Ungeachtet dieser beiden die Errichtung der Kirche thematisierenden Inschriften, machte Eufrasius von einer weiteren Spielart monumentaler Schriftlichkeit Gebrauch, und zwar der des Monogramms. Monogramme taugten zwar weniger gut als Übermittler komplexer Inhalte, sie eigneten sich aber gut dazu, den eigenen Namen besonders prägnant und wirkmächtig im Raum präsent werden zu lassen. ${ }^{640}$ Einmal mehr hatte Eufrasius hierfür den Bereich der Apsis gewählt und sein Monogramm in die bunten opus sectile-Verkleidungen der Wände einsetzten lassen. Die aus buntem Marmor, schimmerndem Perlmutt, Porphyr und Edelsteinen zusammengesetzten Tafeln schmückten die Rückwand des Presbyteriums bis zur Höhe der Fensterzone und bildeten den passenden Rahmen für die dort aufgestellte Kathedra, die, genau in

639 InscrIt X2, 92.

640 Zum Monogramm als eine besondere Spielart von Inschriftlichkeit und zu ihrem Gebrauch als Medium bischöflicher Repräsentation s. auch o. Kap. 2.2.8. 
der Mitte der Apsis gelegen und auf fünf Stufen erhöht, den höchsten Punkt des Kirchenraums besetzte. Von den insgesamt 21 Tafeln zeigen zwei das Monogramm des Eufrasius, womöglich nicht ganz zufällig eben genau jene beiden, über denen sich die Darstellungen der beiden Heiligen Zacharias und Johannes der Täufer erheben (Taf. 38 Abb. 168).

Während die vergleichsweise kleinen und unscheinbaren Monogramme an der Rückwand des Presbyteriums von dem einfachen Kirchenbesucher wohl kaum bemerkt wurden, ging von einer zweiten Gruppe von Monogrammen eine wesentlich größere Wirkung aus, denn diese war prominent an den Kämpfern der Kapitelle im Naos angebracht. Zwei Arkadenreihen mit je neun Säulen trennten den Kirchenraum in zwei schmale Seitenschiffe und ein breites Mittelschiff. Dort saßen die Monogramme gut sichtbar an den Innenseiten der Kämpfer, jeweils von einem doppelten Ring mit stilisierter Blattranke eingerahmt (Abb.60, s. o. S. 190). Es gibt drei verschiedene Typen von Kapitellen: gerahmte Kämpferkapitelle, Kompositkapitelle und Kapitelle mit Tiergestalten in den Ecken, die sich jeweils paarweise aufeinander beziehen. Alle sind aus weiß glänzendem griechischem Marmor gehauen und alle erinnern stark an vergleichbare Stücke aus der Kirche S. Vitale in Ravenna, von der sich Eufrasius womöglich auch hatte inspirieren lassen, sein Monogramm in die Kämpfer einzumeißeln.

Angesichts der gleichsam zur Unübersehbarkeit verdichteten Präsenz seines Namens im Naos, war die Person des Eufrasius hier allgegenwärtig. Sie begegnete dem Besucher in allen Bereichen des Kirchenraums, vor allem in der liturgisch und symbolisch bedeutungsvollsten Zone des Presbyteriums. Dabei spielten sowohl verschiedene visuelle Medien als auch verschiedene Materialien eine Rolle: Bilder, Texte und Schriftzeichen auf der einen Seite, Mosaiken, Marmor und Intarsien auf der anderen Seite, die unterschiedliche Kombinationen und Verbindungen miteinander eingingen. Stellt man sich nun noch vor, dass es Eufrasius vermutlich nicht versäumt hatte, seinen Namen im Fußboden der Kirche zu verewigen, so kristallisiert sich das Bild einer bewusst geplanten und sorgsam durchgeführten Raumgestaltung heraus, die nicht nur die unterschiedlichen Spielarten visueller Präsenz, sondern auch alle Zonen des Kirchenraums berücksichtigte: zunächst den Fußboden, das tatsächliche wie symbolische Fundament des Gotteshauses; die Säulen als unverzichtbare Raumelemente mit tragender und stützender Funktion; ferner das Presbyterium, den liturgisch bedeutungsvollsten Ort des Kirchenraums; und schließlich die Apsis, den visuellen Flucht- und sinnbildlichen Brennpunkt der Basilika, wo auch die Gottesmutter und Christus selbst ihren Platz hatten und wo die Nähe Gottes am deutlichsten zu spüren sein sollte. In Gestalt seines Bilds und Namens war Eufrasius überall dort präsent. Er hatte den gesamten Raum für sich in Anspruch genommen und zu einem Textträger von hoher Symbolkraft gemacht. 


\subsection{Eingeschränkte Präsenz: Klandestine, unsichtbare und unlesbare Inschriften und ihre Wirksamkeit}

Nicht immer waren Inschriften für alle Augen sichtbar und lesbar. Mitunter waren sie in großen Höhen angebracht, an unzugänglichen Orten aufgestellt und durch andere Monumente verdeckt, sodass es selbst dem interessiertesten Betrachter unmöglich war, sich mit ihnen auseinanderzusetzen oder überhaupt erst von ihnen Notiz zu nehmen. Es waren dies Inschriften von eingeschränkter Präsenz, deren Wahrnehmbarkeit in einer bestimmten Art und Weise gestört oder gar nicht vorgesehen war. Sie zu lesen, bereitete dem Betrachter - und hier ist ausdrücklich der literate, also des Lesens mächtige Betrachter gemeint ${ }^{641}$ - erhebliche Schwierigkeiten oder blieb ihm ganz verwehrt. Ihre Präsenz war limitiert, vermindert, gleichsam ,schwach', und ihre Gegenwart erschloss sich weder unmittelbar noch ostentativ. ${ }^{642}$

Das Phänomen der ,eingeschränkten (In)schrift(en)präsenz‘ ist facettenreich und vielschichtig. Es findet seinen Ausdruck in verschiedenen Spielarten und in unterschiedlich stark ausgeprägten Abstufungen. So mochte die Präsenz einiger Inschriften dahingehend eingeschränkt sein, dass sie nicht jedermann, sondern lediglich einem ausgewähltem Publikum präsentiert wurden; dass sie nicht zu jeder Zeit, sondern nur zu bestimmten Anlässen sichtbar waren; dass sie zwar sichtbar, aber nicht lesbar waren; oder aber dass sie immer und vor aller Augen verborgen waren. Und auch was die den Inschriften zugeschriebene Bedeutung angeht, sind Schattierungen und Differenzierungen auszumachen. Denn wenngleich die (wie auch immer geartete) Verborgenheit absichtsvoll evoziert oder zumindest billigend in Kauf genommen wurde, so waren die dahinter stehenden Intentionen doch ebenso verschieden wie es die Funktionen der jeweiligen Inschriften waren. In zweierlei Hinsicht aber hatten alle diese Inschriften etwas miteinander gemein: zum einen den Glauben an ihre Wirkmächtigkeit und Effektivität, die sie aller eingeschränkter Wahrnehmbarkeit und Lesbarkeit zum Trotz - oder gerade deswegen - ungehindert entfalteten; und zum anderen, dass dem Akt des Schreibens bzw. Anfertigens und Darbringens der Inschrift wenigstens genauso große, wenn nicht größere Bedeutung beigemessen wurde als ihrer Rezeption durch den Betrachter und Leser. Ohne anzunehmen, damit sämtliche Varianten eingeschränkter Schriftpräsenz erfasst zu haben, sollen hier zumindest vier denkbare Varianten vor Augen geführt und nach den möglichen Mechanismen ihrer Wirksamkeit gefragt werden.

641 An dieser Stelle soll es ausdrücklich nicht um den Problemkreis des Lesen-Könnens im Sinne eines intellektuellen Verstehens der Inschriften gehen. Wenn hier von ,lesbaren“ Inschriften die Rede ist, dann sind damit solche Inschriften gemeint, die sich aufgrund ihrer uneingeschränkten Sichtbarkeit visuell problemlos wahrnehmen und als Texte rezipieren ließen.

642 Auf das Problem der eingeschränkten Wahrnehmbarkeit und Lesbarkeit von Schrift im weiteren Sinne wies M. Hilgert in seinem Aufsatz zur Materialität und Präsenz von Geschriebenem unter dem Stichwort „restringierte Präsenz“ hin, ohne diesen Aspekt aber näher zu beleuchten: Hilgert 2010, 99 Anm. 20. Eingehender setzt sich der Sammelband Frese/Keil/Krüger 2014 mit dem Phänomen auseinander. 


\subsubsection{Wirksamkeit durch Exklusivität}

Beginnen wir mit solchen Inschriften, deren Anblick nur einem bestimmten Personenkreis vorbehalten war, weil sie an restriktivierten Orten und in nicht frei zugänglichen Räumen zur Aufstellung kamen. ${ }^{643} \mathrm{Zu}$ dieser Gruppe gehören beispielsweise diejenigen Stifterinschriften in Kirchenanlagen, die nicht im weithin offenen Naos, sondern in abgetrennten Bereichen des Kirchenraums angebracht waren, wie etwa im abgeschrankten Presbyterium oder in den Diensträumen der Kleriker. Ein solcher Fall begegnet in der Basilika Sant'Eufemia in Grado, wo der Mosaikboden des sog. Salutatoriums mit einem aufwendigen Inschriftenensemble ausgelegt ist, das die Namen des bischöflichen Stifters der Kirche Elias und seiner engsten Vertrauten aus dem Kreis der hohen Kleriker zeigt (Taf. 20 Abb. 140). In ihrer kunstvollen Gestaltung und Ausführung unter Verwendung vergoldeter tesserae ist die Inschrift bemerkenswert, und man fragt sich, warum ausgerechnet diese Inschrift nicht im Kirchenraum angebracht wurde, wo sie ein größtmögliches Publikum erreicht hätte. Nicht anders verhält es sich mit den ähnlich aufwendigen Inschriften des nördlichen Apsisnebenraums in der Kirche S. Maria delle Grazie in Grado (Taf. 25 Abb.147). Auch diese waren lediglich für einige wenige Angehörige des geistlichen Stands sichtbar, während sie den Augen der Laien verborgen blieben. Offenbar haben die jeweiligen Stifter gerade nicht danach gesucht, die Inschriften einem möglichst großen Kreis von Betrachtern zu präsentieren, sich also vor aller Augen als großzügige Stifter in Szene zu setzten und ihre Wohltätigkeit öffentlich zur Schau zu stellen. Vielmehr ging es ihnen darum, sich der eigenen Frömmigkeit und Pflichterfüllung als Christ zu vergewissern. Dafür brauchte es kein großes Publikum, sondern vor allem die eigene Überzeugung. Der Ort der Inschrift im Kirchenraum vermochte diese Gewissheit zu verstärken: je näher am Allerheiligsten, desto näher an Gott. Weitaus wichtiger als die eigene Inschrift vor möglichst vielen Glaubensbrüdern und -schwestern zur Schau zu stellen, war es, seinen Namen an einem besonders wertvollen Ort einschreiben zu können. Anstelle offenkundiger Sichtbarkeit suchte man eher die Exklusivität bedeutsamer Orte und zahlte dafür den Preis geringerer Aufmerksamkeit durch die breite Masse. Eingeschränkte Präsenz bedeutet in diesem Sinne also vor allem den Anspruch auf außerordentliche Privilegien und den Genuss von Exklusivität.

643 Für Inschriften in privaten Kontexten, wie zum Beispiel Ehreninschriften für den Besitzer eines Wohnhauses oder Weihinschriften in privaten Heiligtümern, galt dies natürlich fast ohne Ausnahme. Doch interessieren wir uns hier in erster Linie für Inschriften in öffentlichen Kontexten, also in Räumen und Gebäuden, die nicht in privatem Besitz waren, und deren Zugang keinen strengen Direktiven unterlag. Für das hier zugrunde liegende Verständnis des Begriffs vom,öffentlichen Raum`s. auch die einleitenden Ausführungen auf S.6f. 


\subsubsection{Wirksamkeit durch Gewissheit}

Eine zweite Gruppe bilden Inschriften, welche zwar für jedermann sichtbar, aber nicht unbedingt lesbar waren. Man denke etwa an in großen Höhen angebrachte Inschriften, wie sie in Form der Beischriften in den Bildern der Apsismosaiken oder auch der Namensinschriften an der Portikus des Forums von Aquileia begegnen. Auch so manche Bau- und Stiftungsinschrift war für den am Boden stehenden Betrachter ohne optische Hilfsmittel sicherlich nicht zu entziffern, obgleich er sich ihrer Präsenz doch vollkommen bewusst war. Empfand man es denn nicht als problematisch, dass derlei Inschriften - zumal nicht selten kunstvoll gestaltet und technisch aufwendig ausgeführt - wenig oder keine Aufmerksamkeit zuteil werden konnte? Verspürte man keinen Widerspruch zwischen ihrer Existenz und ihrer Unlesbarkeit? Waren öffentlich dargebrachte Inschriften nicht eigentlich dazu geschaffen, gelesen zu werden? Offenbar nicht immer: Solche unlesbaren Inschriften erlangten ihre Bedeutung nicht durch ihre tatsächliche, sondern durch ihre potentielle Lesbarkeit. Sie waren nicht dafür geschaffen, wirklich gelesen zu werden, sondern sollten schlichtweg ,da sein' und das Bau- oder Kunstwerk durch ihre Präsenz vervollkommnen. Sie hätten zwar theoretisch gelesen werden können, mussten aber nicht gelesen werden, und es steht zu vermuten, dass sich nur die Wenigsten für den genauen Wortlaut und den vollständigen Inhalt dieser Art von Inschriften interessierten. Stattdessen nahm man sie eher zur Kenntnis, und zwar als das, was sie ihrer Idee nach waren: Schriftzeugnisse, welche die Errichtung eines Denkmals oder Gebäudes dokumentierten, an ein bestimmtes historisches Ereignis erinnerten oder den Namen einer bestimmten Person öffentlich festhielten. Um den ihnen zugeschriebenen Sinn zu erfüllen, brauchten diese Inschriften also keinen lesenden, sondern lediglich einen wahrnehmenden Rezipienten, der um ihre Existenz wusste. Präsenz ist hier also nicht zu verstehen im Sinn einer rein visuell wahrnehmbaren Erfahrung, sondern im Sinn einer unausgesprochenen Gewissheit, gleichsam eines Wechselspiels von aktiver Wahrnehmung und implizitem Wissen. ${ }^{644}$

644 Diese Gedanken zur Unlesbarkeit von Inschriften nehmen Anleihen bei ähnlichen, bereits zuvor formulierten Überlegungen zur Rezeption von monumentalen Bildwerken, die für den Betrachter ohne Hilfsmittel nicht zu erkennen, gewissermaßen nicht zu ,lesen' waren. Die grundlegende und wegweisende Studie zu diesem Themenaspekt legte P. Veyne 1990 vor. Darin setzte er sich mit dem Dilemma der Trajanssäule auseinander, deren bis in kleinste Details ausgearbeiteten Reliefs zum überwiegenden Teil vom Boden aus nicht zu erkennen sind (Veyne 1990). Sein Lösungsvorschlag beruhte auf der Idee, bei der Säule habe es sich nicht um ein Instrument kaiserlicher Propaganda gehandelt, sondern um ein die Person des Trajan und seine Sieghaftigkeit verherrlichendes Denkmal. Wenn die Reliefs also keine komplexen Bedeutungsträger waren, mit denen ideologische Botschaften transportiert werden sollten, sondern ,lediglich“ anspruchsvollen, einem kaiserlichen Denkmal würdigen Dekor darstellten, dann war die umfassende Lesbarkeit der Bilder auch nicht erforderlich, so Veyne. Sie dienten allein dem Schmuck der Säule, ihres Zeichens Ausdruck kaiserlicher Machtdemonstration, Sieghaftigkeit und wortwörtlicher Größe, bei der alles Inhaltliche in den Hintergrund trat, zu- 


\subsubsection{Wirksamkeit durch Performanz}

Eingeschränkte Präsenz vermochte sich zuweilen auch darin Ausdruck verschaffen, dass eine Inschrift nur für einen kurzen Moment oder zu bestimmten Gelegenheiten zu sehen und zu lesen war. Denken wir etwa an eine Inschriftentafel für die Abdeckung eines in die Erde eingelassenen Grabs, die nach der Beisetzung wieder verdeckt wurde oder an die unzähligen Grabinschriften in den christlichen Katakomben, die nach ihrer Anbringung während der Bestattung nur noch selten, nämlich im Rahmen der wiederkehrenden Gedenkfeiern für die Verstorbenen rezipiert wurden, wenn die Angehörigen die unterirdischen Gräber besuchten. Jenseits solcher Gelegenheiten aber waren diese Inschriften dem Betrachter verborgen und niemand nahm von ihnen Notiz - anders übrigens, als es bei den in der Kaiserzeit üblichen Inschriften an den monumentalen Grabmonumenten und Altären entlang den Gräberstraßen der Fall war, die dem entlangschreitenden Betrachter zu jeder Zeit zugänglich und unmittelbar gegenwärtig waren, auch wenn er sie nur en passant und eher unbewusst wahrnahm.

Bei Inschriften, deren Präsenz durch die Dimension der Zeit Grenzen gesetzt bekam, spielte der Aspekt der unaufhörlichen Gegenwart und der immerwährenden Aufmerksamkeit durch einen Rezipienten eine untergeordnete Rolle. Der Wunsch nach Permanenz trat zurück hinter den Effekt der Performanz, also den Effekt des konkreten, in eine absichtsvolle Handlung eingebunden Ereignisses, für das die Inschrift von Bedeutung war. Die Anbringung einer Grabinschrift auf einer Loculusplatte oder die Errichtung eines Epitaphs für den Verstorbenen etwa war eine wesentliche Komponente jeder Bestattungszeremonie, und die Vergegenwärtigung des Toten in Form seines inschriftlich festgehaltenen Namens war unverzichtbares Element jeder Gedenkfeier. In der Rolle solcher Inschriften als Bestandteile für die gelungene Durchführung und Sinnhaftigkeit von Ritualen und Zeremonien, also in ihrer Einbeziehung in eine konkrete, sinnhafte Handlung, lag die Kraft ihrer Bedeutung.

Man könnte diesen Gedanken noch weiterführen und auf Inschriften übertragen, die im Grunde zwar für jeden und immer zugänglich, sichtbar und lesbar waren, die sich im Laufe der Zeit aber zu ,un-gegenwärtigen‘ Inschriften entwickelten, weil sie angesichts ihrer permanenten Präsenz gleichsam ,unsichtbar‘ wurden. Ist dies nicht zum Beispiel für viele Ehreninschriften auf Statuenbasen leicht vorstellbar? Während sie im Rahmen der feierlichen Aufstellung des Standbilds vielleicht noch große Aufmerksamkeit erfuhren, wurde ihnen nach einiger Zeit sicherlich immer weniger Beachtung geschenkt, bis sie irgendwann schließlich gar nicht mehr zur Kenntnis genommen wurden. Auch derlei Inschriften waren in gewissem Sinn ,verborgen und

gunsten ihrer schieren, den Betrachter wegen ihrer gewaltigen Ausmaße und überreichen Verzierung beeindruckenden Präsenz. Zu diesem Themenkomplex s. auch die darauf aufbauende Studie desselben Autors (Veyne 2002) sowie die Entgegnungen von S. Settis (Settis 1992) und T. Hölscher (Hölscher 1991; ders. 2002). 
nur zu bestimmten Gelegenheiten tatsächlich und vollkommen präsent: im Augenblick ihrer Aufstellung, wenn ein Betrachter sich ihnen zum ersten Mal gegenübersah und wenn mit oder an dem dazugehörigen Bildwerk gehandelt wurde, beispielsweise im Rahmen einer Feierlichkeit zu Ehren des Porträtierten oder - ganz im Gegenteil eines Gewaltaktes, in dessen Zuge die Statue mutwillig zerstört und die Inschrift gezielt beschädigt wurde.

\subsubsection{Wirksamkeit durch Existenz}

Eine letzte Variante stellen vollständig verborgene, gleichsam klandestine Inschriften dar, die aufgrund ihres speziellen räumlichen Kontexts von niemandem und zu keinem Zeitpunkt wahrgenommen werden konnten, deren Unsichtbarkeit aber das Resultat konzeptueller Überlegungen war. Darunter fallen etwa beschriftete Statuenbasen und Meilensteine, die als Baumaterial für die Errichtung oder Verstärkung von Stadtmauern und Wehrringen wiederverwendet wurden - und zwar so, dass ihre Inschriften nach innen zeigten und nicht gesehen werden konnten. ${ }^{645}$ Angesichts der Tatsache, dass dabei immer wieder auf Ehreninschriften kaiserlicher Denkmäler und auf Meilensteine mit den Namen ehemaliger oder regierender Herrscher zurückgegriffen wurde, ${ }^{646}$ liegt die Vermutung nahe, dass die wiederverwendeten Steinblöcke nicht bloß als Baumaterial betrachtet wurden, sondern dass man ihnen größere Bedeutung beimaß. Das gilt insbesondere für Meilensteine, die angesichts der eingemeißelten Entfernungsangabe einst in einiger Distanz zum Ort ihrer späteren Wiederverwendung aufgestellt gewesen sein müssen. Bei ihnen stellt sich die Frage, warum man sich die Mühe ihres sicherlich nicht ganz einfach zu bewerkstelligenden Transports gemacht hatte - geeignete Steinblöcke wären gewiss auch bequemer und mit weniger Aufwand $\mathrm{zu}$ haben gewesen. Womöglich hat man den Aufwand nicht gescheut, weil man sich von der Präsenz der Stücke eine spezielle, nämlich apotropäische Wirkung erhoffte. Das dem Kaiser einst zugeeignete Denkmal wurde gleichsam als Unheil abwehrendes, die Verteidigungsmauer mit magischen Kräften verstärkendes Element gedeutet. Die eingemeißelte Inschrift fungierte dabei quasi als Garant, denn sie belegte, dass es sich tatsächlich um ein Monument des Kaisers handelte, welches dessen numen in sich trug und dem daher eine besondere Kraft innewohnte. Ob die Inschrift für den Betrachter sichtbar war oder nicht, spielte dabei keine Rolle. Allein ihre Existenz war für die erhoffte Wirksamkeit entscheidend.

$645 \mathrm{Zu}$ diesem Aspekt der Wiederverwendung von Inschriften als Baumaterial s. auch Kap. 3.3. 646 So zum Beispiel im antiken Mediolanum, wo man für den unter Maximian errichteten spätantiken Mauerring u. a. auf eine diesem selbst errichtete Statuenbasis zurückgriff (CIL V 5807; 5808). Oder auch im antiken Condate (Rennes), in dessen Stadtmauer nicht weniger als 13 Meilensteine verbaut worden waren; vgl. hierzu Dey 2012. 
Aus der entgegengesetzten Perspektive betrachtet, mochte Ähnliches auch für wiederverwendete Inschriften, verhasster' Herrscher gegolten haben. Gemeint sind die Inschriftentafeln mit den Namen der christenfeindlichen Kaiser Diocletian und Maximian, die als Pflastersteine in frühchristlichen Kirchenanlagen eine zweite Verwendung fanden, wie etwa in SS. Alessio e Bonifacio auf dem Aventin, in S. Pancrazio in Monte Verde und in S. Constanza an der Via Nomentana in Rom. ${ }^{647}$ Auch diese Inschriften waren nicht sichtbar, denn sie wurden mit der Schriftseite nach unten in die Böden verlegt. Möchten wir nicht daran glauben, es sei reiner Zufall gewesen, dass man ausgerechnet auf Inschriftensteine mit den Namen der für die Verfolgung und Ermordung von Christen verantwortlich gemachten Kaiser zurückgegriffen hatte, dann liegt auch hier die Deutung einer symbolhaften Praxis nahe. So mochte die Sitte, die Tafeln mit der Schriftseite zum Boden hin zu vermauern, den gleichen Sinn erfüllt haben wie der christliche Brauch, pagane Bildwerke und Statuen mit dem Gesicht nach unten in der Erde zu vergraben, wie es etwa von Statuen aus Athen und Aphrodisias überliefert ist. ${ }^{648}$ Es war dies eine Demonstration von Abneigung, deren Bedeutung auch im Fall der mit ihrer Beschriftung nach unten verlegten Inschriftenspolien zum Tragen gekommen sein könnte. Dass man von den Inschriften keine Notiz mehr nehmen konnte, war dabei ohne Belang - einmal mehr war die bloße Existenz der Inschriften am richtigen Ort und in einer bedeutungsvollen Position auschlaggebend.

647 SS. Alessio e Bonifacio: CIL VI 1131a (+S. 4327); Lanciani 1988, 33; S. Pancrazio in Monte Verde: Armellini 1942, Bd. II, 1186. Die beiden Stücke sind heute verloren. S. Constanza: CIL VI 1129 mit Abbildung bei: http://edh-www.adw.uni-heidelberg.de/edh/foto/F010587.JPG (Stand: 3.5.2019).

648 Zur rituellen Vergrabung paganer Bildwerke mit dem Gesicht zur Erde s. Caseau 2001, 112-116. 
